PROGRAMA DE PÓS-GRADUAÇÃO EM BOTÂNICA

Efeito do alagamento na germinação de sementes e no crescimento de plantas jovens de Genipa americana e Guazuma ulmifolia com ocorrência no Cerrado e na Amazônia

Hérica Ribeiro de Almeida Pires 
Efeito do alagamento na germinação de sementes e no crescimento de plantas jovens de Genipa americana L. e Guazuma ulmifolia Lam. com ocorrência no Cerrado e na Amazônia

Dissertação apresentada ao Programa de Pós-Graduação em Botânica da Universidade de Brasília como parte dos requisitos necessários à obtenção do título de Mestre em Botânica.

Hérica Ribeiro De Almeida Pires Orientadora: Dra. Cristiane da Silva Ferreira 
Hérica Ribeiro de Almeida Pires

\title{
Efeito do alagamento na germinação de sementes e no crescimento de plantas jovens de Genipa americana e Guazuma ulmifolia com ocorrência no Cerrado e na Amazônia
}

\author{
Aprovada em 06/03/2015
}

Banca examinadora:

Dra. Cristiane da Silva Ferreira

Departamento de Botânica, UnB

(Orientadora, Presidente da Banca Examinadora)

Eduardo Rogerio Moribe Barbosa

Departamento de Botânica, UNB

(Membro Titular da Banca Examinadora)

Maria Cristina de Oliveira

Faculdade de Planaltina, UNB

(Membro Titular da Banca Examinadora)

Cássia Beatriz Rodrigues Munhoz

Departamento de Botânica, UNB

(Membro Suplente da Banca Examinadora) 
À minha famítia e meu esposo, por todo carinho dispensado nesses últimos anos, dedico. 


\section{Agradecimentos}

Agradeço primeiramente a Deus, por ter me permitido superar todas minhas limitações e chegar até aqui.

A Capes, que por meio do Programa Nacional de Apoio à Pós-Graduação em Botânica (PNAPB), e o CNPq, através do Edital Universal e bolsa de fomento, financiaram esse trabalho.

À minha família, por comemorar comigo todas as etapas desse processo e por estarem sempre prontos a me apoiar nos momentos difíceis.

Ao meu esposo, que soube com sabedoria durante esse período, entender e superar a minha ausência. Obrigada pela paciência, tolerância e carinho dispensado. A tia Alda por me abrigar em seu lar, nesses dois anos de mestrado.

À Cris, pelo zelo, carinho, confiança e ensinamentos durante os dois anos de orientação. Você foi essencial para que o trabalho se realizasse.

Aos manauaras, Veridiana, Heloíde e familiares que me acolheram em Manaus por um mês em tempos de coleta. A Valdeney, Sr. Mário, Celso, Josephina e Bianca que me ajudaram a coletar por vários dias, em áreas alagadas da Amazônia. Ao Instituto Nacional de Pesquisa da Amazônia (INPA), especialmente à Maitê, que me acolheu e deu apoio essencial na realização da coleta de sementes na Amazônia.

Aos parceiros de laboratório e campo, Rodolfo, André, Sr. Zé, Mendes, Fred, Fábio, Juliana, Karina, Matheus, Jéssika e Will que me apoiaram sempre que precisei no laboratório e em campo.

À Aliny, por ter colaborado em vários momentos do meu trabalho e por ter partilhado tantas conversas, desabafos e alegrias. À Natacha (Girl magia), que ao longo de todo o mestrado estava a postos para ajudar no que era preciso, tanto emocional quanto no trabalho e fazia sempre a minha alegria.

À querida amiga Estela, por todo o tempo dispensado ensinando-me com paciência e dedicação toda a bioquímica realizada nesse estudo. Obrigada, sobretudo pela sua amizade. 
Aos professores, Augusto, Dalva, Sarah, Lúcio e Thomas que de alguma maneira contribuíram muito nesses dois anos, dispensando os seus saberes e me induzindo a buscar sempre mais. 


\section{Sumário}

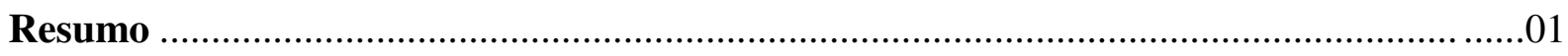

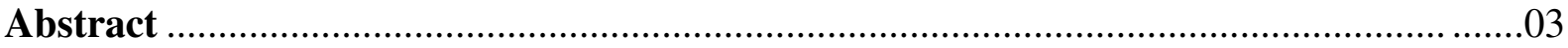

1. INTRODUÇÃO

1.1 Referencial teórico

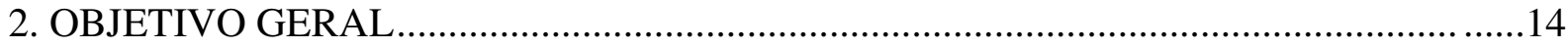

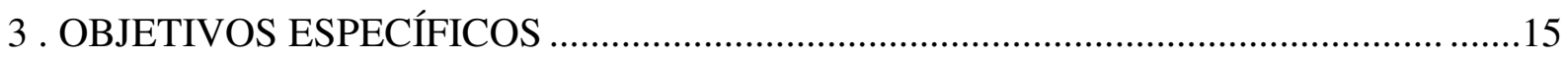

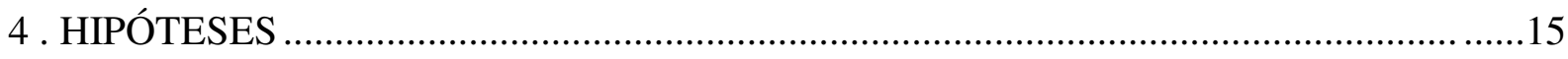

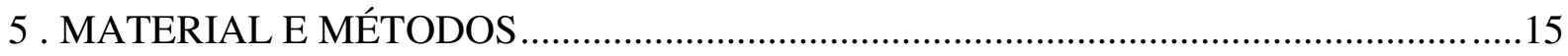

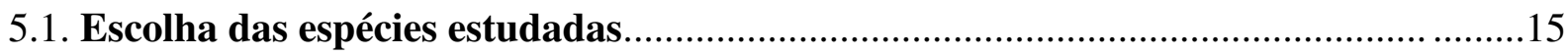

5.2. Áreas de estudo e épocas de coleta de frutos para a obtenção de sementes ……........17

5.3. Biometria e biomassa das sementes ………………….........................................18

5.4. Experimento 1. Germinação das sementes de G. americana e G. ulmifolia em condições

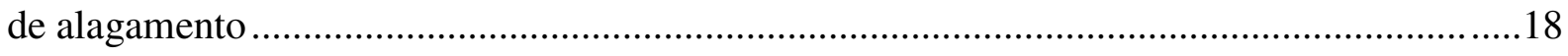

5.5. Experimento 2: Alagamento parcial e total das plantas jovens ..................................18

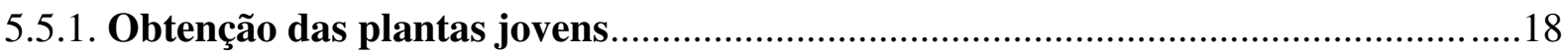

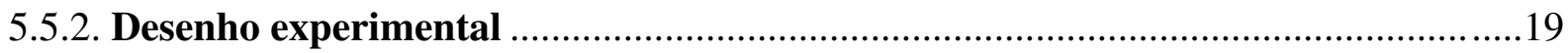

5.5.3. Sobrevivência, crescimento e morfologia e de plantas submetidas aos tratamentos

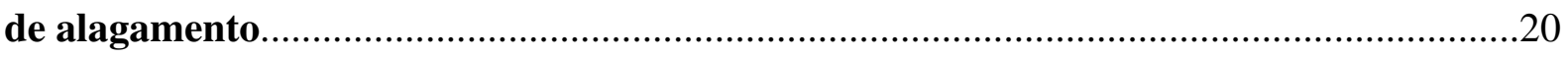

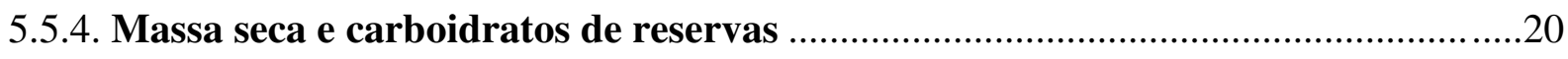

5.5.5. Anatomia da raiz

5.6. Experimento 3. Recuperação das plantas após o alagamento ..............................................22

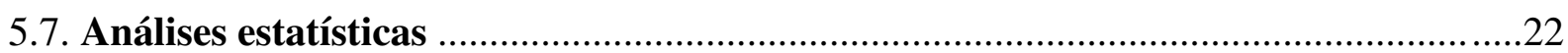




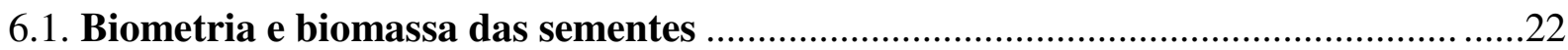

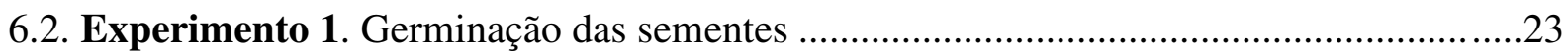

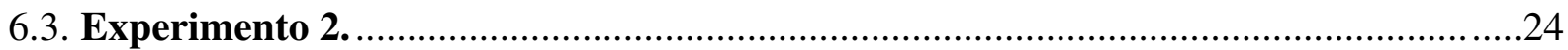

6.3.1. Sobrevivência, crescimento e morfologia de plantas submetidas aos tratamentos de

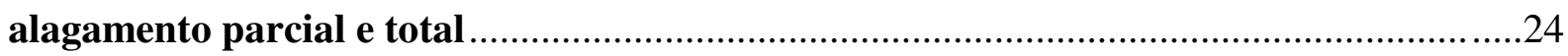

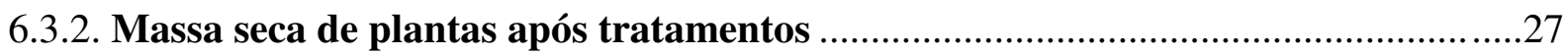

6.3.3. Carboidratos de reservas nas plantas após 30 dias de imposição de tratamentos..29

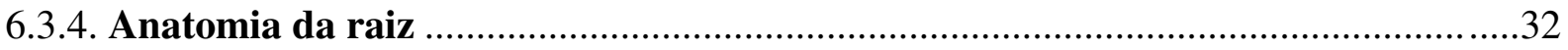

6.4. Experimento 3. Recuperação de plantas após 30 dias de alagamento parcial e total ......34

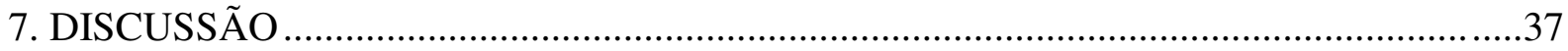

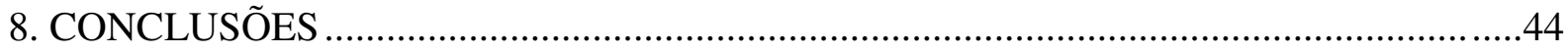

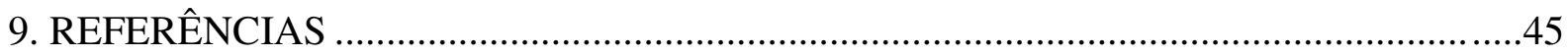

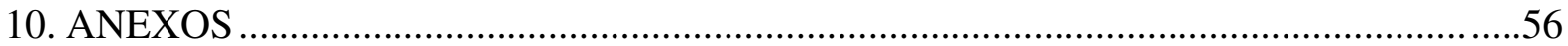




\section{Lista de Tabelas}

Tabela 1. Médias de medidas biométricas \pm desvio padrão de 50 sementes $(\mathrm{n}=50)$ de $G$. americana e G. ulmifolia, coletados no Cerrado e na Amazônia

\section{Lista de Figuras}

Figura 1. Diferentes etapas (a-f) da inundação sobre as planícies inundáveis ao longo do ano. 08

Figura 2. Áreas de várzea da Amazônia na Ilha da Marchantaria (A e B). Seta mostrando marca da inundação no ano anterior (2012).

Figura 3. Espécies estudadas: G. americana (A, B e C) $e$ G. ulmifolia (D, E e F) no período de dispersão de frutos

Figura 4. Sementes de G. americana germinando no tratamento de alagamento (A) e controle (B) com papel filtro umedecido.

Figura 5. Plantas jovens de G. americana (A) e de G. ulmifolia (B) em vaso plástico com Bioplant ${ }^{\circledR}$, antes da imposição dos tratamentos de alagamento parcial e total e experimento montado $(\mathrm{C})$.

Figura 6. Plantas de G.ulmifolia (A) e G. americana (B) mantidas em casa de vegetação para a recuperação por 30 dias.

Figura 7. Porcentagem (\%) de germinação de G. americana e G. ulmifolia coletadas na Amazônia e no Cerrado, submetidas ao alagamento.

Figura 8. Plantas de G. ulmifolia da Amazônia (A) e do Cerrado (B) 30 dias após tratamentos (Controle, Alagamento Parcial e Alagamento Total).

Figura 9. Crescimento acumulado em plantas jovens de G. americana (A) e G. ulmifolia (B) ao longo de 30 dias de tratamento.

Figura 10. Variação no número de folhas de G. americana (A) e G. ulmifolia (B), ao longo de 30 dias de experimento

Figura 11. Lenticelas hipertrofiadas no caule de G. ulmifolia (A e B) e G. americana (C e D) do Cerrado (A e C) e na Amazônia (B e D). Fissuras no caule de G. ulmifolia com origem do Cerrado (A).

Figura 12. Biomassa seca de raiz (A e B), caule (C e D) e folha (E e F) de plantas de $G$. americana e $G$. ulmifolia da Amazônia e do Cerrado, submetidas aos tratamentos. 
Figura 13. Razão entre a massa seca da raiz parte aérea de G. americana (A) e G. ulmifolia (B)

Figura14. Percentual de açucares solúveis totais (AST) (A, C e E) e amido (B, D e F) de raiz, caule e folha de $G$. americana ao final 30 dias de experimento de alagamento.

Figura 15. Percentual de açucares solúveis totais (AST) (A, C e E) e amido (B, D e F) de raiz, caule e folha de G. ulmifolia ao final 30 dias de experimento de alagamento

Figura 16. Visão geral da anatomia da raiz secundária de G. americana.

Figura 17. Visão geral da anatomia da raiz secundária de G. ulmifolia......

Figura 18. Incremento em altura e produção de folhas novas de $G$. americana (B e D) e $G$. ulmifolia (A e C) após 30 dias de recuperação. .35

Figura 19. Biomassa seca de raiz (A e B), caule (C e D) e folha (E e F) de plantas de $G$. americana e G. ulmifolia da Amazônia e do Cerrado, após 30 dias de recuperação. .36 


\section{Resumo}

Amazônia e Cerrado são os maiores e estão entre os importantes biomas brasileiros e são constituídos por ecossistemas com contrastantes regimes hídricos. Na Amazônia ganham destaque as florestas inundadas anualmente pelos principais rios e seus tributários, enquanto no Cerrado, embora áreas úmidas ocorram, a maior parte da vegetação ocorre em solos bem drenados e está exposta a uma seca sazonal periódica. Embora sejam marcantes as diferenças nos regimes hídricos dos dois biomas, é possível encontrar populações de uma mesma espécie que colonizam com sucesso ecossistemas do Cerrado e da Amazônia. O presente trabalho teve como objetivo avaliar o efeito do alagamento na germinação e no crescimento inicial de plantas jovens de Genipa americana L. (Rubiaceae) e Guazuma ulmifolia Lam. (Malvaceae) oriundas de populações que ocorrem na Amazônia (áreas alagáveis) e no Cerrado (cerradão). Para os experimentos de germinação de sementes, foram feitos dois tratamentos: alagados e não alagados (4 repetições x 25 sementes), em câmara de germinação com luz e temperatura controladas, onde avaliou-se o percentual de germinação. A emissão e curvatura gravitrópica da radícula serviram como referência para considerar a semente germinada. Para o experimento de alagamento, foram utilizadas plantas com 90 dias de idade cultivadas em copos plásticos de $500 \mathrm{~mL}$ com solo comercial Bioplant®, submetidas a três tratamentos por um período de 30 dias: controle (irrigação diária com solo na capacidade de campo), alagamento parcial (com uma lâmina de água $2 \mathrm{~cm}$ acima do solo) e alagamento total (submersão da planta). Foram utilizadas 20 plantas por tratamento e todo o experimento foi conduzido em casa de vegetação. Durante o período de experimento, foram observados semanalmente, a sobrevivência, o crescimento e as alterações morfológicas como o número de folhas, desenvolvimento de lenticelas hipertrofiadas no caule e formação de raízes adventícias. Ao final do experimento, avaliou-se a massa seca, carboidratos (açucares solúveis totais - AST e amido) e a formação de aerênquima nas raízes. Após o experimento de alagamento, cinco plantas por tratamento, foram mantidas em casa de vegetação para recuperação, por um período de 30 dias. Os resultados obtidos foram submetidos à análise de variância (ANOVA) e as médias foram comparadas pelo Teste de Tukey a 5\% de significância. Os resultados do experimento de germinação mostraram que, tanto $G$. americana quanto G. ulmifolia, independente da origem, germinam em condições de alagamento. No entanto, o percentual de germinação de G. americana com origem do Cerrado, em condições de alagamento, foi menor (66\%) em relação ao controle (93\%). Para G. ulmifolia, a origem e não o alagamento interferiu nesse parâmetro. As sementes com 
origem da Amazônia exibiram um percentual maior de germinação (23\%), em relação àquelas oriundas de populações do Cerrado (10\%). Ao final de 30 dias de experimento com plantas, o alagamento (parcial e total) não afetou a sobrevivência das duas espécies estudadas, que apresentaram $100 \%$ de sobrevivência, independente da origem. Porém, tanto G. americana, quanto G. ulmifolia, tiveram o crescimento reduzido em relação ao controle, principalmente quando submetidas ao alagamento total, além da queda de folhas ocorrida em G. ulmifolia, independente da origem (Amazônia e Cerrado). Plantas de G. ulmifolia com origem do Cerrado, tiveram seu crescimento comprometido de maneira similar quando submetidas ao alagamento parcial e total. Para minimizar o efeito negativo causado pelo alagamento, plantas de G. americana investiram na produção de lenticelas hipertrofiadas no caule e aerênquima nas raízes, enquanto plantas de G. ulmifolia, além dessas estruturas, produziram raízes adventícias. Após o período de alagamento, em 30 dias, G. americana se recuperou, acompanhando o crescimento das plantas controle, mostrando um elevado nível de tolerância ao alagamento, independente da origem. Porém, as plantas de G. ulmifolia, apesar de sobreviverem e continuarem crescendo, não acompanharam o crescimento das plantas controle. Sugerindo serem mais sensíveis ao alagamento, principalmente aquelas oriundas de populações com origem do Cerrado. Os resultados deste estudo contribuem para orientar planos de manejo e recuperação de áreas submetidas a saturações hídricas do solo.

Palavras chave: tolerância ao alagamento, lenticelas e aerênquima. 


\section{Abstract}

Amazon and Cerrado are the largest and are among the major biomes of Brazil and are constituted by contrasting hydric regimes. In the Amazon the floodplain forests are seasonally flooded by the major rivers and their tributaries, while in the Cerrado although moist areas occur, most of the vegetation occurs in well-drained soils and are exposed to seasonal drought. In spite the striking differences in hydric regimes between the two biomes, some species are able to colonize successfully ecosystems of the Cerrado and the Amazon. This study aimed to evaluate on the effect of flooding on germination and initial growth of Genipa americana (Rubiaceae) and Guazuma ulmifolia (Malvaceae) derived from populations that occur in the Amazon (Varzea forest) and in the Cerrado (cerradão woodland). In the seed germination experiments seeds were subjected to two treatments: flooded and not flooded (4 replicates x 25 seeds) in a growth chamber with controlled light and temperature, which evaluated the percentage of germination. The protrusion and gravitropic curvature of the radicle served as reference to consider that the seed germinated. For the flooding experiment 90 days old plants were used, grown in $500 \mathrm{ml}$ plastic cups with a commercial soil (Bioplant ${ }^{\circledR}$ ), that were subjected to three treatments for 30 days: control (daily irrigation with soil at field capacity), partial flooding (water height at about $2 \mathrm{~cm}$ above the soil surface), and total flooding (submersion of the whole plant). A total of 20 plants were used per treatment and the entire experiment was conducted in a greenhouse. Survival, growth and morphological changes as the number of leaves, development of hypertrophied lenticels on the stems and formation of adventitious roots were evaluated weekly. At the end of the experiment, the plants were harvested to determine dry mass, carbohydrates (starch and AST) and root samples were taken to assess the formation of aerenchyma in the roots. After flooding experiment, five plants per treatment were maintained in the greenhouse at the end of the experiment to follow recovery for a period of 30 days. The results were submitted to analysis of variance (ANOVA) and the means were compared by the Tukey test at 5\% significance. Regardless of plant origin, both $G$. americana and G. ulmifolia, source, germinated under flooding conditions. However, percentage germination of flooded seeds of G. americana from the Cerrado was lower (66\%) compared to controls (93\%). For G. ulmifolia, the origin, and not the flooding treatment, interfered with this parameter. Seeds from the Amazon region exhibited a higher percentage of germination (23\%), compared to those collected from the Cerrado populations (10\%). Flooding (partial and total) did not affect the survival of both species, which showed $100 \%$ survival, regardless of origin. However, 
growth of both species was reduced compared to controls, especially when plants were subjected to total flooding. Leaf abscission occurred in flooded (partial and total) plants of $G$. ulmifolia, regardless of origin (Amazon and Cerrado). G. ulmifolia plants with the Cerrado origin, had their growth compromised similarly when subjected to partial and full flooding. To minimize the negative effect caused by flooding, G. americana plants invested in the production of hypertrophied lenticels and aerenchyma in the roots, while plants of $G$. ulmifolia, besides these structures, produced adventitious roots. After the flooding period, within 30 days, G. americana recovered, following the growth of control plants, showing a high level of tolerance to flooding, regardless of origin. Although, plants of G. ulmifolia also survived and were able to grow, they were not able to follow the growth of control plants, which suggests that they are more sensitive to flooding, especially those from the Cerrado. The findings contribute to guide plans of management and recovery of areas subject to ground water saturations.

Keywords: flooding tolerance, lenticels and aerenchyma. 


\section{INTRODUÇÃO}

Amazônia e Cerrado são os maiores e estão entre os mais importantes biomas brasileiros e são constituídos por ecossistemas com contrastantes regimes hídricos (Oliveira Filho e Ratter, 2002; Klink e Machado, 2005; Scariot et al., 2005). Na Amazônia ganham destaque as florestas inundadas anualmente pelos principais rios e seus tributários (Parolin, 2000; 2001), enquanto no bioma Cerrado embora áreas úmidas ocorram, a maior parte da vegetação ocorre em ecossistemas com solos bem drenados sendo exposta a uma seca sazonal periódica, além da deficiência nutricional e o fogo (Franco, 2004; Giambelluca et al., 2009; Rossatto et al., 2009).

Em áreas alagáveis da Amazônia, durante o período de inundação, a vegetação das várzeas podem ser parcialmente ou totalmente alagadas. Nessas condições, os poros do solo são preenchidos por água dificultando a difusão de gases, como o oxigênio, comprometendo todo o desenvolvimento das plantas (Pezeshki, 2001; Pisicchio et al., 2010). Desta forma, o excesso de água atua como um fator de estresse podendo diminuir ou inibir a germinação de sementes, restringir o crescimento e consequentemente afetar o seu estabelecimento e até mesmo interferir na sobrevivência ou mortalidade da planta (Kozlowski, 1997; Dantas et al., 2000; Ferreira et al., 2009; Medina et al., 2009).

Para sobreviver ao estresse causado pelo alagamento, as plantas que habitam essas áreas possuem estratégias de germinação e desenvolvimento, que permitem o sucesso de colonização em ambientes sujeitos a um pulso de inundação que pode durar até mais de 200 dias, com uma coluna de água que atinge em média, uma altura de 10 metros (Junk et al., 1989; Lobo e Joly, 2000; Parolin, 2001). Espécies tolerantes ao alagamento desenvolvem respostas morfológicas, anatômicas, bioquímicas e fisiológicas que minimizam o efeito do estresse causado pelo alagamento, garantindo a sobrevivência e desenvolvimento nessas condições (Koslowisk, 1997; Parolin, 2003; Ferreira et al., 2007, 2009; Menegucci, 2008).

Enquanto nas florestas alagáveis da Amazônia, a vegetação está sujeita ao pulso anual de inundação, em ecossistemas bem drenados do bioma Cerrado, como no cerrado sentido restrito e cerradão, a vegetação está exposta a uma seca sazonal periódica (déficit hídrico) (Franco, 2004; Giambelluca et al., 2009; Rossatto et al., 2009), que limitam a produtividade da planta (Medina, 1987). Nesses ecossistemas, as plantas são fisiologicamente adaptadas a 
responder ao estresse causado pela seca sazonal (Franco, 2000; Silva et al., 2009), a fim de obterem sucesso na sua colonização. No entanto, quando expostas a saturação hídrica do solo, mostram ser pouco tolerantes (Hoffmann et al., 2004). Gregório et al. (2008), trabalhando com plantas jovens de Tabebuia heptaphylla (ipê-rosa), espécie comumente encontrada no Cerrado (Medeiros, 2011), observaram que quando submetida ao alagamento em condições experimentais, não desenvolvem estruturas que minimizem o efeito do alagamento, apresentando alta taxa de mortalidade.

A intolerância ao alagamento pode ser também observada, em espécies que ocorrem em terra firme na Amazônia. Ferreira et al. (2007), observaram diferenças na tolerância ao alagamento em plântulas de mesma espécie de Himatanthus sucuuba, oriundas de populações que habitam áreas de várzea e de florestas de terra firme na Amazônia. Quando submetidas a experimentos que simularam diferentes condições de alagamento (parcial e total), as respostas das plantas estavam muito relacionadas ao ambiente de origem das sementes, tanto de várzea, quanto de terra firme. Entretanto, a amplitude do alagamento foi o fator determinante naquele estudo, pois as plântulas de terra firme apresentaram injúrias, seguida de morte de $100 \%$ dos indivíduos quando estes foram submetidos à submersão total, o mesmo não foi verificado para as plântulas oriundas da várzea (70\% de sobrevivência). Esse estudo mostra que populações de mesma espécie, com representantes em ecossistemas com pressões ambientais contrastantes, podem estar tão adaptadas ao local de origem, que são capazes de responder de forma diferente quando submetidas a determinado estresse, presente em apenas um desses ambientes.

Segundo Dias-Filho (2006) as respostas das plantas ao alagamento pode variar amplamente entre as espécies, ou mesmo entre a mesma espécie (diferentes ecótipos) de acordo com a plasticidade e a intensidade do estresse causado pelo alagamento. Assim sendo, a tolerância das plantas ao alagamento, depende da sua plasticidade ou capacidade de aclimatação (Armstrong et al., 1994). Além de diferir em função do tempo de exposição e altura da coluna de água.

Embora sejam marcantes as diferenças nos regimes hídricos nas áreas alagáveis da Amazônia e nos ecossistemas bem drenados do Cerrado, inventários florísticos mostram ser possível encontrar populações pertencentes a uma mesma espécie de ampla distribuição, que colonizam com sucesso ecossistemas da Amazônia, como as áreas alagáveis e do Cerrado, como o cerradão (Silva-Júnior, 2005; Lorenzi, 2008; Wittmann et al., 2010; Silva Júnior e 
Lima, 2010; Kuhlmann, 2012). Essas espécies podem não ser especificamente adaptadas à seca ou ao alagamento do solo, estritamente, mas sim tolerantes à sazonalidade previsível nesses ambientes (Worbes et al., 1992).

Até então, não foram encontrados estudos comparativos de tolerância ao alagamento, entre arbóreas pertencentes à mesma espécie e que ocupam ecossistemas do Cerrado e da Amazônia. Dessa forma torna-se importante entender os mecanismos morfoanatômicos, bioquímicos e fisiológicos que permitem a germinação de sementes e o desenvolvimento de plantas jovens, em diferentes regimes hídricos. Além disso, saber se essas populações respondem de maneira similar quando submetidas ao alagamento.

Neste trabalho, foram avaliados dados biométricos das sementes das espécies arbóreas de Genipa americana L. (Rubiaceae) e Guazuma ulmifolia Lam. (Malvaceae) oriundas da Amazônia (áreas alagáveis) e do Cerrado (cerradão), bem como a germinação de sementes, quando submetidas ao alagamento. Além de avaliar o efeito do alagamento parcial e total na morfoanatomia, fisiologia e bioquímica de plantas jovens dessas espécies.

\subsection{Referencial Teórico}

\section{Amazônia}

Anualmente, os principais rios da Amazônia, transbordam causando alagamento de extensas planícies ao longo dos rios e seus tributários. Esse transbordamento se deve ao grande volume de água nas cabeceiras durante a época chuvosa na região (Fig. 1), o que impõem principalmente às plântulas, a longos períodos de inundação (Parolin, 2000; 2001), com uma coluna de água que pode chegar a uma altura média de 10 m (Junk et al., 1989; 1993). Nestas florestas o período de seca, dura em média quatro meses e essas condições ambientais estabelecem no ambiente ao longo do ano, uma fase aquática e uma fase terrestre para as espécies que ali habitam (Junk et al., 1989). 
(a)

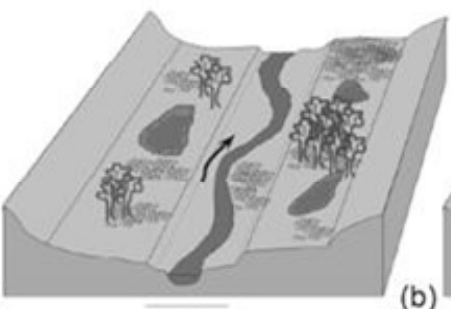

(d)

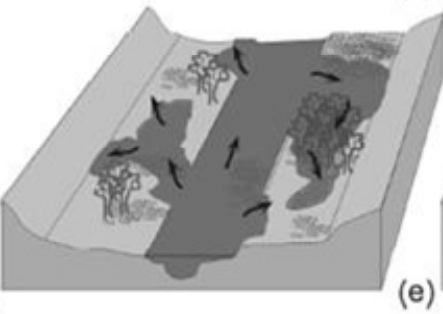

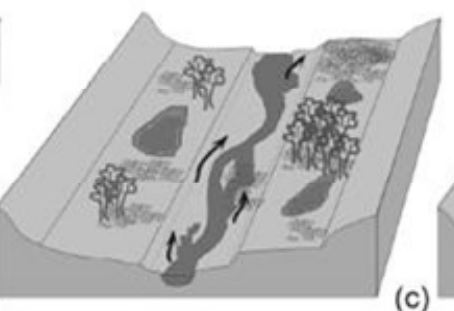

(c)

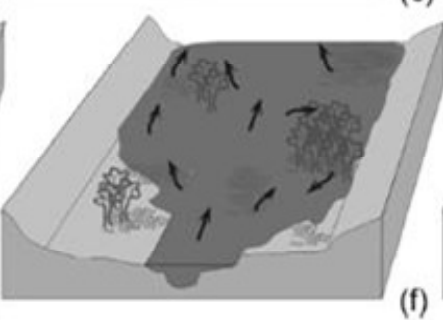

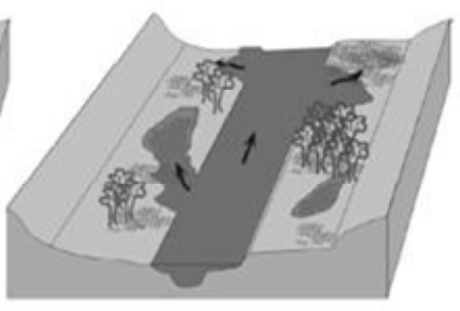

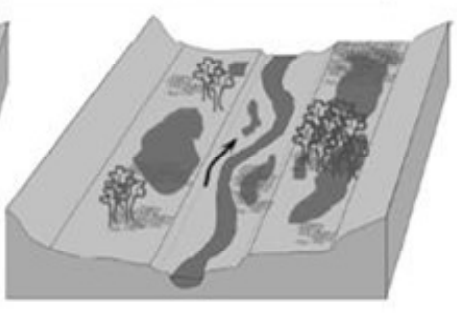

Figura 1. Diferentes etapas (a-f) da inundação sobre as planícies inundáveis ao longo do ano. Adaptado Paz, A. R., 2010.

Entre as áreas inundáveis da Amazônia pode se destacar as áreas de várzea, que são planícies banhadas por rios de água branca ou barrenta, oriunda dos Andes ou áreas préandinas (fig. 2). O solo dessas regiões é considerado rico em minerais e sedimentos que ao serem transportados conferem a cor branca ou barrenta da água, com pH entre 6,5 e 7,0 (Sioli, 1968).
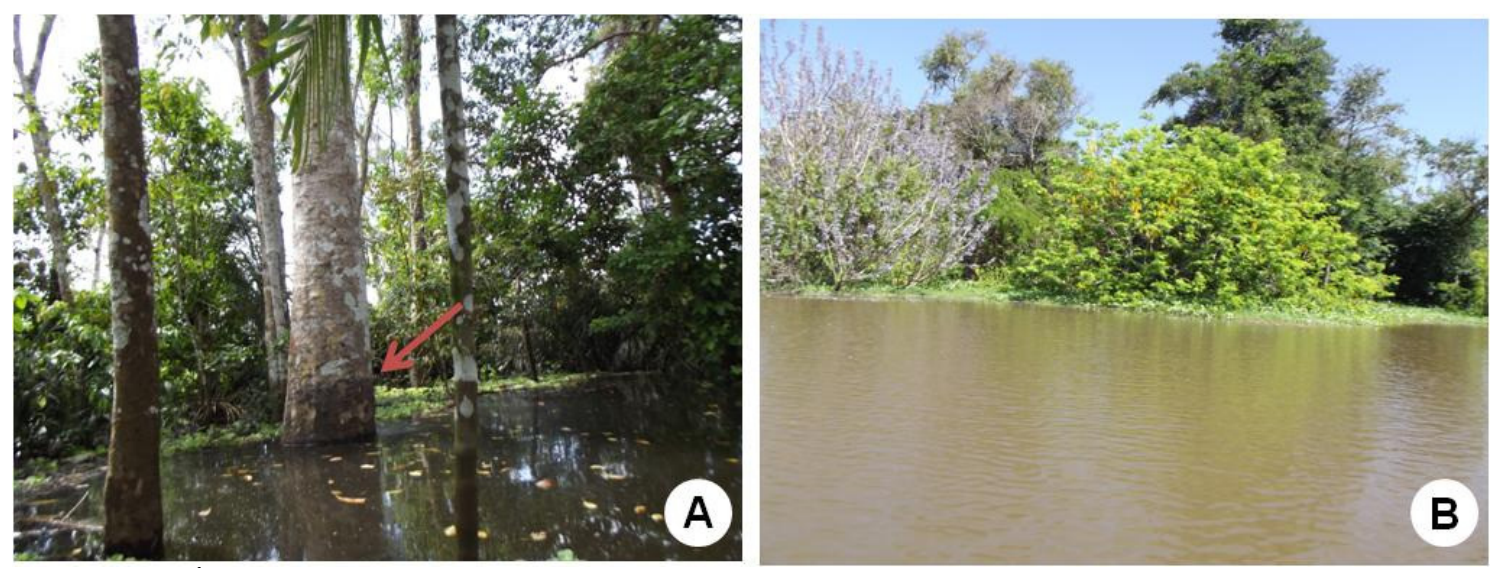

Figura 2. Áreas de várzea da Amazônia na Ilha da Marchantaria nas proximidades de Manaus - AM (A e B). Seta aponta marca da inundação no ano anterior a coleta (2012).

Em condições de alagamento o nível de oxigênio no solo torna-se menor, dado que os espaços do solo ficam preenchidos por água, o que pode dificultar a respiração nas raízes (Pezeshki, 2001; Pisicchio et al., 2010). Longos períodos de alagamento e a alta coluna de água resultam em condições de anóxia nos espaços radiculares, levando a redução da atividade radicular, déficit hídrico na copa (Worbes, 1995) e a diminuição da assimilação fotossintética (Piedade et al. 2000). A tolerância ao estresse devido à privação de oxigênio 
pode variar de poucas horas a muitos dias, ou mesmo semanas, conforme a espécie, os órgãos afetados e estágio de desenvolvimento da planta (Vartapetian e Jackson, 1997). Dessa maneira, somente plantas que possuem eficientes adaptações para tolerar a submersão conseguem se estabelecer (Maurenza et al., 2009).

Ao longo do processo evolutivo, as espécies arbóreas tolerantes ao alagamento, desenvolveram várias respostas morfológicas, fisiológicas e anatômicas como estratégia de adaptação que minimizem o impacto do estresse (Kozlowski, 1997) e garantam a sobrevivência da planta (Jackson e Ram, 2003). Dentre as principais estratégias observadas destacam-se o rápido crescimento do caule em plântulas, como estratégia de refugiar dos efeitos da submersão (Parolin, 2001), queda das folhas (Junk et al., 1989; Mielke et al., 2003; Gonçalves et al., 2013) e aparecimento de raízes adventícias (Kozlowski, 1997; Lopez e Kursar, 2003; Parolin, 2009; Ferreira et al., 2009), importante adaptação para a absorção de gases dissolvidos na água. Durante o período de alagamento, há espécies que investem menos ou paralisam o crescimento, reduzindo o consumo de energia, sendo este retomado ao final do período de estresse (Medri et al., 2007; Parolin, 2009; Ferreira et al., 2009).

Para muitas espécies arbóreas a tolerância à inundação ocorre em função do desenvolvimento de estruturas morfoanatômicas como, a formação de lenticelas hipertrofiadas e aerênquimas (Ezin et al., 2010), que facilitam a circulação de gases. Além disso, pode ocorrer também desvio na rota metabólica de aeróbia, para anaeróbia, redução do metabolismo e consequente queda da produção e no consumo de açucares (Kozlowski, 1997; Lobo e Joly, 1998; Ferreira et al., 2009).

\section{Cerrado}

O bioma Cerrado é caracterizado por uma grande variedade de tipos fisionômicos, sendo considerado o segundo maior bioma brasileiro (Oliveira Filho e Ratter, 2002). Dentre os tipos fitofisionômicos destacam-se, o cerrado sentido restrito, o cerradão, as matas ciliares, matas secas e matas de galerias (Silva Júnior, 2012).

O Cerrado é constantemente submetido a uma extrema sazonalidade pluviométrica; os verões são quentes e chuvosos e os invernos são frios e secos, além da baixa disponibilidade nutricional no solo (Goodland e Pollard, 1973) e a presença frequente de fogo, sendo esses 
fatores determinantes no estabelecimento das espécies no ecossistema. Os solos do Cerrado são predominantemente bem drenados, no entanto, áreas úmidas ocorrem e estas são indispensáveis na manutenção dos cursos d'água e na conservação da flora e fauna do bioma (Meirelles et al., 2004, Palhares et al., 2010). Nessas áreas sujeitas ao alagamento, principalmente próximo a rios, a vegetação fica exposta a períodos de alagamento e períodos de seca (Palhares et al., 2010).

Dentre os fatores citados, a água é considerada o mais importante na determinação da fisionomia, na composição florística, nas adaptações funcionais da vegetação e na distribuição das espécies (Palhares et al., 2010). Segundo Franco (2002) a fisionomia dos vegetais é influenciada pela exploração diferenciada de água no solo. Apesar das deficiências hídricas presentes no Cerrado, o bioma é rico em espécies que para garantir a sobrevivência, possuem respostas adaptativas, morfoanatômicas e bioquímicas que minimizam o efeito do estresse causado pela seca sazonal (Palhares et al., 2010).

Em condições de déficit hídrico, as plantas podem sofrer mudanças morfoanatômicas e bioquímicas, com intensidade que depende da espécie de planta e do grau de duração desse estresse (Kramer, 1983). Estudos destacam a queda da atividade fotossintética (Smirnoff, 1993), devido ao fechamento dos estômatos e consequente redução na captação de $\mathrm{CO}_{2}$ (Baker, 1993). Parte da composição vegetal é marcada por árvores com troncos tortuosos, com ramificações irregulares e retorcidas e as folhas são geralmente coriáceas (Goodland e Ferri, 1979; Ribeiro e Walter, 1998).

Outras adaptações são referidas, como o desenvolvimento de raízes profundas, o investimento de biomassa em órgãos de reserva, rápida regulação no mecanismo de abertura de estômatos, maior cutinização da epiderme foliar e perda de folhas com o propósito de diminuir a transpiração e manter o balanço hídrico da planta (Franco, 1998; Larcher, 2000). Além da redução da parte aérea em favor das raízes, limitando sua capacidade de competir por luz, com consequente redução na produtividade (Nabinger, 1997).

Se por um lado plantas do Cerrado possuem adaptações de tolerância a seca sazonal (Silva et al., 2009), por outro, apesar de áreas úmidas ocorrerem, estudos relatam uma alta sensibilidade ou até mesmo intolerância de muitas espécies ao alagamento (Hoffmann et al., 2004; Gregório et al., 2008). 


\section{Estresse hídrico e o Efeito do alagamento no solo}

O estresse pode ser definido, como uma influencia negativa de fatores externos ao desenvolvimento da planta, podendo causar danos em alguma parte da planta, ou em todo o vegetal levando-o a morte (Larcher, 2000; Taiz e Zeiger, 2004; 2009).

Plantas, por serem seres sésseis, estão expostas a diversos componentes ambientais que são ou podem se tornar estressantes em curto período de tempo. Por exemplo, um recurso essencial como a água pode se tornar um fator estressante quando em falta (déficit hídrico) ou em excesso (alagamento) (Larcher, 2000). Em ambas as situações de estresse hídrico, tanto a germinação, quanto o crescimento das plantas podem ser comprometidos, dependendo da espécie e do tempo de duração do estresse (Kozlowski, 1997; Larcher, 2000).

Contudo, muitas espécies colonizam com sucesso fitofisionomias sujeitas a alterações nas condições hídricas do ambiente, como é o caso de áreas bem drenadas do Cerrado e das áreas alagáveis amazônicas, onde a falta e o excesso de água, respectivamente, representam fortes fatores estressantes (Hoffmann et al., 2004). As plantas que colonizam esses ambientes desenvolvem adaptações hormonais que geram mudanças no metabolismo e na morfologia, amenizando o efeito causado pelo estresse hídrico e garantem a sua sobrevivência (Joly, 1991; Crawford e Brandle, 1996; Larcher, 2000; Taiz e Zeiger, 2009).

Em áreas periodicamente ou permanentemente alagadas, durante o período de inundação, o ar presente nos poros solo é substituído por água, diminuindo a difusão de gases nas raízes das plantas provocando diversos danos as mesmas, que podem ser irreversíveis (Castro et al., 2009). A diminuição na difusão de gases, principalmente do oxigênio nas raízes, afeta o metabolismo da planta e consequentemente o seu desempenho é comprometido (Taiz e Zeiger, 2004). Sendo este o fator que mais dificulta o estabelecimento e a sobrevivência das plantas em ambientes alagados (Kozlowski, 1997; Crawford e Braendle, 1996).

Sob alagamento do solo, além da baixa disponibilidade de oxigênio, há também diminuição na difusão do etileno, que em condições de alagamento é continuamente produzido pela planta e acumulado, sendo um dos principais responsáveis pela senescência e abscisão foliar, além de influenciar na produção de raízes adventícias e aerênquimas (Brailsford et al., 1993; Voesenek et al., 1993).

Desse modo, os efeitos causados pelo alagamento do solo podem determinar o tipo, a estrutura da vegetação e a sua capacidade de adaptação às condições impostas pelo alagamento (Junk, 1993). Apesar do alagamento do solo impor condições extremas às plantas, 
estudos mostram que várias espécies são capazes de colonizar com sucesso, ecossistemas inundáveis (Andrade et al., 1999; Wittmann et al., 2010; Parolin et al., 2010; Gonçalves et al., 2013).

\section{Tolerância ao alagamento}

Em ambientes florestais sujeitos à inundação ocorre variação em relação à duração, à frequência e à amplitude do alagamento. Nas várzeas amazônicas, por exemplo, a inundação é sazonal chega a cobrir as copas de muitas árvores durante um período aproximado de seis meses (Scarano, 1998). Essa variação na frequência e amplitude do alagamento pode refletir na composição florística e na estrutura da vegetação (Rodrigues, 1989).

Em geral plantas de ambientes permanentemente inundados, ou possuem adaptações que lhes possibilitam se estabelecer e sobreviver em ambientes hipóxicos, ou necessitam aproveitar os períodos em que o nível da água diminui, para germinar e desenvolver (Marques e Joly, 2000). O sucesso no estabelecimento de uma planta em áreas alagáveis, depende também da estratégia de frutificação e dispersão dos frutos, associada à capacidade de sobrevivência na água (Marques e Joly, 2000).

Tanto espécies tolerantes, quanto as não tolerantes ao alagamento, sofrem uma queda na respiração aeróbica quando expostas a condições de déficit de oxigênio, causando diminuição na produção de energia e, consequentemente restringindo o desenvolvimento da planta (Liao e Lin, 2001). Além disso, produtos do metabolismo anaeróbico, como aldeídos, ácidos orgânicos e etanol podem causar injúrias ou até mesmo a morte das plantas em condições de alagamento (Crawford et al., 1984; Andrev, 1992). Espécies tolerantes produzem alterações morfoanatômicas em resposta ao efeito causado pelo alagamento, que facilitam a difusão de gases e ajusta o seu metabolismo, diminuindo o consumo de energia e consequentemente apresentam um menor investimento no crescimento (Medri et al., 2002).

O alagamento diminui a permeabilidade de água das raízes (Kozlowski, 1982), diminuindo assim, a absorção de água e nutrientes pela planta. Plantas adaptadas ao alagamento, para facilitar a absorção de água, nutrientes e a difusão de gases como o oxigênio e o etileno, desenvolvem aerênquimas nas raízes (Vartaperian e Jackson, 1997; Yin et al., 2010), raízes adventícias e lenticelas hipertrofiadas na base caulinar, que facilitam a difusão de gases e eliminação de compostos tóxicos resultante do metabolismo anaeróbio, como o etanol (Joly, 1991; Lobo e Joly, 2000; Batista et al., 2008). 
Estudos revelam que o alagamento, diminui significativamente a assimilação fotossintética das plantas (Fernandez et al., 1999; Piedade et al., 2000; Parolin et al., 2001). Espécies tolerantes fecham os estômatos, elevando a chance de sobrevivência das plantas, já que reduzem a demanda por água e nutrientes e restringem a absorção de íons tóxicos (Jackson, 1994). Além do fechamento de estômatos, plantas submetidas ao alagamento, apresentam queda das folhas (Junk, 1993; Lobo e Joly, 2000), o que compromete ainda mais a fotossíntese.

Segundo Junk (1993), plantas adaptadas ao alagamento, podem apresentar pouco ou nenhum crescimento durante o período de alagamento. Além da diminuição no crescimento caulinar (Batista et al., 2008), a raiz pode ter seu crescimento mais comprometido por ser o órgão mais exposto a saturação hídrica do solo (Lobo e Joly, 2000). Para espécies não tolerantes, a saturação hídrica além de inibir o crescimento da planta inteira (Lobo e Joly, 2000; Oliveira e Joly, 2010; Gonçalves et al., 2013), pode levar a morte (Costa et al., 2006). Gregório et al. (2008), observou alta taxa de mortalidade em plantas de Tabebuia heptaphylla (Ipê rosa) submetidas ao tratamento de alagamento, que não produziram estruturas que permitem a sobrevivência em ambientes alagados, mostrando não serem tolerantes ao alagamento.

\section{Germinação}

O processo de germinação tem início com a embebição da semente, que induz a reativação do metabolismo gradativamente e a retomada do crescimento do embrião, com o consequente rompimento do tegumento pela radícula e sua emergência (Borges e Rena 1993; Bewley e Black, 1994). Durante a germinação, ocorre uma sequência de reações bioquímicas onde as substâncias de reserva são quebradas e mobilizadas ao eixo embrionário (Höfs et al., 2004).

Entre as mais importantes substâncias de reservas armazenadas na semente estão, os carboidratos, lipídeos e proteínas (Corte et al., 2006). Na germinação, estas reservas orgânicas são metabolizadas para atender a demanda de crescimento do eixo embrionário, fornecendo energia e metabólitos para o desenvolvimento da plântula até o seu completo estabelecimento autotrófico e sua adaptação aos mais variados ambientes (Buckeridge et al., 2000; Kidson e Westoby, 2000; Ferreira e Borghetti, 2004).

Entre as reservas, os carboidratos armazenados no endosperma constituem a principal fonte de energia para o processo germinativo e crescimento inicial das plântulas (Buckerigde 
et al., 2004). Desse modo, o teor de reservas nas sementes, está relacionado com o vigor das plântulas originadas (Carvalho e Nakagawa, 2000). Sementes maiores, com uma maior quantidade de reserva aumentam a chance de sucesso no estabelecimento da plântula até mesmo em ambientes desfavoráveis, já que produzem plântulas com maior vigor (Haig e Westoby, 1991; Paz e Martínez-Ramos, 2003; Alves et al., 2005; Klein et al., 2007).

Além das reservas utilizadas pelo embrião na germinação, outros fatores podem influenciar fortemente como, a dormência da semente, a disponibilidade de água, luz, temperatura e oxigênio, que combinados criam condições favoráveis para o sucesso da germinação (Válio e Scarpa, 2001; Neto et al., 2003). Entretanto, o grau de exigência dos fatores ambientais é variável entre as espécies e, na maioria das vezes, determinado pelo genótipo e pelas condições ambientais que prevalecem durante a formação das sementes (Mayer e Poljakoff-Mayber, 1975).

Dentre esses fatores, a água é essencial para que ocorra a germinação da semente, uma vez que a ativação do metabolismo é iniciada com a embebição (Bewley e Black, 1994). Porém, o excesso de água pode ser prejudicial, por reduzir a disponibilidade de oxigênio (Taiz e Zeiger, 2004) requerida para que ocorra o metabolismo das reservas e a consequente germinação das sementes. A maioria das sementes de plantas terrestres que possui alta taxa de germinação no solo, não germinam na água, uma vez que estas perdem rapidamente a viabilidade sob tais condições (Parolin, 2001). O alagamento em volta da semente pode causar danos severos em nível celular, impedindo a germinação, induzindo a dormência ou mesmo a morte do embrião (Kozlowiski, 1997; Scarano, 2003; Kolb e Joly, 2010). Segundo Liberato (2010), sementes de Hevea spruceana que germinam em solos na capacidade de campo e em solos encharcados, não germinam em solos totalmente inundados de várzea da Amazônia Central. Logo, o requerimento de água para a germinação pode variar com a espécie e o ambiente em que a mesma está adaptada.

\section{OBJETIVO GERAL}

Este estudo teve como objetivo geral, avaliar a germinação de sementes e o comportamento de plantas jovens de Genipa americana e Guazuma ulmifolia, que ocorrem em ecossistemas alagáveis da Amazônia e áreas bem drenadas do Cerrado (cerradão), ao alagamento parcial e total. 


\section{OBJETIVOS ESPECÍFICOS}

- Analisar a biometria e a massa seca das sementes de G. americana e G. ulmifolia, coletadas na Amazônia (florestas alagáveis) e no Cerrado (cerradão).

- Avaliar o percentual de germinação de sementes das espécies selecionadas, em condições de alagamento.

- Avaliar a sobrevivência, o crescimento, as alterações morfoanatômicas e bioquímicas das plantas, quando submetidas ao alagamento parcial e total.

- Avaliar a recuperação das plantas depois de retiradas do alagamento parcial e total.

\section{HIPÓTESES}

1) Sementes de G. americana e G. ulmifolia procedentes das coletas na Amazônia (áreas alagáveis) germinarão e formarão plântulas em condições de alagamento. Já as sementes das mesmas espécies procedentes do Cerrado do Brasil Central (cerradão) não germinarão em condições de alagamento.

2) Plantas jovens de G. americana e G. ulmifolia oriundas de sementes coletadas na Amazônia ou no Cerrado, mostrarão níveis diferentes de tolerância às condições experimentais de alagamento (parcial e total), em função do ambiente de origem (Amazônia ou Cerrado), com as plantas oriundas do cerrado apresentando elevada taxa de mortalidade quando submetidas às condições de alagamento total.

\section{MATERIAL E MÉTODOS}

\section{1. Escolha das espécies estudadas}

O estudo foi realizado com duas espécies arbóreas que possuem populações ocorrendo nos ecossistemas inundáveis da Amazônia e em áreas que não sofrem com a saturação hídrica do solo no bioma Cerrado. A escolha das espécies se deu a partir de consulta dos dados de literatura e lista florísticas disponíveis para os dois ambientes (Silva-Júnior, 2005; Lorenzi, 2008; Wittmann et al., 2010; Silva Júnior e Lima, 2010; Kuhlmann, 2012) e em função da disponibilidade de frutos na época da coleta desejada. 


\section{Caracterização das espécies selecionadas}

\section{Genipa americana L. (Rubiaceae)}

Conhecida popularmente como jenipapeiro é uma árvore que possui em média 8-14m, podendo atingir até 30m de altura. Originária das Américas Central, sul e Antilhas, ocorre em todo Brasil nos domínios da Amazônia, Caatinga, Cerrado, Mata Atlântica, Pantanal. Em grande parte do Brasil, a espécie pode ser encontrada em formações florestais situadas em várzeas úmidas e encharcadas. No Cerrado ocorre em vegetação de mata seca, cerradão e mata de galeria. Apresentam frutos comestíveis, com polpa adocicada, que podem medir até $10 \mathrm{~cm}$ de diâmetro e servem como alimento à fauna que atuam como dispersores da espécie. As sementes apresentam coloração amarelada e medem $1,2 \mathrm{~cm}$ de diâmetro. Além de outras utilidades, a espécie é indicada na recuperação de áreas degradadas, visto que seus frutos são importantes na alimentação da fauna (Santarelli, 2001; Lorenzi, 2008; Wittmann et al., 2010; Silva Júnior e Lima, 2010; Kuhlmann, 2012) (Fig. 3A, B e C).

\section{Guazuma ulmifolia Lam. (Malvaceae)}

Conhecida como mutamba, é uma árvore com altura que pode variar entre $8 \mathrm{e} 16 \mathrm{~m}$. A espécie ocorre em quase todo o Brasil, desde a Amazônia até o Paraná, nos domínios do Cerrado, Caatinga, Amazônia e Mata Atlântica. O habitat predominante da espécie é em florestas latifoliadas semidecíduas, ocorrendo em cerradão, mata seca e mata de galeria. Suas flores amarelas são polinizadas por abelhas (Deus et al., 1993). Seus frutos medem até 2,5 cm de diâmetro e quando maduros apresentam a cor preta com polpa seca, adocicada e servem como alimento para a fauna silvestre. Os mamíferos atraídos pelos frutos como o quati (Nasua nasua), a anta (Tapirus terrestris), o macaco prego (Cebus apella) e aves, atuam como importantes dispersores da espécie, além de peixes (Brina, 1998) quando a ocorrência da mesma é em ambientes alagáveis. A sua semente mede até $2 \mathrm{~mm}$ de comprimento, e pode aparecer mais de 50 sementes por fruto. A espécie possui diversas utilizações, e é considerada importante no reflorestamento e indicada para o paisagismo. (Ribeiro e Walter, 1998; Lorenzi, 2008; Wittmann et al., 2010; Kuhlmann, 2012) (Fig. 3 D, E e F). 


\section{2. Áreas de estudo e épocas de coleta de frutos para a obtenção de sementes}

Os frutos das espécies localizados na Amazônia foram coletados em áreas alagadas de várzea, banhadas pelo rio Solimões na Ilha da Marchantaria ( $3^{\circ}$ 1'28.36"S; 60 8'48.12 "O) nas proximidades de Manaus - AM. No bioma Cerrado, a coleta se realizou no município de

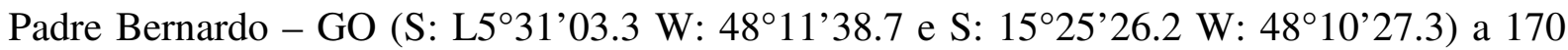
km de Brasília - DF em fitofisionomias de cerradão. Nesses locais, os frutos foram coletados diretamente das árvores (3 a 4 matrizes) em áreas de vegetação nativa (Fig. 3). Após a coleta, os frutos foram devidamente acondicionados em caixas de isopor e encaminhados ao laboratório de Ecofisiologia Vegetal da Universidade de Brasília (UNB) para o beneficiamento. As sementes obtidas foram misturadas para a obtenção de lotes compostos, para garantir a aleatoriedade das amostras. Foram conduzidos três experimentos: o primeiro para avaliar a germinação das sementes, o segundo com plantas jovens, ambos submetidos ao alagamento e o terceiro, para avaliar a capacidade de recuperação das plantas após o experimento de alagamento. Nesse estudo, o termo planta jovem será utilizado para se referir a plantas com idade mínima de 90 dias.

Na Amazônia a coleta dos frutos das duas espécies ocorreu em junho de 2013, enquanto no Cerrado os frutos de G. ulmifolia foram coletados em agosto e de G. americana em outubro do mesmo ano.
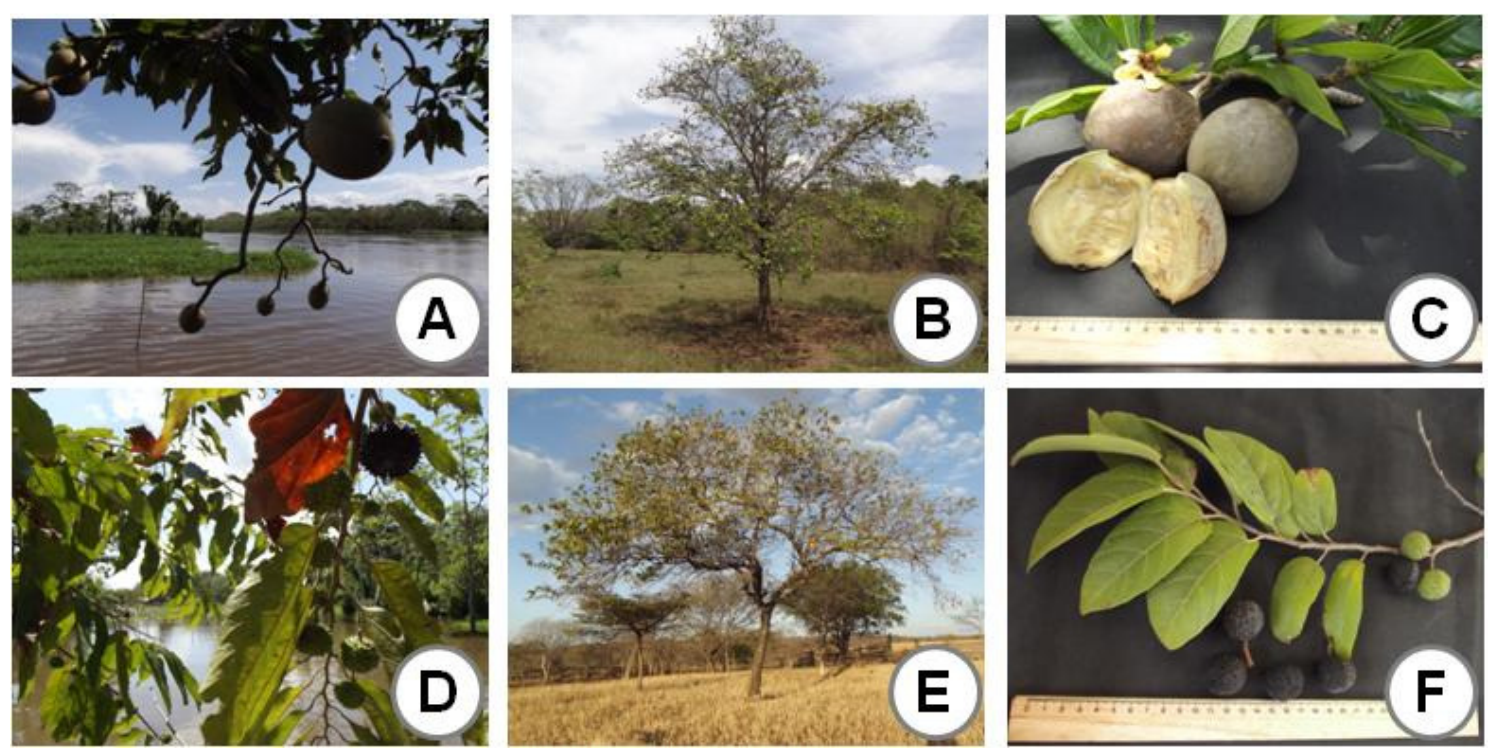

Figura 3. Espécies estudadas: Genipa americana L. (A, B e C) e Guazuma ulmifolia Lam.(D, E e F) no período de dispersão de frutos. 


\subsection{Biometria e biomassa das sementes}

A biometria das sementes foi obtida a partir das medições de comprimento $(\mathrm{cm})$, largura $(\mathrm{cm})$ e espessura $(\mathrm{cm})$ de 50 sementes $(\mathrm{n}=50)$ de cada espécie estudada, com o uso de um paquímetro digital. Em seguida essas sementes foram liofilizadas por 72 horas, pesadas em balança com precisão de $0,0001 \mathrm{~g}$, para obtenção de massa seca.

\subsection{Experimento 1. Germinação das sementes de G. americana e G. ulmifolia em condições de alagamento}

Inicialmente foi feita a desinfestação das sementes com hipoclorito de sódio a $2 \%$, durante 15 minutos e posteriormente as mesmas foram lavadas em água corrente para retirada do excesso de hipoclorito. O experimento foi montado, em caixas do tipo "Gerbox" ( $3 \mathrm{x} 11 \mathrm{x}$ $11 \mathrm{~cm}),(4$ repetições x 25 sementes) ( $\mathrm{n}=100)$, mantidas em câmara de germinação B. O. D a $28{ }^{\circ} \mathrm{C}$ com fotoperíodo de 12 horas. As sementes das espécies coletadas nos dois ambientes foram submetidas a dois tratamentos: alagado (submerso em água destilada) e controle (não alagado com papel filtro duplo). A emissão e curvatura gravitrópica da radícula serviram como referência para considerar a semente germinada. Ao final do experimento foi analisado o percentual de germinação conforme Laboriau, (1983) e a formação de plântulas (Fig. 4).
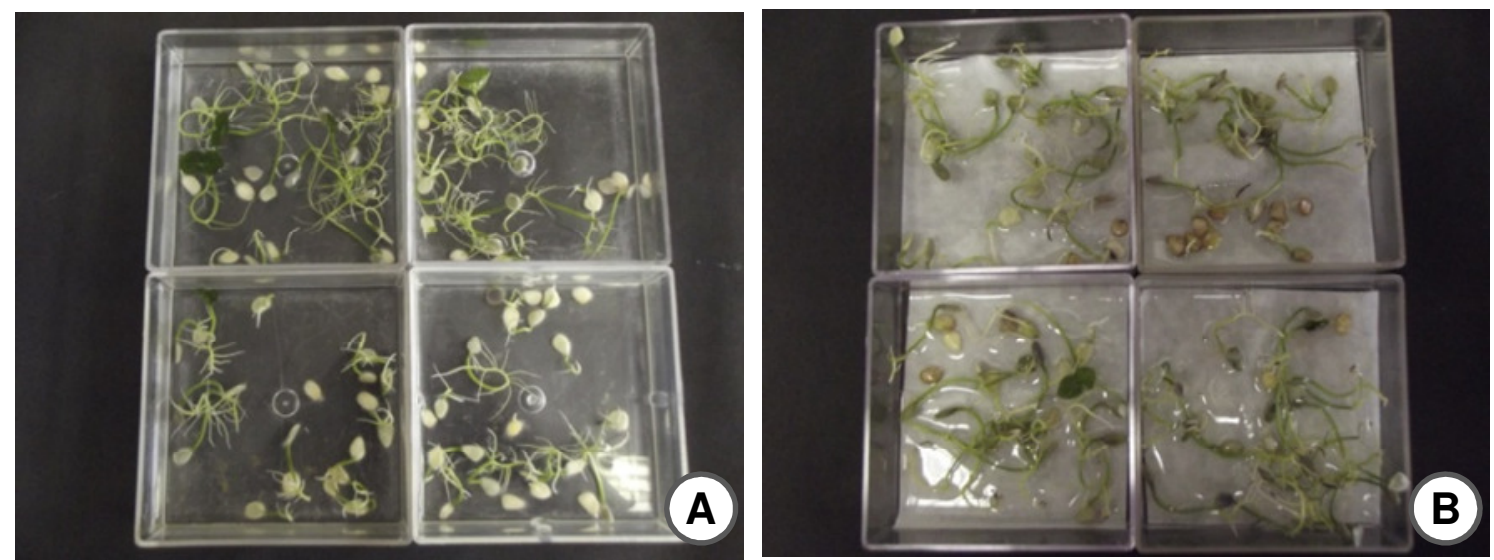

Figura 4. Sementes de Genipa americana germinando no tratamento de alagamento (A) e no controle com papel filtro umedecido (B).

\subsection{Experimento 2. Alagamento parcial e total das plantas jovens}

\subsubsection{Obtenção das plantas jovens}

Para obtenção das plantas jovens, sementes das duas espécies, foram colocadas para germinar em bandejas $(5 \times 43 \times 28 \mathrm{~cm})$ contendo substrato vermiculita umedecido. Após a 
emergência das plântulas, estas foram transferidas para copos plásticos de $500 \mathrm{~mL}$, sendo uma plântula por copo, com solo comercial Bioplant ${ }^{\circledR}$ (Fig. 5 A) e mantidas em casa de vegetação até o início dos experimentos (Fig. 5 B). A fim de obter quantidade de plantas suficientes para o experimento 2, foi aplicado tratamento pré-germinativo nas sementes de G. ulmifolia, com origem do cerradão, para isso as sementes foram imersas em água quente a $100{ }^{\circ} \mathrm{C}$ por um minuto antes da semeadura.

\subsubsection{Desenho experimental}

Para os tratamentos de alagamento foram utilizados baldes de polietileno de $50 \mathrm{~L}$ (duas plantas por balde), sendo uma de G. americana e uma de G. ulmifolia. Cada balde foi considerado uma unidade amostral (Fig. 5 C). Plantas de G. americana (Fig. 5 A) e $G$. ulmifolia (Fig. 5 B) com 90 dias foram submetidas a três diferentes condições hídricas (tratamentos): (1) Controle (regas diárias até a capacidade de campo), (2) Alagamento parcial (coluna de água até $2 \mathrm{~cm}$ acima do substrato) e (3) Alagamento total (planta totalmente submersa). Em cada tratamento, foram utilizadas lotes de 20 plantas por espécie de cada ecossistema de coleta (Amazônia ou Cerrado). O experimento foi realizado em casa de vegetação na Estação Biológica da Universidade de Brasília (UnB), em Brasília - Distrito Federal (DF) e teve a duração de 30 dias.
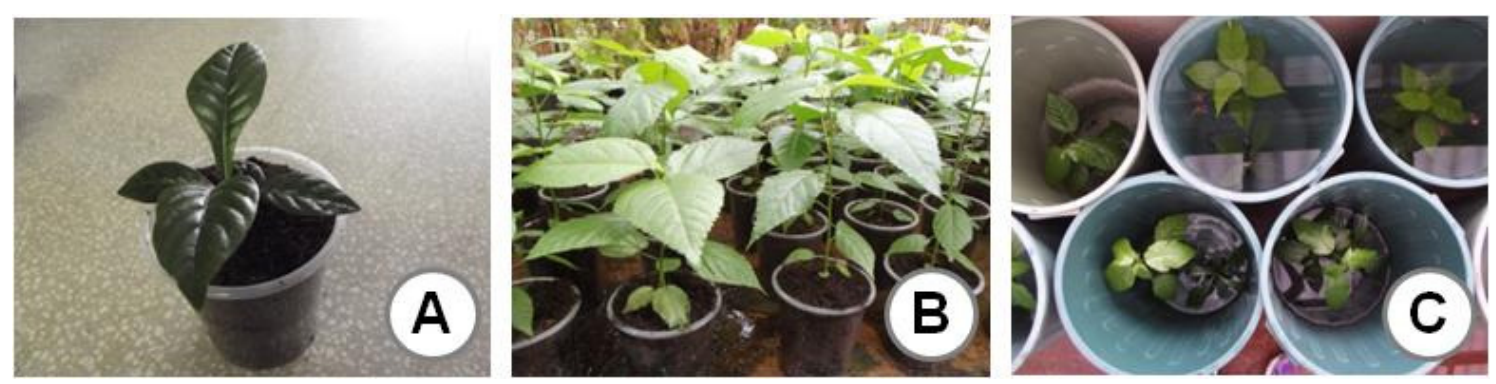

Figura 5. Plantas jovens de Genipa americana (A) e de Guazuma ulmifolia (B) em vaso plástico com Bioplant ${ }^{\circledR}$, antes da imposição dos tratamentos de alagamento parcial e total e experimento montado $(\mathrm{C})$.

Ao longo dos 30 dias de experimentação, foram feitos cinco censos para coleta de dados, incluindo o tempo zero (imediatamente antes do início dos tratamentos), onde se avaliou as alterações morfológicas, alterações no número de folhas e o crescimento caulinar das plantas. A concentração de oxigênio dissolvido na água foi medida semanalmente com o auxílio de um oxímetro digital (Lutron, modelo DO - 5519). Ao final do experimento, 15 
indivíduos, por tratamento, foram coletados para a realização das análises de biomassa, anatômicas e bioquímicas, conforme metodologia descrita abaixo. O restante das plantas, cinco indivíduos, por tratamento, foram retiradas dos tratamentos de alagamento parcial e total para drenagem e passaram a ser mantidos em casa de vegetação, na capacidade de campo, por um período de 30 dias para acompanhar a recuperação após o alagamento (experimento 3 ).

\subsubsection{Sobrevivência, crescimento e morfologia de plantas submetidas aos tratamentos de alagamento}

Foram realizados cinco censos no período de um mês (no tempo zero e um censo a cada semana), com a finalidade de medir a altura da plântula, número de folhas, verificar a emergência de raízes adventícias e o aparecimento de lenticelas. O comprimento da parte aérea (coleto ao ápice caulinar) foi obtido com o auxílio de uma régua milimetrada, enquanto a queda e produção de folhas foram quantificadas por meio de contagem. Foi observada também a sobrevivência das plantas submetidas aos tratamentos, durante o período experimental (30 dias).

\subsubsection{Massa seca e carboidratos de reservas das plantas}

Para obtenção da massa seca das plantas, ao final de 30 dias de experimento, foram coletados 10 indivíduos, por tratamento, utilizando nitrogênio líquido que serviu para paralisar o metabolismo no momento da coleta e não interferir nos resultados bioquímicos. $\mathrm{O}$ material vegetal foi fracionado em raiz, caule e folha e no laboratório, liofilizado por $48 \mathrm{~h}$ e pesados em balança de precisão $(0,0001 \mathrm{~g})$. Depois de pesado, o material vegetal foi moído e peneirado em uma peneira granulométrica. Em seguida, procedeu-se a pesagem da amostra em uma balança de precisão, em triplicata, de acordo com a necessidade de cada protocolo descrito abaixo. Foi feito então, a análise de açucares solúveis totais (AST) e amido das partes seccionadas do material vegetal, submetidos aos tratamentos de alagamento parcial e total.

Os açúcares solúveis totais (AST) foram extraídos e dosados pelo método fenolsulfúrico, adaptado de Dubois et al. (1956). Em cada $10 \mathrm{mg}$ de amostra seca, foi adicionado $500 \mu \mathrm{l}$ de álcool (etanol) a 80\%, agitado em vortex e em seguida levado ao banho-maria a $80^{\circ} \mathrm{C}$ por 20 minutos. Após esse período, a amostra foi centrifugada a $13.000 \mathrm{rpm}$, por 10 
minutos e o sobrenadante coletado (procedimento repetido por três vezes). Na alíquota de 50 $\mu \mathrm{L}$ de cada amostra, foi adicionado $450 \mu \mathrm{L}$ de água, $500 \mu \mathrm{L}$ de Fenol (5\%) e $2.500 \mu \mathrm{L}$ de ácido sulfúrico $\left(\mathrm{H}_{2} \mathrm{SO}_{4}\right)$. A leitura foi realizada em espectrofotômetro (Thermo Spectronic Genesys 2), com absorbância de 490 nm, analisado com base em uma curva padrão glicose.

Para extração e dosagem do amido, foi utilizado o método enzimático de Amaral et al., (2007). O resíduo da extração de AST foi seco em liofilizador e em seguida adicionado à amostra, $480 \mu \mathrm{L}$ da enzima $\alpha$-amilase termoestável, que foi agitada em vortex e levada ao banho-maria a $75^{\circ} \mathrm{C}$ por 30 minutos (repetido $2 \mathrm{x}$ ). Após esse procedimento, adicionou-se 480 $\mu \mathrm{L}$ da enzima amiloglucosidase (AMG) às amostras que foram agitadas e incubadas em banho-maria a $50^{\circ} \mathrm{C}$ por 30 minutos (repetido $2 \mathrm{x}$ ). Foi adicionado $100 \mu \mathrm{L}$ de ácido perclórico $(0,8 \mathrm{M})$ às amostras, que foram centrifugadas a $10.000 \mathrm{rpm}$, por 2 minutos. Em seguida, foram coletados $20 \mu \mathrm{L}$ do sobrenadante da amostra e adicionado $300 \mu \mathrm{L}$ de glicose enzimática líquida (GODPOD), para leitura em espectrofotômetro leitor de microplacas (Spectra Max® 900) com absorbância a 510nm, utilizando uma curva padrão glicose.

Nas análises de carboidratos, utilizou-se cinco $(n=5)$ repetições biológicas em triplicata e para a leitura das extrações, utilizaram-se duplicatas.

\subsubsection{Anatomia da raiz}

Após 30 dias de tratamento em condições de alagamento parcial e total, foram coletados cinco indivíduos para análises anatômicas. A coleta foi feita utilizando uma solução de FAA (formol, ácido acético e álcool 70\%) e após 24 horas o meio foi trocado por etanol $70 \%$ e conservado para sua utilização. Entre os cinco indivíduos coletados para análises anatômicas, foram selecionados por meio de sorteio três indivíduos por espécie e por tratamento, para realização dos cortes anatômicos. Foram analisadas secções transversais nas raízes secundárias desses indivíduos, com objetivo de verificar a capacidade da espécie de produzir aerênquima. Foram montadas lâminas com secções transversais, obtidas com o auxílio de um micrótomo de mesa (R. Jungag Heidelberg) e coradas com azul de alcian e safranina, seguindo protocolo usual para técnicas em anatomia vegetal (Paiva et al., 2006). As fotomicrografias foram obtidas em fotomicroscópio Leica DM750, na resolução de 2048 x 1536 px, analisadas no software Leica Aplication Suite LAS EZ, 2010. 


\subsection{Experimento 3. Recuperação das plantas após o alagamento}

Ao final dos 30 dias do experimento de alagamento parcial e total das plantas, cinco (5) indivíduos de cada tratamento por espécie foram mantidos em casa de vegetação, com irrigação diária até a capacidade de campo (Fig. 6). Durante o período de 30 dias foi avaliado a sobrevivência, alterações na morfologia, crescimento em altura e o acumulo de biomassa (seguindo a metodologia descrita no Experimento 2).
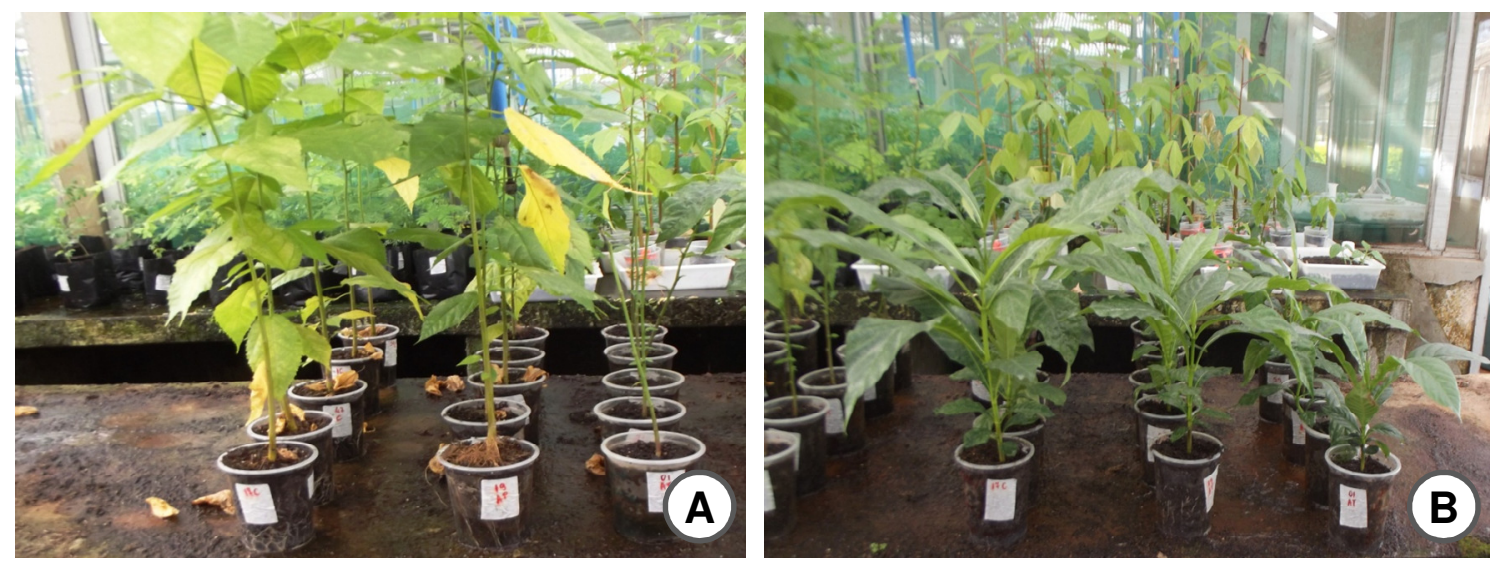

Figura 6. Plantas de Guazuma ulmifolia (A) e Genipa americana (B) mantidas em casa de vegetação para a recuperação por 30 dias.

\subsection{Análises estatísticas}

Para a comparação de médias dos dados biométricos das sementes, foi utilizado o teste-t com $(\mathrm{p} \leq 0,05)$. Os dados de germinação foram avaliados de acordo com Laboriau (1983).

Para avaliar os dados obtidos neste estudo com plantas, foram utilizadas ANOVAs com repetição no tempo para comparar os fatores de tratamento (controle, alagamento parcial e alagamento total). Para as análises de comprimento e número de folhas, foram utilizados os tempo $0,1,2,3$ e 4 . As demais medidas foram obtidas ao final de 30 dias de experimento. As ANOVAs foram seguidas do teste de comparações múltiplas de Tukey, a 5\% de significância $(\mathrm{p} \leq 0,05)$, utilizando o programa Statistic versão 8.0.

\section{RESULTADOS}

\subsection{Biometria e biomassa das sementes}


As análises biométricas mostraram diferenças significativas $(\mathrm{p} \leq 0,05)$ entre as sementes de mesma espécie, coletadas nos dois ecossistemas. Ao menos para dois parâmetros avaliados, as populações de G. ulmifolia e G. americana com origem da Amazônia, apresentaram sementes maiores que aquelas coletadas de populações do bioma Cerrado. Com relação à massa seca, os resultados foram significativos apenas para G. umifolia (Tab. 1).

Tabela 1. Médias \pm desvio padrão de medidas biométricas de sementes $(\mathrm{n}=50)$ de Genipa americana e Guazuma ulmifolia, coletadas no Cerrado e na Amazônia.

\begin{tabular}{lccccc}
\hline Espécies & Origem & Comprimento/mm & Largura/mm & Espessura/mm & Massa seca/mg \\
\hline G. americana & Cerrado & $9,19 \pm 0,90$ & $6,98 \pm 0,71^{*}$ & $1,25 \pm 0,25^{*}$ & $52,0 \pm 0,007$ \\
G. americana & Amazônia & $9,32 \pm 0,85$ & $7,33 \pm 0,75^{*}$ & $2,02 \pm 0,31^{*}$ & $53,0 \pm 0,008$ \\
G. ulmifolia & Cerrado & $2,84 \pm 0,19^{*}$ & $2,03 \pm 0,25^{*}$ & $1,66 \pm 0,18$ & $5,0 \pm 0,0007^{*}$ \\
G. ulmifolia & Amazônia & $3,02 \pm 0,24^{*}$ & $1,86 \pm 0,16^{*}$ & $1,64 \pm 0,17$ & $6,0 \pm 0,001^{*}$ \\
\hline
\end{tabular}

Médias seguidas de $(*)$, indicam diferenças significativas para a mesma espécie testadas pelo Teste-t com $\mathrm{p} \leq 0,05$.

\subsection{Experimento 1. Germinação das sementes}

Tanto a origem, quanto o tratamento afetaram significativamente a germinação das sementes de $G$. americana ( $\mathrm{p} \leq 0,05)$. Sementes de $G$. americana do Cerrado apresentaram menor porcentagem de germinação quando submetidas ao alagamento (Fig. 7A). Já para a espécie G. ulmifolia, apenas a origem interferiu na porcentagem de germinação, uma vez que as sementes coletadas de populações da Amazônia apresentaram maior percentual de germinação que aquelas coletadas no Cerrado, independente do tratamento (Fig. 7B).

Todas as sementes que germinaram, tanto do controle quanto em condições de alagamento, formaram plântulas.

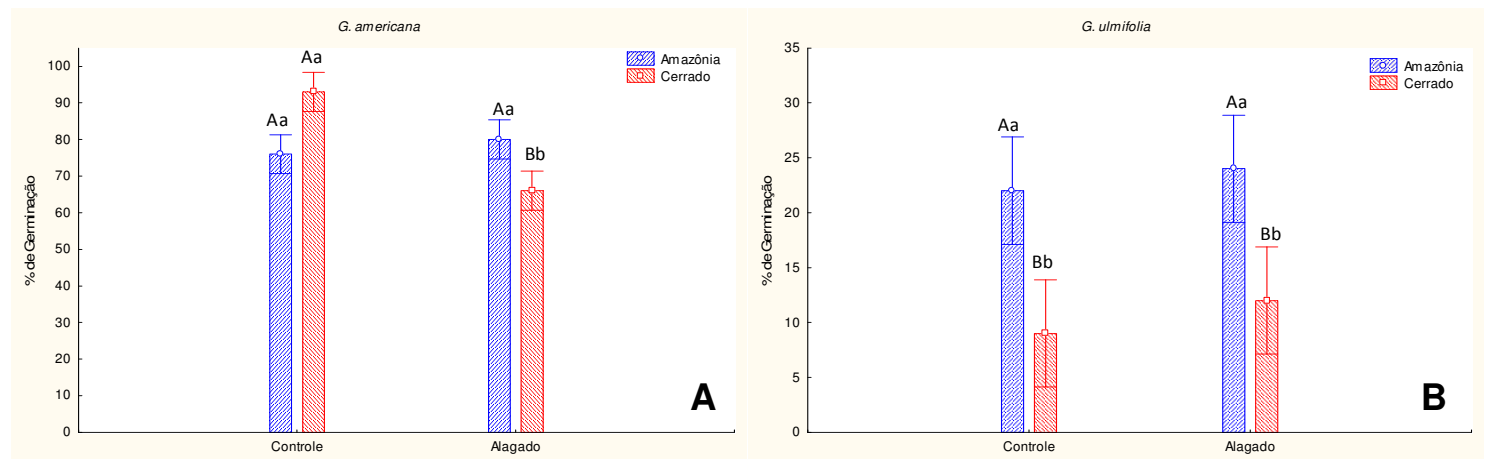

Figura 7. Média ( \pm erro padrão) da porcentagem $(\%)$ de germinação de $G$. americana e $G$. ulmifolia coletadas na Amazônia e no Cerrado, submetidas ao alagamento $(\mathrm{n}=100)$. As médias seguidas de mesma letra não diferem entre si pelo teste Tukey $(\mathrm{p} \leq 0,05)$. Letras maiúsculas representam comparações entre espécies quanto à origem e letras minúsculas representam comparações entre os tratamentos (controle e alagamento). 


\subsection{Experimento 2}

\subsubsection{Sobrevivência, crescimento e morfologia de plantas submetidas aos tratamentos de alagamento parcial e total}

Ao final dos 30 dias de experimento, a taxa de sobrevivência para ambas as espécie (G. americana e G. ulmifolia) submetidas aos tratamentos de alagamento parcial e total foi de $100 \%$, no entanto houve diferenças significativas no crescimento e no número de folhas, tanto para as espécies coletadas na Amazônia, quanto no Cerrado $(\mathrm{p} \leq 0,05)$ (Fig. 8). Alterações morfológicas como aparecimento de raízes adventícias e lenticelas hipertrofiadas, também foram observadas. Os sinais de injúrias foram observados com maior intensidade nas plantas de G. ulmifolia com origem do Cerrado.

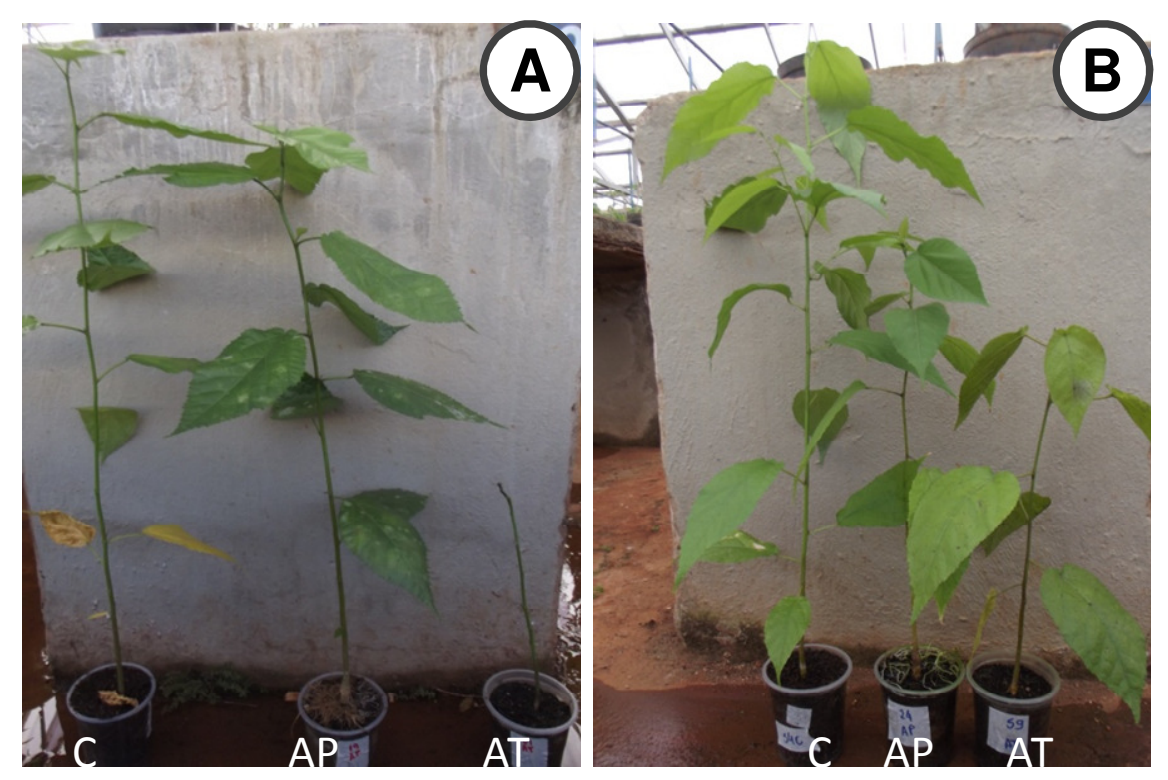

Figura 8. Plantas de Guazuma ulmifolia da Amazônia (A) e do Cerrado (B) 30 dias após tratamentos (Controle (C), Alagamento Parcial (AP) e Alagamento Total (AT)).

Ao longo dos 30 dias de experimento, independente do ambiente de origem, as plantas de G. americana e G. ulmifolia dos tratamentos controles continuaram o seu crescimento, porém as plantas oriundas de sementes do Cerrado apresentaram maior incremento em altura em relação as da Amazônia $(\mathrm{p} \leq 0,05)$. Contudo, as duas espécies responderam de forma distinta ao alagamento. As plantas de G. americana, tanto do Cerrado quanto da Amazônia, quando submetidas ao alagamento parcial, continuaram crescendo, embora menos que o controle $(\mathrm{p} \leq 0,05)$, enquanto que no alagamento total as plantas tiveram o crescimento paralisado (Fig. 9 A). G. ulmifolia do Cerrado, quando submetidas ao alagamento, tanto 
parcial quanto total, paralisaram o crescimento. Resultado diferente foi observado para a mesma espécie coletada na Amazônia, que paralisou o crescimento apenas quando submetida ao alagamento total. Sob alagamento parcial, essa espécie mostrou crescimento continuado com valores de incremento menores que o controle ( $\mathrm{p} \leq 0,05)$ (Fig. 9 B).
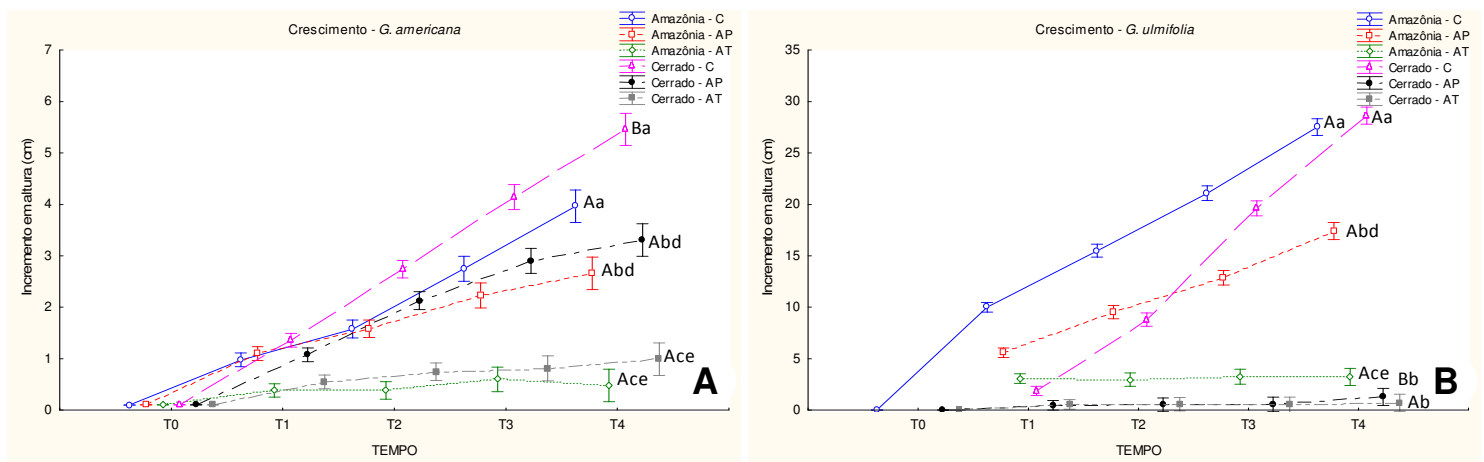

Figura 9. Média ( \pm erro padrão) do crescimento acumulado em plantas jovens de $G$. americana (A) e G. ulmifolia (B) ao longo de 30 dias de tratamento. C (controle), AP (alagamento parcial) e AT (alagamento total) $(\mathrm{n}=20)$. Médias seguidas de mesma letra não diferem entre si pelo teste Tukey $(\mathrm{p} \leq 0,05)$. Letras maiúsculas representam comparações entre espécies quanto à origem e letras minúsculas representam comparações entre os tratamentos.

Em G. americana, não houve diferença significativa no número de folhas entre os tratamentos. Já entre a origem, a espécie do Cerrado quando submetida ao alagamento parcial aumentou significativamente o número de folhas $(\mathrm{p} \leq 0,05)$ em relação ao mesmo tratamento da Amazônia (Fig.10 A).

A origem das plantas de G. ulmifolia interferiu de forma significativa no número de folhas observadas no tratamento controle (Fig. 10B), plantas do Cerrado se destacaram em relação às da Amazônia. As plantas dessa espécie da Amazônia e do Cerrado submetidas aos tratamentos de alagamento (parcial e total) apresentaram queda de folhas. No entanto, no alagamento total a queda de folhas foi mais acentuada para as plantas da Amazônia (até 100\% para alguns indivíduos, ao final dos 30 dias) em relação ao alagamento parcial, que não diferiu do controle. Enquanto para as plantas do Cerrado houve diferença no número de folhas entre o controle e os tratamentos de alagamento (parcial e total), porém estes não diferiram entre si $(\mathrm{p} \leq 0,05)$ (Fig. 10 B). 

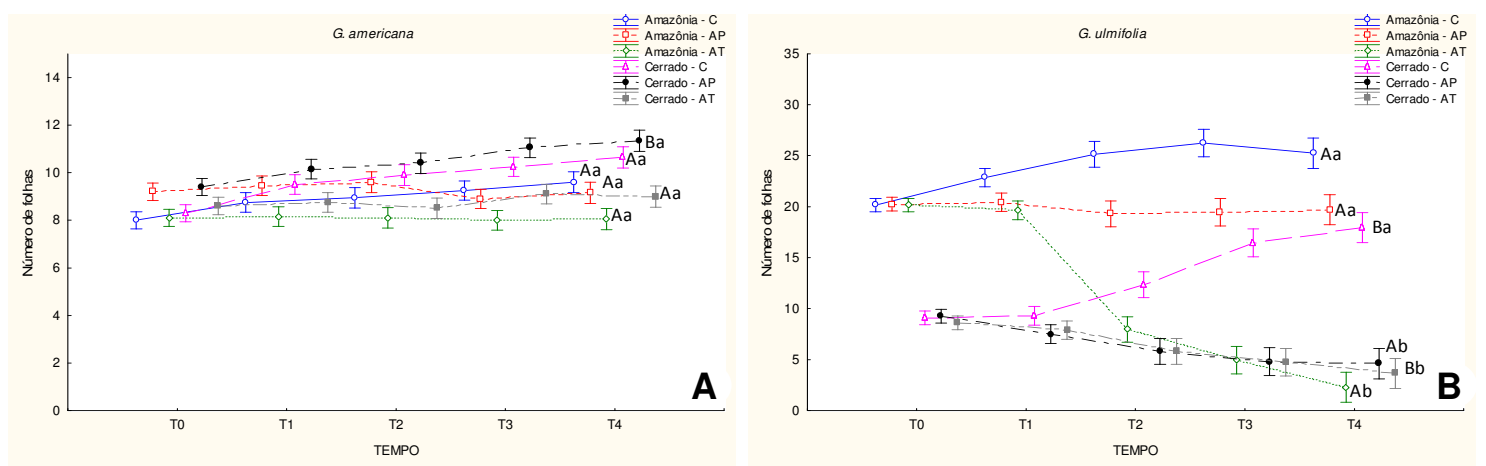

Figura 10. Média ( \pm erro padrão) da variação no número de folhas de $G$. americana (A) e $G$. ulmifolia (B), ao longo de 30 dias de experimento $(\mathrm{n}=20)$. C (Controle), AP (alagamento parcial) e AT (alagamento total). Para o número de folhas ao final de 30 dias de tratamento, as médias seguidas de mesma letra não diferem entre si pelo teste Tukey $(\mathrm{p} \leq 0,05)$. Letras maiúsculas representam comparações entre espécies quanto à origem e letras minúsculas representam comparações entre os tratamentos.

No tratamento de alagamento parcial, foram observadas alterações morfológicas em plantas das duas espécies estudadas, tanto aquelas com origem do Cerrado quanto da Amazônia, entretanto, essas alterações não foram observadas em todos os indivíduos. As plantas de G. americana desenvolveram lenticelas hipertrofiadas a partir da terceira semana de experimento, no entanto, não desenvolveram raízes adventícias (Fig. 11 C e D).

Em G. ulmifolia, todas as plantas submetidas ao alagamento parcial, tanto da Amazônia quanto do Cerrado, desenvolveram lenticelas, ainda na primeira semana de experimento (Fig. 11 A e B). Além das lenticelas, as plantas do Cerrado submetidas ao mesmo tratamento apresentaram fissuras no caule (Fig. 11 A). Para essa espécie, as raízes adventícias foram formadas apenas na quarta semana de experimento. 


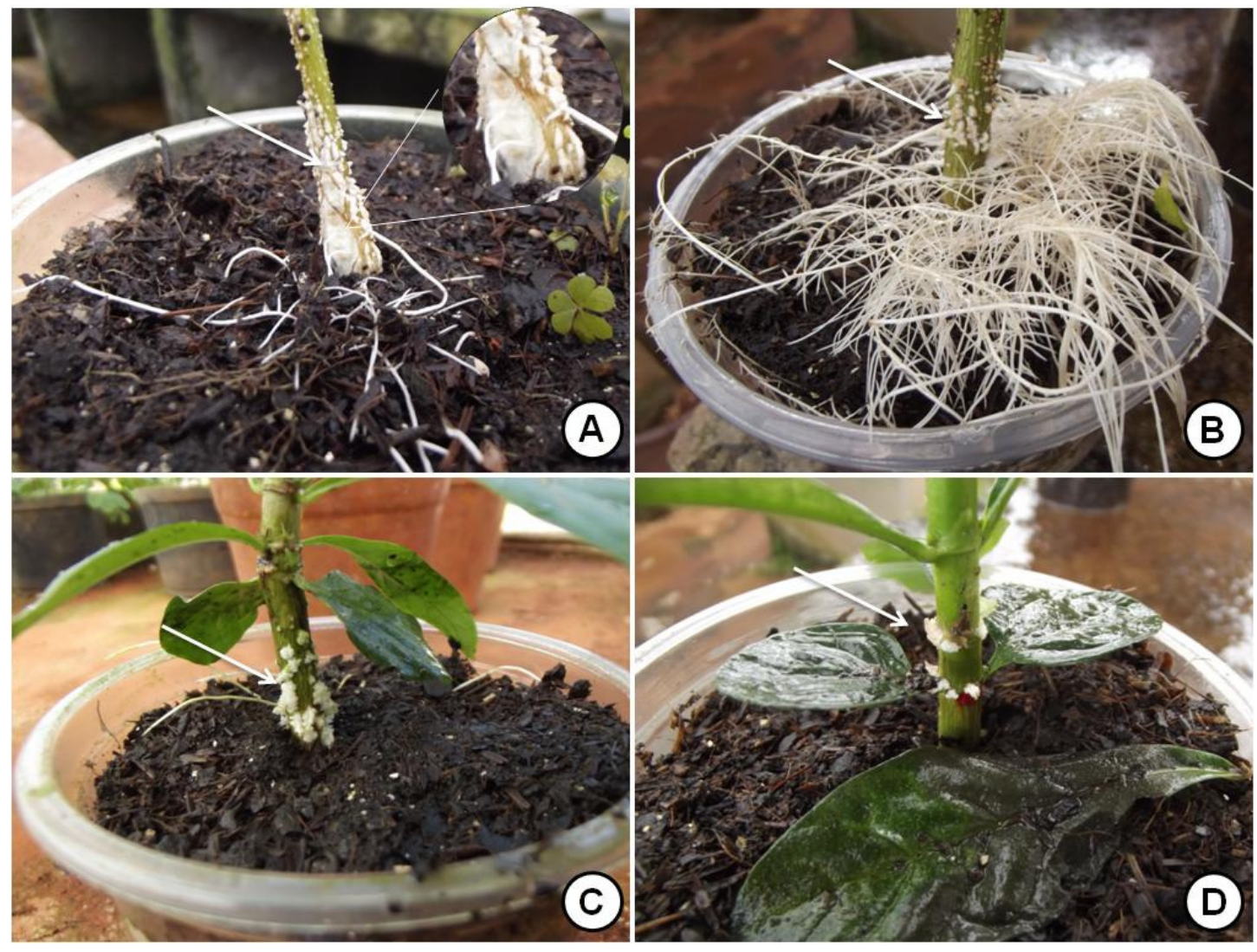

Figura 11. Lenticelas hipertrofiadas (seta) no caule de Guazuma ulmifolia (A e B) e Genipa americana (C e D) do Cerrado (A e C) e da Amazônia (B e D). Fissuras no caule (detalhe) de Guazuma ulmifolia com origem do Cerrado (A).

\subsubsection{Massa seca de plantas após tratamentos (alagamento parcial e total)}

O acúmulo de biomassa seca da raiz (Fig. 12 A) e do caule (fig. 12 C) em $G$. americana com origem da Amazônia, não foi afetado pelos tratamentos, sendo que somente a biomassa da folha foi afetada pelo alagamento total, em relação ao controle (fig. 12 E). Entre os tratamentos da mesma espécie oriunda do Cerrado, plantas do alagamento total apresentaram menor biomassa na raiz e na folha em relação ao controle e no caule a biomassa foi menor no alagamento total em relação ao controle e ao alagamento parcial. Entre os controles (Amazônia x Cerrado) e o alagamento parcial (Amazônia x Cerrado), a biomassa da raiz e do caule, respectivamente, apresentou um maior investimento em biomassa na espécie oriunda do Cerrado, em relação aquelas coletadas na Amazônia ( $\leq$ 0,05) (Fig.12 A e C).

Em G. ulmifolia com origem da Amazônia e do Cerrado, o acúmulo de biomassa da raiz, do caule e da folha foi significativamente menor em plantas submetidas ao alagamento parcial e total em relação ao controle (Fig. 12 B, D e F). No entanto, o alagamento total tem 
efeito mais acentuado que o alagamento parcial nas plantas oriundas da Amazônia. Já para mesma espécie oriunda do Cerrado, a biomassa do caule é afetada de forma similar tanto pelo alagamento parcial, quanto pelo alagamento total. Entre os controles, o acúmulo de biomassa em plantas de G. ulmifolia oriunda do Cerrado foi menor na raiz e no caule, em relação aquelas oriundas da Amazônia, e entre os tratamentos de alagamento parcial, o caule e a folha das plantas com origem do Cerrado também apresentaram uma menor biomassa, em relação aquelas coletadas na Amazônia ( $\mathrm{p} \leq 0,05)$ (Fig. 12 B, D e F e anexo 1).
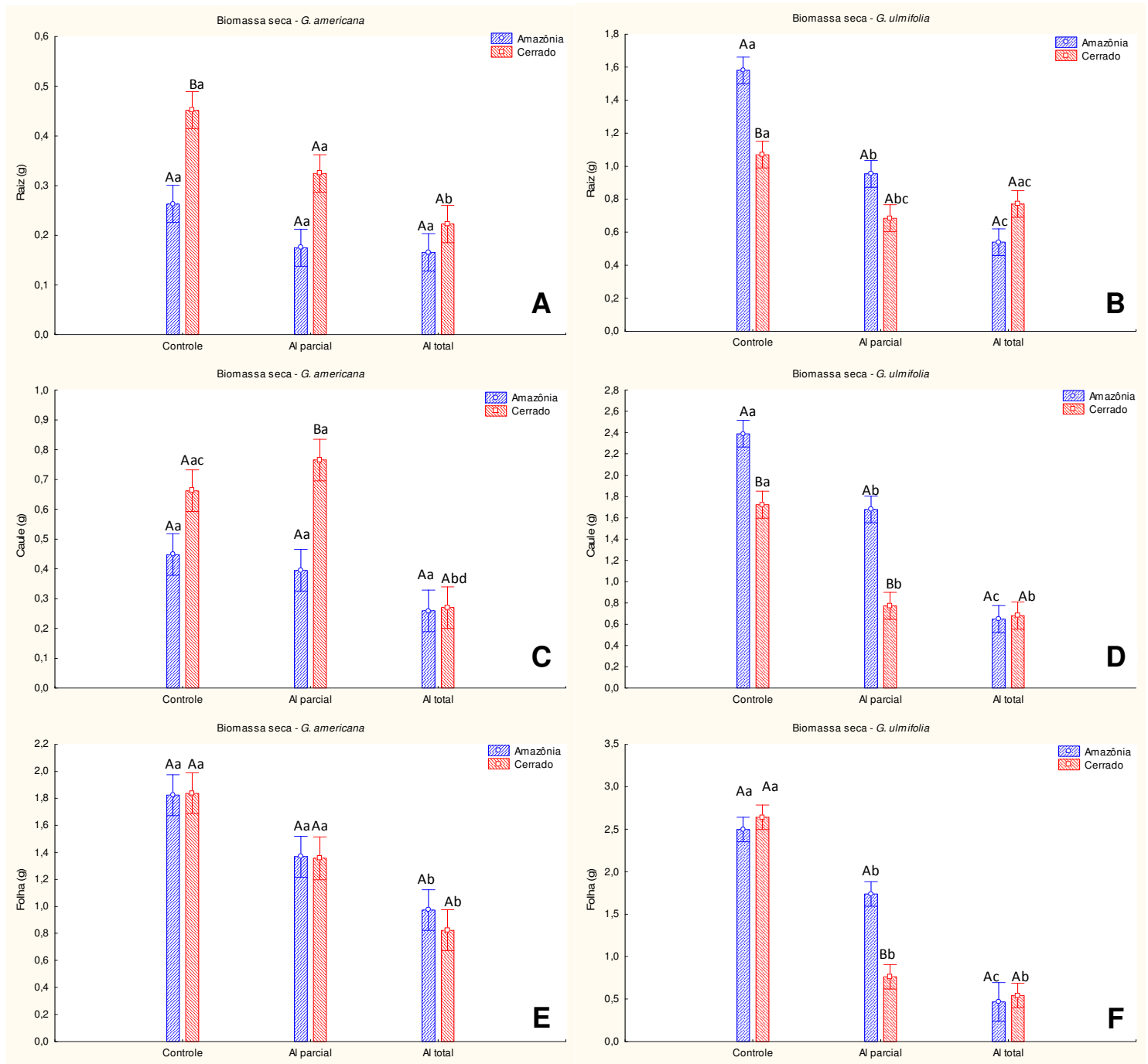

Figura 12. Média ( \pm erro padrão) da biomassa seca de raiz (A e B), caule $(C$ e D) e folha (E e F) de plantas de Genipa americana e Guazuma ulmifolia da Amazônia e do Cerrado, submetidas aos tratamentos de Al parcial e Al total $(n=10)$. Para a biomassa da raiz, caule e folha ao final de 30 dias de tratamento, as médias seguidas de mesma letra não diferem entre si pelo teste Tukey $(p \leq 0,05)$. Letras maiúsculas representam comparações entre espécies quanto à origem e letras minúsculas representam comparações entre os tratamentos. 
Em relação à razão entre a raiz/parte aérea, quando analisada pelo teste de variância (ANOVA), mostrou que a origem interferiu significativamente nesse parâmetro $(\mathrm{p}=0$, 001643) em G. americana, sendo que os indivíduos da Amazônia apresentaram razão menor em relação aqueles com origem do Cerrado. Para G. ulmifolia, o teste Tukey não mostrou diferenças significativas (Fig. 13).
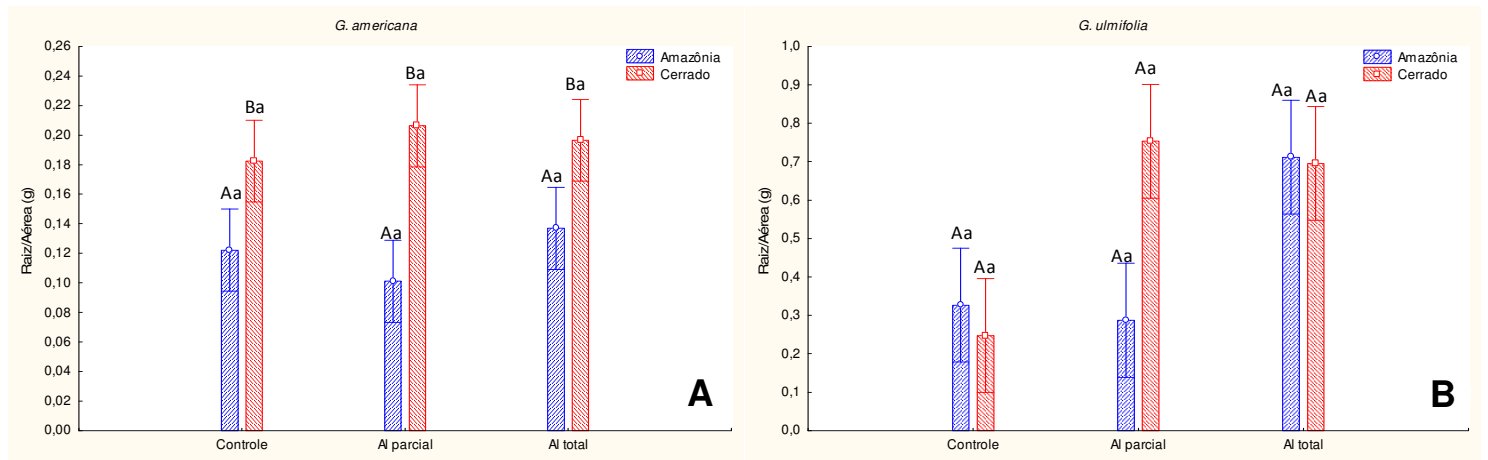

Figura 13. Média ( \pm erro padrão) da razão entre a massa seca da raiz/aérea de G. americana (A) e $G$ ulmifolia $(\mathrm{B})(\mathrm{n}=10)$. Para a razão raiz parte aérea ao final de 30 dias de tratamento, as médias seguidas de mesma letra não diferem entre si pelo teste Tukey $(\mathrm{p} \leq 0,05)$. Letras maiúsculas representam comparações entre espécies quanto à origem e letras minúsculas representam comparações entre os tratamentos.

\subsubsection{Carboidratos de reservas nas plantas após 30 dias de imposição de tratamentos}

Ao final dos 30 dias de experimento de alagamento parcial e total, as plantas de $G$. americana e G. ulmifolia apresentaram diferentes respostas quanto ao teor de açucares solúveis totais (AST) e amido, em seus órgãos vegetativos.

De acordo com o teste de Tukey, G. americana não apresentou diferença significativa entre origem e tratamentos, quanto o teor de AST (Fig. 14 A, C e E). Porém, o mesmo teste mostrou diferenças significativas quanto ao teor de amido. As plantas com origem do Cerrado apresentaram maior teor de amido na raiz, em relação às plantas com origem da Amazônia. Quanto ao caule, foi observado nas plantas da Amazônia, oriundas do alagamento total um maior teor de amido em relação ao controle. Já nas folhas, observou-se diferença significativa apenas entre os tratamentos de alagamento parcial de G. americana com origem do Cerrado, que apresentou maior teor de amido, em relação aquelas submetidas ao alagamento total, da mesma origem $(p \leq 0,05)$ (Fig. 14 B, D e F). 

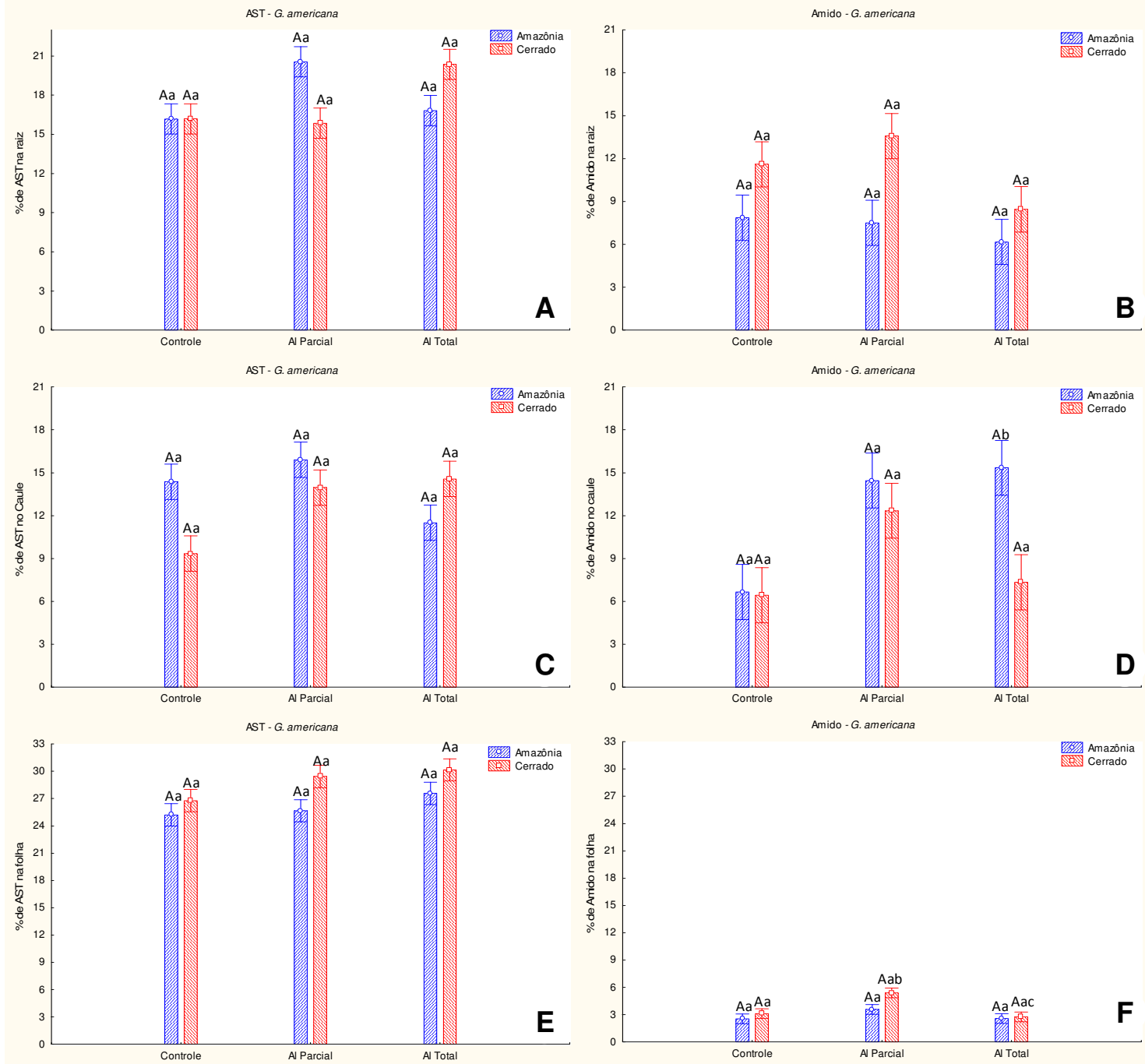

Figura 14. Média ( \pm erro padrão) do percentual de açucares solúveis totais (AST) (A, C e E) e amido (B, D e F) de raiz, caule e folha de Genipa americana ao final 30 dias de experimento de alagamento (parcial e total) $(n=5)$. Para AST e amido ao final de 30 dias de tratamento, as médias seguidas de mesma letra não diferem entre si pelo teste Tukey $(\mathrm{p} \leq 0,05)$. Letras maiúsculas representam comparações entre espécies quanto à origem e letras minúsculas representam comparações entre os tratamentos.

Em G. ulmifolia, o teste Tukey mostrou diferenças significativas nos teores de AST e amido, tanto em relação à origem, quanto aos tratamentos.

Em relação aos açúcares solúveis totais (AST), as plantas com origem do Cerrado submetidas ao alagamento parcial, apresentaram maior teor de açúcar, em relação aquelas com origem da Amazônia, submetidas ao mesmo tratamento. O mesmo foi observado apenas nas folhas das plantas submetidas ao alagamento total $(\mathrm{p} \leq 0,05)$. Independente dos tratamentos, o caule das plantas com origem do Cerrado apresentou maior teor de açúcar, em relação aquelas com origem da Amazônia $(\mathrm{p} \leq 0,05)$. 
Entre os tratamentos, foi observado um maior teor de AST na raiz de plantas controle, com origem da Amazônia, em relação aquelas submetidas ao alagamento parcial, da mesma origem ( $\mathrm{p} \leq 0,05)$ (Fig.). Já nas folhas, as plantas submetidas ao alagamento parcial e total com origem do Cerrado, apresentaram maior teor de AST em relação ao controle, da mesma origem $(\mathrm{p} \leq 0,05)($ Fig. 15 A, C e E).

Em relação aos teores de amido, plantas com origem do Cerrado, submetidas ao alagamento total, apresentaram maior teor de amido na raiz e no caule, em relação aquelas com origem da Amazônia, do mesmo tratamento $(\mathrm{p} \leq 0,05)$.

Entre os tratamentos, os testes mostraram menor teor de amido na raiz das plantas submetidas ao alagamento total, com origem da Amazônia, em relação ao controle. Quanto ao caule, observou-se um maior teor de amido no caule das plantas submetidas ao alagamento total, com origem do Cerrado, em relação ao controle. Já nas folhas, as plantas submetidas ao alagamento parcial e total apresentaram menor teor de amido, em relação ao controle, independente da origem $(\mathrm{p} \leq 0,05)$ (Fig. $15 \mathrm{~B}, \mathrm{D}$ e F). 

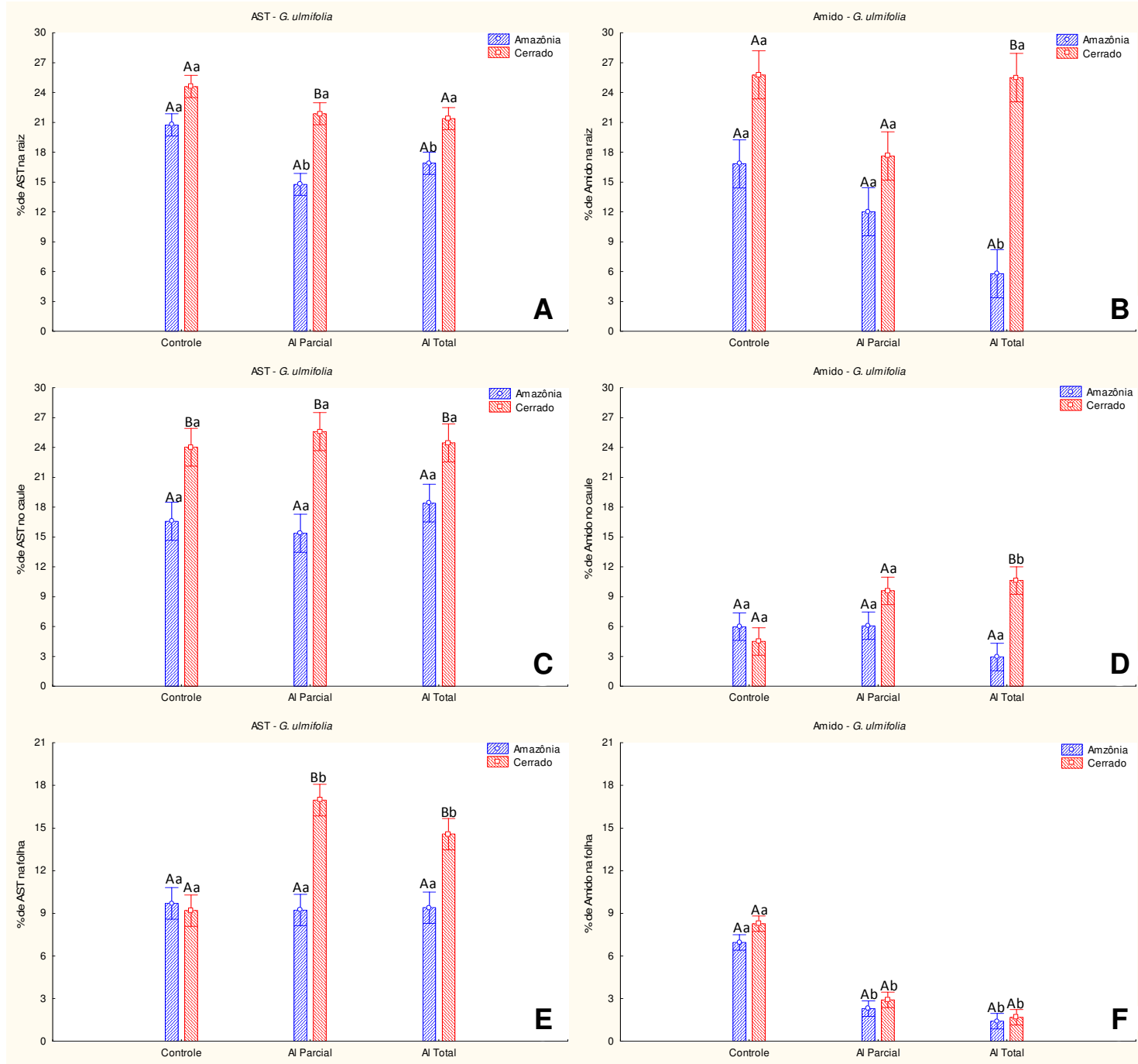

Figura 15. Média ( \pm erro padrão) do percentual de açucares solúveis totais (AST) (A, C e E) e amido (B, D e F) de raiz, caule e folha de Guazuma ulmifolia ao final 30 dias de experimento de alagamento (parcial e total) $(n=5)$. Para AST e amido ao final de 30 dias de tratamento, as médias seguidas de mesma letra não diferem entre si pelo teste Tukey ( $p$ $\leq 0,05)$. Letras maiúsculas representam comparações entre espécies quanto à origem e letras minúsculas representam comparações entre os tratamentos.

\subsubsection{Anatomia da raiz}

Independente da origem, tanto G. americana, quanto G. ulmifolia, quando submetidas aos tratamentos de alagamento parcial e total apresentaram a formação de aerênquima (Fig. 16 e 17). 


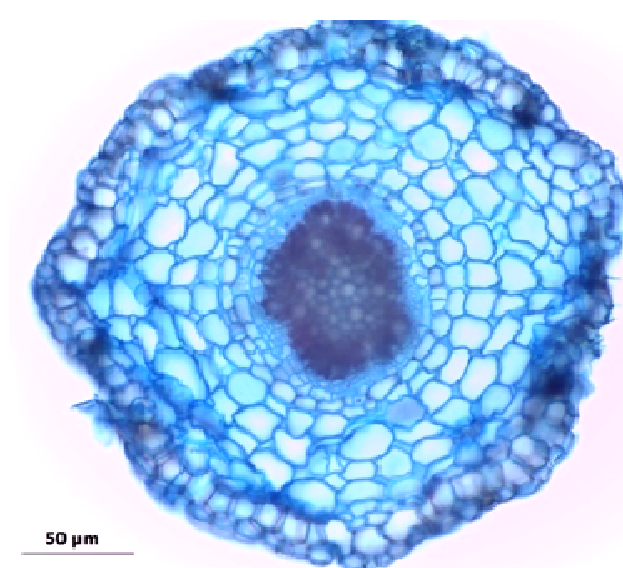

(A)
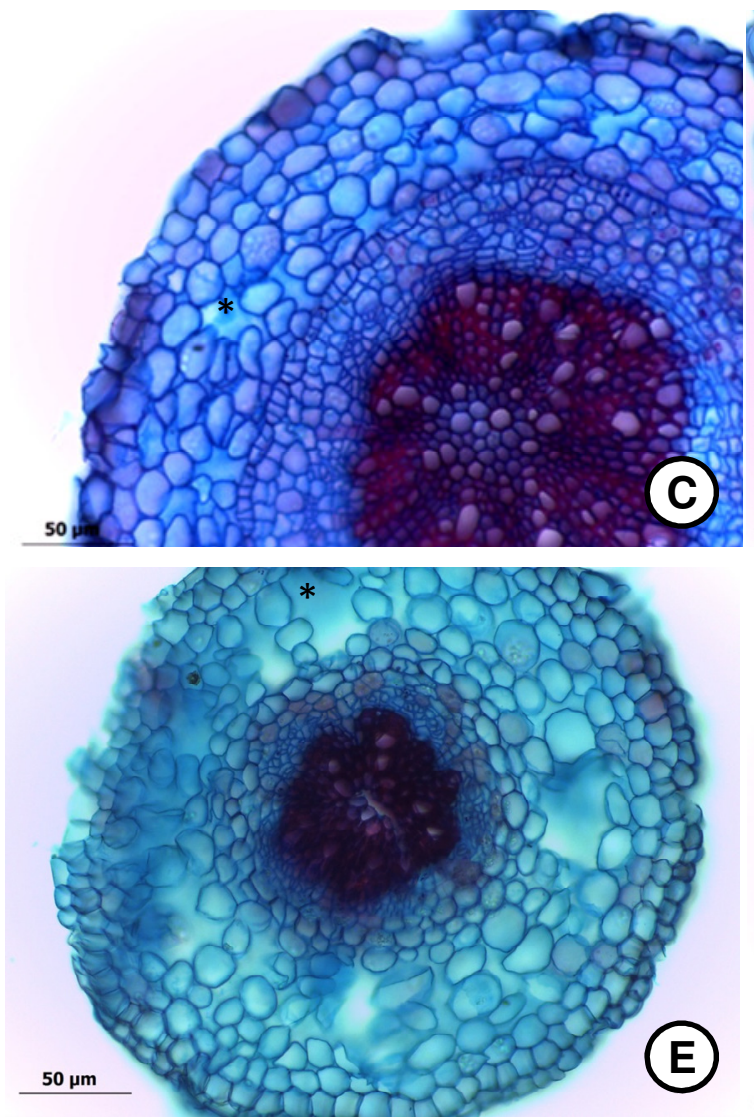

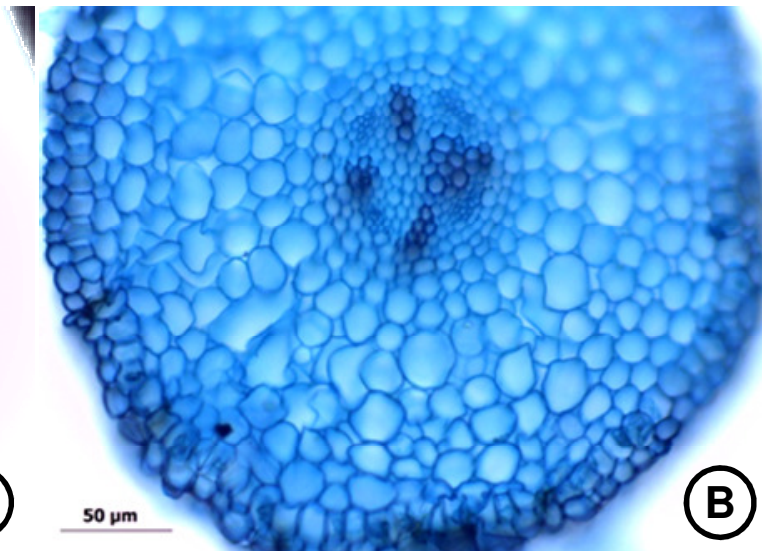

(B)
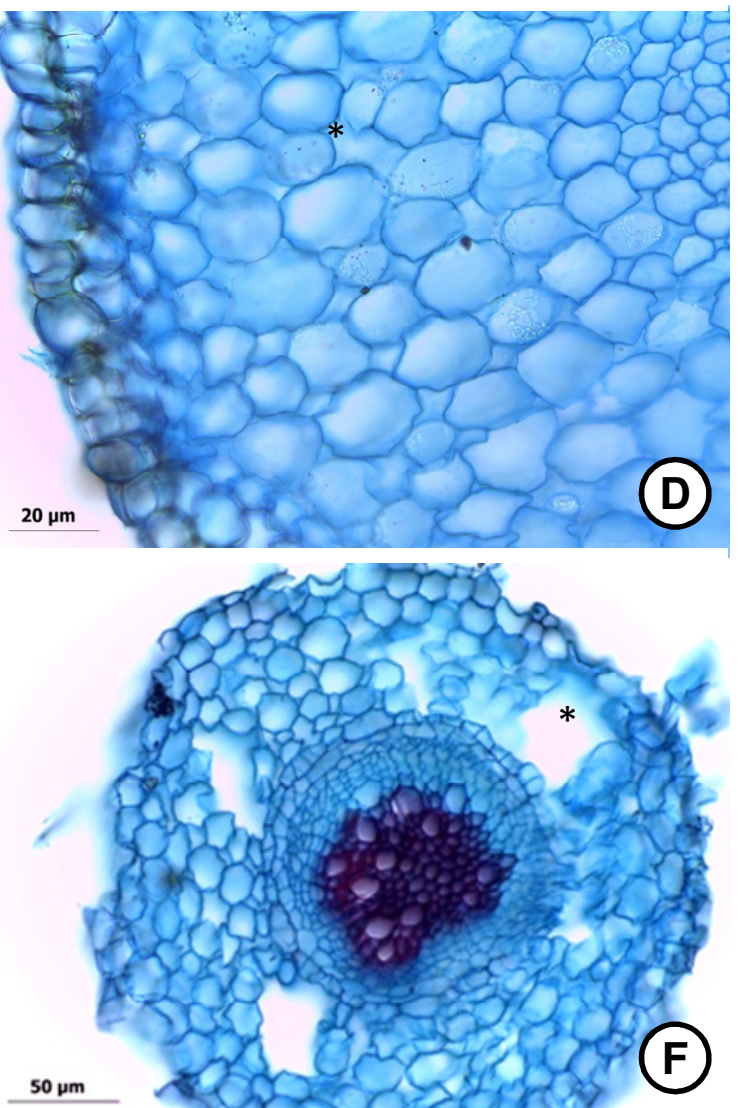

Figura 16. Visão geral da anatomia da raiz secundária de Genipa americana A (controle), C (alagamento parcial) e E (alagamento total) com origem da Amazônia e B (controle), D (alagamento parcial) e F (alagamento total) com origem do Cerrado. Formação de espaços intercelulares (aerênquima) nos tratamentos de alagamento parcial e total (*). 

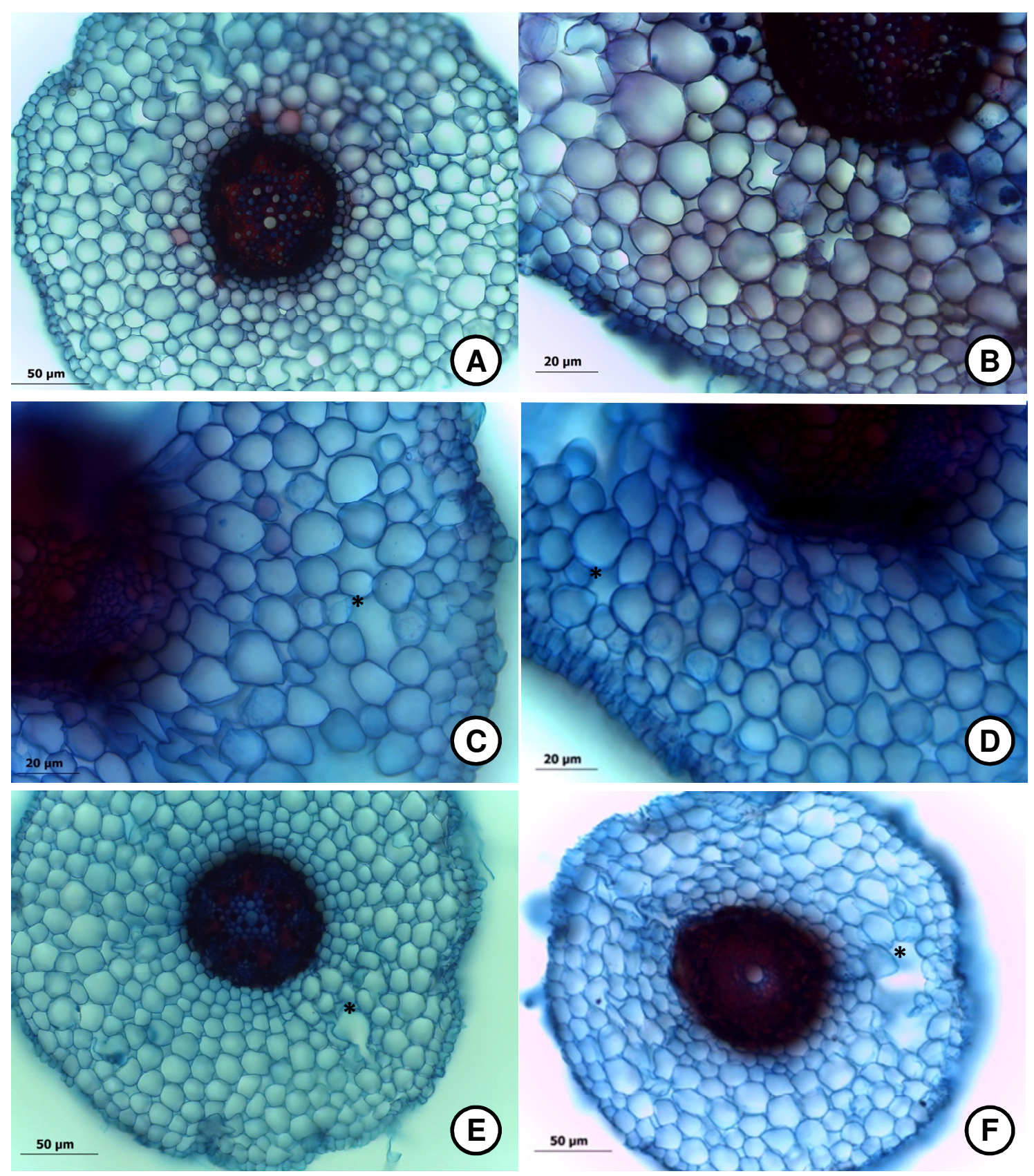

Figura 17. Visão geral da anatomia da raiz secundária de Guazuma ulmifolia A (controle), C (alagamento parcial) e E (alagamento total) com origem da Amazônia e B (controle), D (alagamento parcial) e F (alagamento total) com origem do Cerrado. Formação de espaços intercelulares (aerênquima) nos tratamentos de alagamento parcial e total $(*)$.

\subsection{Experimento 3. Recuperação de plantas após 30 dias de alagamento parcial e total}

Ao final de 30 dias de recuperação (re-aeração) em casa de vegetação, após os tratamentos de alagamento, tanto as plantas de G. americana, quanto G. ulmifolia se desenvolveram bem e apresentaram 100\% de sobrevivência. Quanto ao incremento em altura, 
plantas de G. americana não apresentaram diferença significativa, entre os tratamentos e origem (Fig. 18 A e B). Para G. ulmifolia da Amazônia, as plantas que se recuperavam do alagamento parcial apresentaram maior incremento em altura em relação ao controle e ao alagamento total. Já entre os tratamentos do Cerrado, a espécie não apresentou diferença significativa no incremento. Plantas que haviam sido submetidas ao alagamento parcial com origem da Amazônia apresentaram maior incremento em altura em relação aquelas com do mesmo tratamento, com origem do Cerrado $(p \leq 0,05)$ (Fig. 18 A e B).

Em G. americana da Amazônia, durante o período de recuperação, a produção de folhas novas foi significativa apenas nas plantas que se recuperavam do alagamento total (Fig. 18 D). Enquanto a mesma espécie do Cerrado, o aumento significativo na produção de folhas novas foi observado nas plantas que se recuperavam do alagamento parcial. Entre os controles, as plantas com origem do Cerrado apresentaram maior produção de folhas, em relação às plantas da Amazônia $(\mathrm{p} \leq 0,05)$ (Fig. 18 C). Em G. ulmifolia com origem da Amazônia, observou-se um aumento significativo no número de folhas novas nas plantas que se recuperavam do de alagamento total, em relação ao controle e aquelas que se recuperavam do alagamento parcial, que não diferiram. Em relação à origem, plantas que se recuperavam do alagamento total da Amazônia apresentaram um aumento significativo no número de folhas, em relação ao mesmo tratamento do Cerrado ( $\leq \leq 0,05)$ (Fig. 18 D).
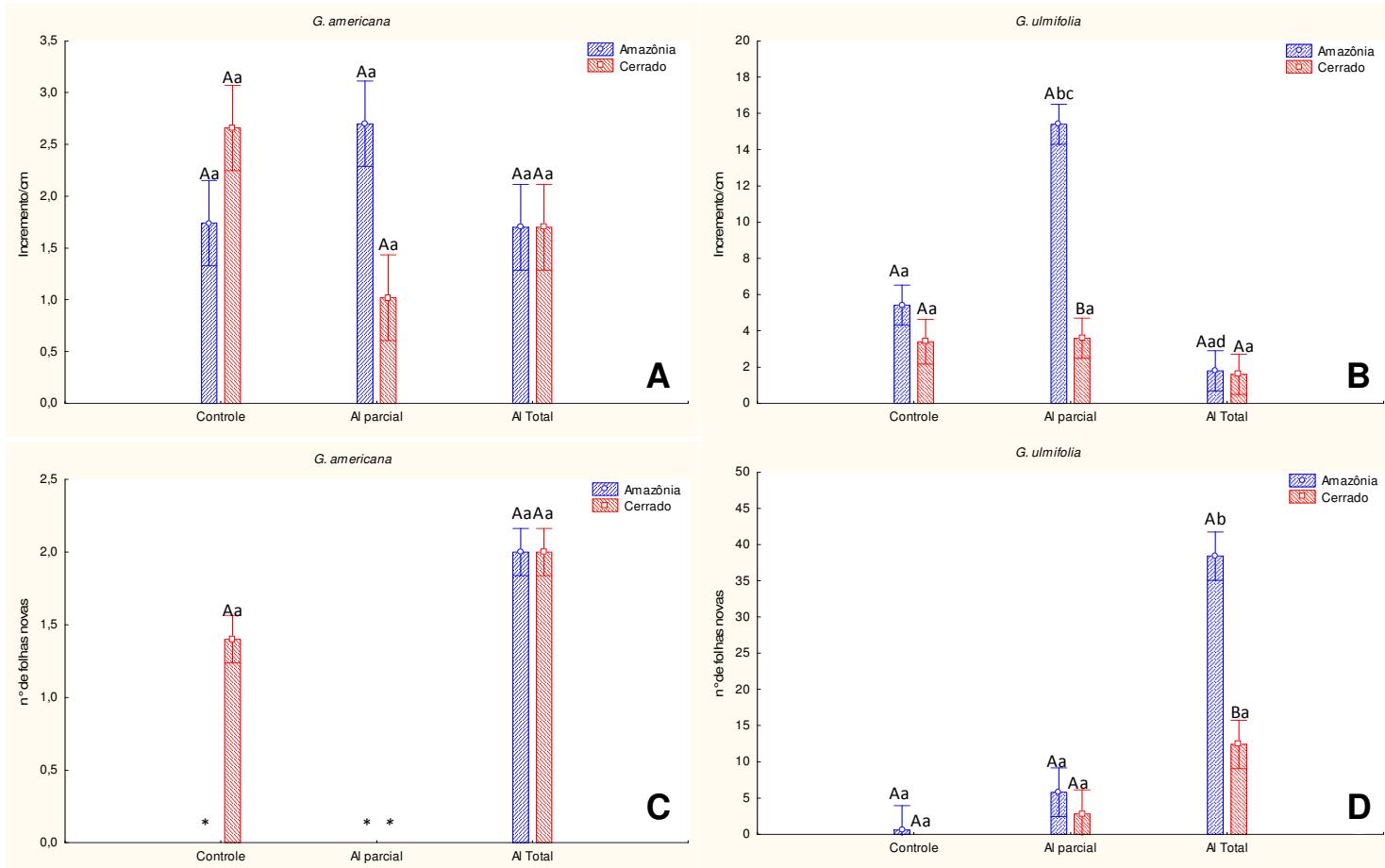

Figura 18. Média ( \pm erro padrão) do incremento em altura e produção de folhas novas de Genipa americana (B e D) e Guzuma ulmifolia (A e C) após 30 dias de recuperação (n = 5). 
Para o incremento em altura e o número de folhas ao final de 30 dias de recuperação, as médias seguidas de mesma letra não diferem entre si pelo teste Tukey $(\mathrm{p} \leq 0,05)$. Letras maiúsculas representam comparações entre espécies quanto à origem e letras minúsculas representam comparações entre os tratamentos. Onde não houve crescimento no número de folhas, usou-se o $(*)$.

Após 30 dias de recuperação, as plantas de G. americana que haviam sido submetidas ao alagamento parcial e total, apresentaram aumento na biomassa, sem diferença significativa em relação ao controle (p < 0,05) (Fig. 19 A, C e E). Já as plantas de G. ulmifolia, mostraram resultados diferentes. Ao final dos 30 dias de recuperação, houve aumento significativo apenas na biomassa da raiz e folhas das plantas de G. ulmifolia da Amazônia, que haviam sido submetidas ao alagamento parcial, sem diferença $(\mathrm{p}<0,01)$ para o controle. As plantas que foram submetidas ao alagamento total, tanto da Amazônia quanto do Cerrado, não conseguiram recuperar a biomassa ao final de 30 dias (Fig. 19 B, D e F).
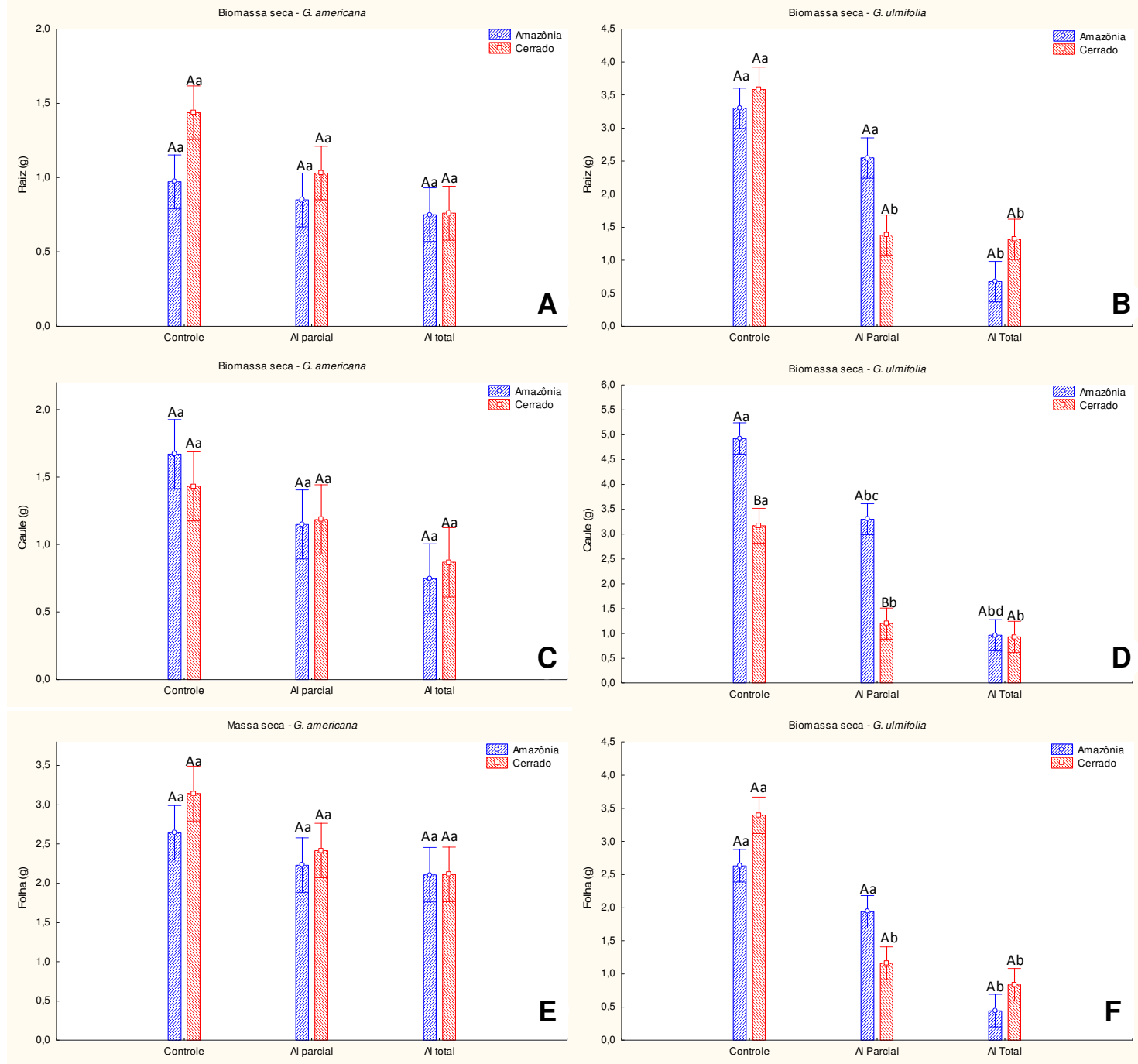

Figura 19. Média ( \pm erro padrão) da biomassa seca de raiz (A e B), caule (C e D) e folha (E e F) de plantas de Genipa americana e Guazuma ulmifolia da Amazônia e do Cerrado, após 30 dias de recuperação $(n=5)$. Para a biomassa seca da raiz, caule e folha ao final de 30 dias de 
recuperação, as médias seguidas de mesma letra não diferem entre si pelo teste Tukey $(\mathrm{p} \leq$ $0,05)$. Para cada espécie letras maiúsculas representam comparações quanto à origem e letras minúsculas representam comparações entre os tratamentos.

\section{DISCUSSÃO}

Os resultados de germinação, análises morfológicas, anatômicas e bioquímicas, obtidos neste estudo, mostraram que o alagamento, afeta o desenvolvimento das plantas no estágio inicial de estabelecimento. Contudo, mesmo para uma espécie frequente em áreas alagáveis, as respostas podem variar não apenas com o nível de alagamento, se parcial ou total, mas também com o ambiente de origem das matrizes, tendo em vista que as plantas $G$. ulmifolia oriundas do Cerrado, apresentaram alterações mais acentuadas em resposta ao alagamento.

O tamanho da semente tem sido um fator referido como uma estratégia para aumentar as chances de sucesso no estabelecimento da plântula, até mesmo em ambientes desfavoráveis. Em geral, sementes maiores, como as sementes de G. americana e G. ulmifolia provenientes de frutos coletados na Amazônia, tendem a possuir maior quantidade de reservas necessárias para a germinação e o crescimento inicial da plântula (Haig e Westoby, 1991; Paz e Martínez-Ramos, 2003; Alves et al., 2005; Klein et al., 2007).

Em G. americana, o alagamento afetou apenas a germinação das sementes oriundas de frutos coletados no Cerrado, que apresentaram menor porcentagem de germinação, nessas condições. $\mathrm{O}$ alagamento causa uma diminuição do oxigênio disponível ao embrião, atrasando ou inibindo a germinação das sementes de várias espécies (Kozlowski e Pallardy, 1997; Taiz e Zeiger, 2004). Como observado por Khosravi e Andersen (1990) em milho (Zea mays), por Marques e Joly (2000) em Calophyllum brasiliense, onde a germinação sofreu maior inibição, com o aumento do período de alagamento. Segundo Marques e Joly (2000), existem algumas espécies, como Calophyllum brasiliense, que não conseguem germinar em condições de alagamento, porém suas sementes se apresentam viáveis após vários meses de alagamento e suas plântulas são capazes de crescer tanto em solo inundado, quanto em solo drenado. Segundo Parolin (2001), a maioria das sementes de espécies terrestres que apresentam alta taxa de germinação no solo, perde a viabilidade quando submetidas ao alagamento e não germinam. 
Por outro lado, existem espécies típicas de solos sujeitos a inundação que exibem alto percentual de germinação, como Inga laurina (Okamoto, 1998), Genipa americana, Eugenia inundata, Laetia corymbulosa e Crateva tapia (Melo, 2013) quando submetidas ao alagamento. No entanto no presente trabalho, apesar do alagamento ter diminuído a porcentagem de germinação de G. americana com origem do Cerrado, os valores encontrados para germinação podem ser considerados altos, indicando certa tolerância à saturação hídrica do solo.

Diferentemente, para G. umifolia, a origem foi que afetou o percentual de germinação, com as sementes provenientes do Cerrado mostrando valores significativamente menores. $\mathrm{O}$ baixo percentual de germinação observado, independente do tratamento, deve-se provavelmente ao fato da espécie possuir dormência causada pelo tegumento presente na semente (Araújo Neto e Aguiar, 1999), requerendo um tratamento pré-germinativo como água com temperatura elevada $\left(60^{\circ} \mathrm{C}\right)$, para elevar o percentual de germinação (Araújo Neto e Aguiar, 2000; Sobrinho et al., 2012).

Os resultados do presente estudo mostraram que plantas das duas espécies estudadas são tolerantes ao alagamento a um período de até 30 dias. Uma vez que, ao final do experimento, $100 \%$ das plantas de G. americana e G. ulmifolia com origem do Cerrado e da Amazônia, sobreviveram aos dois níveis de alagamento a que foram submetidas. No entanto, até mesmo plantas com origem de áreas alagáveis, mostraram algum sinais de injúrias quando submetidas ao alagamento, com G. ulmifolia com origem do Cerrado, sendo a espécie que teve seu crescimento mais comprometido.

A elevada tolerância do gênero Genipa ao alagamento foi observada em estudos com plantas jovens de G. americana (Andrade et al., 1999) e G. espruceana (Parolin et al., 2010; Gonçalves et al., 2013), onde estas não apresentaram mortalidade e que as consideraram tolerantes ao alagamento. Menegucci, (2008) ao estudar o efeito do alagamento parcial em plantas de G. ulmifolia por um período de 126 dias, não observou mortalidade nas plantas e considerou a espécie tolerante ao alagamento. $\mathrm{O}$ alto índice de sobrevivência das espécies estudadas, explica à alta frequência das mesmas em planícies de inundação na Amazônia. Os resultados mostram que essas espécies apresentam elevado grau de plasticidade e tolerância ao alagamento, pois mesmo as plantas com origem do Cerrado, onde não ocorrem pulsos de inundação com mesmo tempo e amplitude das várzeas amazônicas, nenhum indivíduo morreu durante o experimento. Por outro lado, o alagamento pode ser letal em espécies pouco ou não 
tolerantes ao alagamento. Gregório et al., (2008), ao estudar o efeito do alagamento parcial em plantas de Tabebuia heptaphylla (Ipê rosa), comumente encontrada no Cerrado, observou $100 \%$ de mortalidade nas plantas com dois meses de experimento, estas não produziram estruturas que permitem a sobrevivência em ambientes alagados, mostrando não serem tolerantes ao alagamento. Ferreira et al., (2007) estudando o efeito da submersão em Himatanthus sucuиba coletados em terra firme observou que as plantas apresentaram 100\% de mortalidade, diferente daquelas coletadas em áreas alagáveis da Amazônia que apresentaram apenas 30\% de mortalidade. Mostrando que as respostas observadas são influenciadas pelas condições ambientais impostas pelo meio ao qual ocorrem.

A tolerância ao alagamento varia não apenas com a espécie e o ambiente, mas com o nível e o tempo de duração do alagamento. Henrique et al., (2010) observaram para Caesalpinia peltophoroides, espécie comum em mata ciliar, 50\% de mortalidade no décimo dia de alagamento total. Do mesmo modo, Aegiphila sellowiana, espécie utilizada na recuperação de áreas degradadas, algumas das quais são ribeirinhas, quando submetida ao encharcamento do solo, nos primeiros dez dias, mais de $30 \%$ das plantas, apresentaram murcha completa seguida de morte (Medri et al., 2012). Esses resultados indicam que nem todas as espécies com ocorrência na Amazônia e no Cerrado possuem plasticidade para tolerar ao alagamento.

Estudos realizados com plantas submetidas ao alagamento mostram que a manutenção da vida das plantas nessas condições, está relacionada com as respostas morfoanatômicas, fisiológicas e bioquímicas, como ocorreu com G. americana e G. ulmifolia neste estudo. No caso das alterações morfoanatômicas, pelo aumento da difusão de gases e eliminação de compostos tóxicos resultante do metabolismo anaeróbio (Koslowski, 1997; Medri et al., 1998, Lobo e Joly, 2000).

Dentre as alterações morfológicas observadas durante o período de alagamento, no tratamento de alagamento parcial, observou-se no aparecimento de lenticelas hipertrofiadas e raízes adventícias nas plantas de G.ulmifolia, enquanto em plantas de G. americana observouse apenas, a hipertrofia de lenticelas no caule. Para Joly (1996), as lenticelas hipertrofiadas e as raízes adventícias são estruturas funcionais e representam importante adaptação na sobrevivência da espécie submetida ao alagamento, já que facilitam a difusão de gases e eliminação de compostos tóxicos resultante do metabolismo anaeróbio (Lobo e Joly, 2000; Batista et al., 2008; Menegucci, 2008). 
O aerênquima, outra importante resposta ao alagamento, foi observado nas plantas das duas espécies submetidas ao alagamento parcial e total. Para Drew, (1997) o desenvolvimento de parênquimas aerífero é uma estratégia das plantas em condições de alagamento que possibilita a difusão de gases, permitindo assim a manutenção do metabolismo aeróbico, durante o período de estresse. Além de ampliar a permeabilidade nas raízes, facilitando a absorção de água e nutrientes (Vartaperian e Jackson, 1997; Yin et al., 2010). A ocorrência dessas estruturas, assim como de lenticelas e raízes adventícias, tem sido relatadas em espécies tolerantes ao alagamento por Davanso et al. (2002) em Tabebuia vellanedae, Ferreira et al., (2006) em Himatanthus sucuuba, Santiago e Paoli (2007) em G. americana, Batista et al. (2008) em Cecropia pachystachya e em Genipa spruceana, (Gonçalves et al., 2013). Em plantas de G. ulmifolia com origem do Cerrado, quando submetidas ao alagamento parcial, foram observadas fissuras na base caulinar. Essa característica já foi observada em Sebastiana virgata (Davanso-Fabro, 1998), Schinus terebinthifolius (Grisi et al., 2011) e em Tabebuia rosea (Oliveira, 2012) que sugeriram que a estrutura exerça a mesma função de lenticelas. $\mathrm{Na}$ fissura caulinar ocorre a formação de aerênquima secundário, com função de transportar oxigênio do caule para as raízes (Shimamura et al., 2010; Yamauchi et al., 2013; Andrade, 2013). Por outro lado, estudos relatam que plantas como Tabebuia heptahyllus, que não desenvolvem lenticelas hipertrofiadas, aerênquimas e raízes adventícias quando submetidas ao alagamento parcial, apresentam altas taxas de mortalidade (Gregório et al., 2008).

Embora as duas espécies tenham apresentado $100 \%$ de sobrevivência das plantas e tenham desenvolvido estruturas que minimizem o efeito do alagamento durante o período experimental, o alagamento afetou negativamente o desenvolvimento de ambas, que tiveram o crescimento reduzido ou paralisado. O tipo e a intensidade da resposta, mais uma vez variou com a espécie, o nível de alagamento e o ambiente de origem.

Diversos estudos revelam que a maioria das plantas apresentam uma diminuição na taxa de crescimento durante o período de alagamento, especialmente devido as limitações de aeração das raízes (Worbes, 1997; Parolin, 2001; Medri et al., 2002; Ferreira et al., 2006 e Oliveira e Joly, 2010), inclusive do gênero Genipa (Mielke et al., 2003; Gonçalves et al., 2013). O que sugere que esse efeito inibitório é típico de espécies tolerantes ao alagamento e estaria relacionado à economia de energia pelas plantas, ou "trade-off”, pois implica em uma redução ou uso controlado de reservas, com a finalidade de manter as atividades vitais do metabolismo da planta, afetada pela redução de oxigênio (Armonstrong et al., 1994). Estudos 
de Parolin (2009) com lenhosas de áreas alagáveis da Amazônia, mostraram que, a paralisação no crescimento pode ser de grande importância para algumas espécies nesses ambientes, pois possibilita à planta manter uma quantidade de reserva que a permita ter um rápido crescimento tão logo as águas comecem a descer, a fim de expor as folhas acima da coluna de água para possibilitar a fotossíntese. Essa estratégia é conhecida como "fuga da inundação", sendo, portanto, uma característica de plantas tolerantes ao alagamento.

Dentre as plantas avaliadas no presente estudo, G. americana mostrou atividade de crescimento semelhante ao observado para outras espécies tolerantes ao alagamento (Ferreira et al., 2006; Davanso et al., 2002; Batista et al., 2008), assim como G. ulmifolia com origem da Amazônia. No entanto, em G. umifolia com origem do Cerrado, o efeito do alagamento foi mais severo, já que o nível do alagamento, se parcial ou total, afetou de igual maneira. Diferentes resultados foram observados para G. ulmifolia, provenientes de diferentes populações do pantanal, que quando submetidas ao alagamento parcial por 126 dias, não apresentaram diferenças significativas no crescimento em comprimento (Menegucci, 2008).

Aos 30 dias de experimento, G. americana independente da origem, não apresentou perda de folhas, no entanto, estudos com G. americana (Mielke et al., 2003) e G. sprueana (Gonçalves et al., 2013) mostrou que após 43 e 30 dias de inundação, respectivamente, apresentaram abscisão foliar e com 90 dias de experimento, em G. spruceana essa perda foi total. Possivelmente o tempo de experimento utilizado neste estudo, não foi suficiente para induzir a perda de folhas em G. americana, pois a espécie preservou as folhas por 30 dias, mesmo totalmente submersa. Dessa maneira, o efeito do estresse pode variar de acordo com a sua duração. Tanto o alagamento parcial quanto total, estimulou a abscisão foliar em plantas de G. ulmifolia, independente da origem. Menegucci, (2008) não observou diferença no número de folhas em G. ulmifolia provenientes do pantanal, quando submetidas ao alagamento parcial por 126 dias, em relação ao controle. Em condições de alagamento, a difusão de etileno, fica comprometida e o acúmulo desse hormônio resulta em uma maior abscisão foliar (Voesenek et al., 1993). Além disso, para Medri et al. (1998), a perda de folhas compromete a capacidade fotossintética, o que pode levar a um menor crescimento da planta inteira.

De maneira geral, no presente estudo, tanto G. americana, quanto G. ulmifolia, tiveram uma limitação no crescimento e produção de folhas e consequentemente menor incorporação de biomassa. Para G. americana com origem da Amazônia, somente a biomassa 
das folhas foi comprometida no alagamento total, enquanto para a mesma espécie com origem do Cerrado a planta inteira mostrou redução na biomassa, no mesmo tratamento. Nesse caso, o alagamento parcial não comprometeu tal parâmetro, enquanto o alagamento total afetou principalmente a espécie com origem do Cerrado. De maneira geral, é recorrente a redução da massa seca da parte aérea em plantas submetidas ao alagamento (Sorte et al., 1995). Mielke et al. (2003) verificou a redução de mais de $40 \%$ na biomassa das raízes e folhas de $G$. americana, após 63 dias de alagamento, enquanto Gonçalves et al. (2013) estudando G. sprucena, constatou uma diminuição na biomassa das folhas e aumento na biomassa do caule em condições de submersão por um período de 90 dias. Já Davanso et al. (2002) ao estudar o efeito do alagamento na massa seca de plantas de Tabebuia avellanedae, oriunda de locais sujeito ao alagamento, não observou redução na biomassa das folhas, somente da raiz e do caule.

Por sua vez G. ulmifolia com origem da Amazônia teve sua biomassa comprometida de maneira mais acentuada quando submetidas ao alagamento total, enquanto a mesma espécie com origem do Cerrado teve a biomassa comprometida, de maneira similar no alagamento parcial e total. Diferentes resultados foram encontrados por Menegucci, (2008) estudando a mesma espécie proveniente do pantanal, quando submetidas ao alagamento parcial. Em Caesalpinia peltophoroides, espécie comum em mata ciliar, foi observada a diminuição da massa seca nas raízes de maneira mais acentuada em plantas submetidas ao alagamento total, por um período de 30 dias (Henrique et al., 2010). Em condições de alagamento, a respiração das raízes fica comprometida e consequentemente a produção de ATP diminui, afetando diretamente o crescimento do órgão e sua biomassa (Batista et al., 2008). A redução na massa seca de G. ulmifolia, esta ligado a perda de folhas que foi bastante acentuada nas plantas submetidas ao alagamento total e aos danos causados pelo alagamento na raiz, afetando de modo direto na produção total de massa.

Quanto ao acúmulo de carboidratos, G. americana e G. ulmifolia, responderam aos tratamentos de forma variada. Colmer e Voesenek, (2009) destacam a depleção de carboidratos, já que o $\mathrm{CO}_{2}$ e a luz quando as plantas em condição de submersão limitam a aquisição e consequente reposição dos mesmos. A diminuição dos carboidratos pode prejudicar a capacidade de sobrevivência e competitiva das plantas (Dias-Filho, 2012). Esse decréscimo de carboidratos (amido e AST) foi observado neste experimento nas raízes e folhas das plantas de G. ulmifolia com origem da Amazônia, quando submetidas aos 
tratamentos de alagamento parcial e total. Já em G. ulmifolia com origem do Cerrado a diminuição de amido foi observada apenas nas folhas. A diminuição de carboidratos na raiz e nas folhas foi observada em plantas de Caesalpinia peltophoroides, submetidas ao alagamento total (Henrique et al., 2010). G. americana aumentou o teor de amido no caule e folha e manteve o teor de AST, ao final do experimento. Segundo Lião e Lin (2001), o alagamento pode reduzir a taxa de translocação de carboidratos das folhas para as raízes, acarretando um acúmulo de amido nas folhas. O elevado teor de carboidratos, já foi observado por Singh et al. (2001) em plantas de arroz em condições de alagamento. O mesmo autor sugere que, a manutenção dos carboidratos favorece a planta durante o alagamento e garantem sua rápida recuperação após o estresse. A preservação das folhas, durante o período de alagamento pode ter permitido a fotossíntese subaquática em G. americana, o que garantiu a manutenção dos carboidratos. Plantas de G. spruceana, submetidas ao alagamento durante um período de 90 dias, manteve o funcionamento do aparato fotossintético, indicando alta plasticidade ecofisiológica da espécie (Gonçalves et al., 2012). G. americana é uma espécie com elevado nível de tolerância e estudos que avaliem seu comportamento fisiológico se fazem necessários, para maior entendimento de suas respostas.

Após o período de alagamento, as plantas devem possuir estratégias de recuperação dos danos causados durante o estresse. A capacidade de recuperação das injúrias provocadas pelo alagamento, de crescer e de re-aclimatar, é crucial para o sucesso do estabelecimento das plantas após o período de submersão (Luo et al., 2011). No entanto, a rápida exposição das plantas ao oxigênio pode ser danoso, ocasionando um estresse oxidativo nas plantas. $\mathrm{O}$ rápido fornecimento de oxigênio pode levar a formação de produtos tóxicos em diferentes células e órgãos, comprometendo a recuperação das plantas (Blohkina et al., 2003). Portanto, quando retiradas do alagamento, as plantas intolerantes costumam sofrer danos oxidativos severos quando em contato com o oxigênio, que podem comprometer a sua sobrevivência (Rawyler $e t$ $a l .$, 2002). No presente estudo, quando plantas de G. americana e G. ulmifolia foram retiradas dos tratamentos, passaram por um período de 30 dias de recuperação e nesse período, apresentaram rápida recuperação dos danos causados pelo alagamento. Tal comportamento, sugere a existência de mecanismos de prevenção ou reparo aos danos oxidativos no período de reaeração das plantas (Blohkina et al., 2003). Durante o período de recuperação, as plantas que anteriormente estavam submetidas ao alagamento total, tiveram um maior investimento na produção de folhas, enquanto aquelas que estavam anteriormente submetidas ao alagamento parcial, investiram mais no crescimento caulinar. Quanto à recuperação em 
biomassa, observou-se que G. americana, tanto da Amazônia quanto do Cerrado, se recuperou e atingiu o mesmo ritmo de crescimento do controle, o que não ocorreu com $G$. ulmifolia em 30 dias de recuperação. Sugerindo ser necessário um tempo maior de observação, a fim de verificar se a espécie se recuperaria e atingiria o crescimento das plantas controle.

\section{CONCLUSÕES}

Genipa americana e Guazuma umifolia são espécies tolerantes ao alagamento. Suas sementes germinam e as plantas sobrevivem por longo período, mesmo totalmente submersas. Contudo, a intensidade das respostas varia com a espécie estudada, com a origem das plantas (áreas alagáveis da Amazônia ou bem drenadas do Cerrado) e com a intensidade do alagamento.

Plantas de G. americana mostraram elevado nível de tolerância ao alagamento, independente da origem (Amazônia ou Cerrado), pois suas plantas continuaram crescendo e acumulando biomassa quando parcialmente alagada, o crescimento cessou apenas quando a planta foi totalmente submersa.

O alagamento afetou negativamente o crescimento de $G$. ulmifolia, que teve efeito da origem, pois enquanto as plantas oriundas da Amazônia mostraram comportamento semelhante às de $G$. americana, as plantas oriundas do Cerrado tiveram o crescimento paralisado ainda em condições de alagamento parcial.

Os resultados do presente trabalho reforçam a importância de estudos ecofisiológicos com espécies submetidas a diferentes pressões ambientais, especialmente quando se trata de uma espécie com ampla distribuição. Tais informações contribuem para orientar planos de manejo e recuperação de áreas submetidas a saturações hídricas do solo. Tendo em vista que, dependendo do objetivo, a origem de coleta das sementes é importante quando se considera as escolhas das espécies. 


\section{REFERÊNCIAS}

ALVES, E. U.; BRUNO, R. L. A.; OlIVEIRA, P. O.; AlVES, A. U.; AlVES, U. A.; PAULA, R. C. Influência do tamanho e da procedência de sementes de Mimosa caesalpiniifolia Benth sobre a germinação e vigor. Revista Árvore, v.29, n.6, p.877-85, 2005.

AMARAL, L. I.; GASPAR, M.; MOREIRA, P.; BUCKERIDGE, M. S. Novo método enzimático rápido e sensível de extração e dosagem de amido em materiais vegetais. Hoehnea, v. 34, n. 4, p. 425-431, 2007.

ANDRADE, A. C. S.; RAMOS, F.N.; SOUZA, A.F.; LOUREIRO, M. B. E BASTOS, R. Flooding effects in seedlings of Cytharexyllum myrianthum Cham. and Genipa americana L.: responses of two neotropical lowland tree species. Revista Brasileira de Botânica 22 (2): 281-285, 1999.

ANDRADE, C. A. O papel do peróxido de hidrogênio na tolerância de soja (Glicine max) ao alagamento. Dissertação de Mestrado (Agronomia/Fisiologia Vegetal) - UFLA. Lavras MG, 2013.

ANDREV, V. Y.; VARTAPETIAN, B. B. Induction of alcoholic and lactic fermentation in the early stages of anaerobic incubation of higher plants. Phytochemistry, v. 31 p. 18591861, 1992.

ARAÚJO NETO, J. C.; AGUIAR, I. B. Desarrollo ontogénico de plántulas de Guazuma ulmifolia (Sterculiaceae). Revista de Biologia Tropical, San José, v.47, n.4, p.785-790, 1999.

ARAÚJO NETO, J.C.; AGUIAR, I.B. Germinative pretreatments to dormancy break in Guazuma ulmifolia Lam. seeds. Scientia Forestalis, Piracicaba, n.58, p.15-24, 2000.

ARMSTRONG, W.; BRAENDLE, R.; JACKSON, M. B. Mechanisms of flood tolerance in plants. Acta Botanica Neerlandica, Amsterdam, v. 43, n. 4, p. 307-358, 1994.

BAKER, N.R.; Light-use efficiency and photoinhibitionof photosynthesis in plants under environmental stress. In: Smith JAC, Griffiths H (eds.), Water deficits plantresponses from cell to community. Bios Scientific Publisher, Oxford.pp.221-235, 1993.

BATISTA, C. U. N.; MEDRI, M. E.; BIANCHINI, E.; MEDRI, C.; PIMENTAJ. A.Tolerância à inundação de Cecropia pachystachya Trécul (Cecropiaceae): aspectos ecofisiológicos e morfoanatômicos. Acta Botanica Brasilica, v.22, p.91- 98, 2008.

BEWLEY, J. D. e BLACK, M. Seeds: physiology of development and germination. $2^{\text {nd }}$ ed. Plenum Press, New York, 1994.

BLOKHINA, O; VIROLAINEN, E; FAGERSTEDT, K. V. Antioxidants, oxidative damage and oxygen deprivation stress: a review. Annals of botany, v. 91, n. 2, p. 179-194, 2003.

BORGES, E. E. L.; RENA, A. B. Germinação de semente. In: AGUIAR, I. B.; PINÃ RODRIGUES, F. C. M.; FIGLIOLIA, M. B (Coord). Sementes florestais tropicais.Brasília: Abrates, p.83-136, 1993. 
BRAILSFORD, R.W., VOESENEK, L.A.C.J., BLOOM, C.W.P.M., SMITH, A.R., HALL, M.A. \& JACKSON, M.B. Enhanced ethylene production by primary roots of Zea mays L. in response to sub-ambient partial pressures of oxygen. Plant Cell \& Env. 16:1071-1080, 1993.

BRINA, A. E. Aspectos da dinâmica da vegetação associada a afloramentos calcários na APA Carste de Lagoa Santa, MG. Dissertação (Mestrado) - Instituto de Ciências Biológicas, Universidade Federal de Minas Gerais. Belo Horizonte. 105 f, 1998.

BRUCKERIDGE, M. S.; SANTOS, H. P.; TINÉ, M. A. S.; AIDAR, M. P. M. Mobilização de reservas. In: FERREIRA, A. G.; BORGHETTI, F. (Ed.) Germinação: do básico ao aplicado. Porto Alegre: Artimed, p.163-185, 2004.

BUCKERIDGE, M. S., SANTOS, P.H.; TINÉ, M. A. S. Mobilisation of storage celw all polysacharides in seeds. Plant Physiology Biochemistry, 38(1/2):141-156, 2000.

CARVAlHO, N. M.; NAKAGAWA, J. Sementes: Ciência, Tecnologia e Produção. $4^{\circ}$ Ed. Jaboticabal - SP: FUNEP.588p, 2000.

CASTRO, E. M.; PEREIRA, F. J.; PAIVA, R. Histologia vegetal: estrutura e função dos órgãos vegetativos. Lavras, Editora da UFLA, 234 p, 2009.

COLMER, T. D. E VOESENEK, L.A.C.J. Flooding tolerance: suites of plants traits in variable environments. Functional Plant Biology 36: 665-681, 2009.

CORTE, B. V.; BORGES, E. E. L.; PONTES, C. A.; LEITE, I. T. A.; VENTRELLA, M. C.; MATHIAS, A. A. Mobilização de reservas durante a germinação das sementes de Caesalpinia peltophoroides Benth. (Leguminosae Caesalpinoideae). Revista Árvore, v.30, n.6, p.941-949, 2006.

COSTA, A. M.; GOBBI, E. L.; DEMUNER, V. G.; HEBLING, S. A. O efeito da inundação do solo sobre o crescimento inicial de Schizolobium parahyba (Vell.) S. F. Blake, guapuruvu. Natureza on line, Santa Tereza, v. 4, n. 1, p. 7-13, 2006.

CRAWFORD, R. M. M. e BRANDLE, R. Oxygen deprivation stress in achanging environment. Journal of Experimental Botany47: 145-159, 1996.

CRAWFORD, R. M. M.; ZOCHOWSKI, Z. M. Tolerance of anoxia and ethanol toxicity in chickpea seedlings (Cicerarietinum L.). Journal of Experimental Botany, v. 35, n. 10, p. 1472-1480, 1984.

DANTAS, B. F., ARAGÃO, C. A., CAVARIANI, C., NAKAGAWA, J.; RODRIGUES, J. D. Efeito da duração e da temperatura de alagamento na germinação e no vigor de sementes de milho. Revista Brasileira de sementes, 22(1), 88-96, 2000.

DAVANSO-FABRO, V. M.; MEDRI, M. E.; BIANCGINI, E. \& PIMENTA, J. A. Tolerância à inundação: aspectos da anatomia ecológica e do desenvolvimento da Sesbania virgata (CAV.) Pers. (Fabaceae). Brazilian Archives of Biology and Technology 41: 475-482, 1998. 
DAVANSO, V.M.; SOUZA, L.A.; MEDRI, M.E.; PIMENTA, J.A. \& BIANCHINI, E. Photosynthesis, growth and development of Tabebuia avellanedae Lor. Ex Griseb. (Bignoniaceae) in flooded soil. Brazilian Archives of Biology and Technology 45: 375-384, 2002.

DEUS, C. E.; WEIGAND JUNIOR, R.; KAGEYAMA, P. Y.;VIANA, V. M.; FERRAZ, P. de A.; BORGES, H. B. N.;ALMEIDA, M. C.; SILVEIRA, M.; VICENTE, C. A. R. Comportamento de 28 espécies arbóreas tropicais sob diferentes regimes de luz em Rio Branco, Acre. Rio Branco: Universidade Federal do Acre, 170 p, 1993.

DREW, M. C. Oxygen deficiency and root metabolism injury and acclimation under hipoxia and anoxia. Annual Review of Plant Physiology and Plant Molecular Biology 48: 223-250, 1997.

DIAS-FILHO, M. B. Características Morfofisiológicas Associadas à Tolerância de Gramíneas ao Alagamento e ao Encharcamento. Embrapa ISSN 1983-0513, Documentos, 383, 2012.

DIAS FILHO, M. B. Opções forrageiras para áreas sujeitas ao encharcamento ou alagamento temporário. Embrapa Amazônia Oriental, 2006.

DUBOIS, M.; GILLES, K. A.; HAMILTON, J. K.; REBERS, P.; SMITH, F. Colorimetric method for determination of sugars and related substances. Analytical chemistry, v. 28, n. 3, p. 350-356, 1956.

EZIN, V.; PENA, R. L.; A, A. Flooding tolerance of tomato genotypes during vegetative and reproductive stages. Brazilian Journal Plant Physiology, v. 22, n. 1, p. 131-142, 2010.

FERNANDEZ, M. D.; PIETERS, A.; DONOSO, C.; HERRERA, C.; TEZARA, W. Seasonal changes in photosynthesis of trees in the flooded forest of the Mapire River. Tree Physiology, 19: 79-85, 1999.

FERREIRA, A. G.; BORGHETTI, F. Germinação: do básico ao aplicado. Porto Alegre: Artmed. 2004.

FERREIRA, C. S.; PIEDADE, M. T. F.; BONATES, L. C. "Germinação de sementes e sobrevivência de plântulas de Himatanthus sucuuba (Spruce) Wood. em resposta ao alagamento, nas várzeas da Amazônia Central." Acta Amazonica 36.4, 2006.

FERREIRA, C.S., M.T.F. PIEDADE, W.J. JUNK e P. PAROLIN. Floodplain and upland populations of Amazonian Himatanthus sucuuba: Effects of flooding on germination, seedling growth and mortality. Environmental and Experimental Botany. 60:477-483, 2007.

FERREIRA, C.S.; PIEDADE, M.T.F.; FRANCO, A.C.; GONÇALVES, J.F.C.; JUNK, W.J. Adaptive strategies to tolerate prolonged flooding in seedlings of floodplain and upland populations of Himatanthus sucuuba, a Central Amazon tree. Aquatic Botany, 90: 246$252,2009$.

FRANCO, A. C. Seasonal patterns of gas exchange, water relations and growthof Roupala montana, an evergreen savana species. Plant Ecology. v. 136, p.69-76, 1998. 
FRANCO, A.C. Water and light use strategies by cerradowood plants. In Tópicos atuais em botânica (T.B.Cavalcanti \& B.M.T. Walter, coords.) SBB, Embrapa/CPAC, Brasília, p.292$298,2000$.

FRANCO, A. C. Ecophysiology of woody plants. Pp. 178-197. In: P. S. Oliveira e R. J. Marquis (eds.). The cerrados of Brazil. New York, Columbia University Press. 2002.

FRANCO, A.C. Estratégias funcionais de plantas lenhosas das savanas do Brasil Central: relação ao déficit hídrico e ao regime luminoso. In Fisiologia ecológica em plantas: mecanismos y respuestas a estrés em los ecosistemas (H. M. Cabrera, ed.). EUV, Valparaíso, pp 173-178, 2004.

GIABELLUCA T.W., SCHOLZ F. G., BUCCI S. J., MEINZER F. C., GUILLERMO GOLDSTEIN, HOFFMANN W. A., FRANCO A C., BUCHERT M. P. Evapotranspiration and energy balance of Brazilian savannas with contrasting tree density. Agricultural and Forest Meteorology 149. 1365-1376, 2009.

GONÇALVES, C. J. F.; MELO, F. E. G.; FERREIRA, M. J.; SILVA, C. E. M., E GOMES, I. B. Crescimento, partição de biomassa e fotossíntese em plantas jovens de Genipa spruceana submetidas ao alagamento. Cerne, Lavras, 19(2), 193-200, 2013.

GONÇALVES, J. F. C, MELO, F. E. G., SILVA, C. E. M., FERREIRA, M. J. e JUSTINO, G. C. Estratégias no uso da energia luminosa por plantas jovens de Genipa spruceana Steyerm submetidas ao alagamento. Acta Botanica Brasilica, 26 (2), 391-398, 2012.

GOODLAND, R; FERRI, M.G. Ecologia do Cerrado. São Paulo, Editora da Universidade de São Paulo, 1979.

GOODLAND, R. e POLLARD, R. The Brazilian cerrado vegetation: a fertility gradient. Journal of Ecology 61: 219-224, 1973.

GREGÓRIO T. A.; GOBBO L. G.; CARDOSO J. F.; DEMUNER V. G. e HEBLING AS. Efeito do alagamento sobre o crescimento inicial de Tabebuia heptaphylla (Vell.) Toledo (Ipê-rosa) Natureza on line 6 (2): 91-98, 2008.

GRISI, F. A; ANGELO, A. C; BOEGER, M. R. T; LEITÃO, C. A. E; GALVÃO, S. F; WENDLING, I. Morfoanatomia foliar em mudas de Schinus terebinthifolius sob diferentes níveis de saturação hídrica. Floresta, Curitiba, PR, v. 41, n. 4, p. 881-894, 2011.

HAIG, D. WESTOBY, M. Seed size, pollination casts and angiosperm success. Evolutionary Ecology, London, v. 5, p. 231-247, 1991.

HENRIQUE, P. C.; ALVES, J. D.; GOULART, P. F. P.; DEUNER, S.; SILVEIRA, N. M.; ZANANDREA, L.; CASTRO, E. V.; Características fisiológicas e anatômicas de plantas de sibipiruna submetidas à hipoxia. Ciência Rural, Santa Maria, v. 40, n. 1, p. 70-76, 2010.

HÖFS, A; SCHUC, L. O. B; PESKE, S. T. e ALBUQUEREQUE, A. C. S. Emergência e crescimento de plântulas de arroz em resposta à qualidade fisiológica de sementes. Revista Brasileira de Sementes, v. 26, n. 1, p. 92-97, 2004. 
HOFFMANN, W.A., BIRGIT O., and A.C. Franco."Constraints to seedling success of savanna and forest trees across the savanna-forest boundary." Oecologia" $140.2,252-260$, 2004.

JACKSON, M. B., e RAM, P. C. Physiological and Molecular Basis of Susceptibility and Tolerance of Rice Plants to Complete Submergence. Annals of Botany, 91, 227-241, 2003.

JACKSON, M. B. Root-to-shoot communication in flooded plants: involvement of abscisic acid, ethylene, and 1-aminocyclopropane-1- carboxylic acid. Agronomy Journal, v. 86, n. 5, 775-782, 1994.

JOLY, C. A. Flooding tolerance in tropical trees. In: Jackson, M.B.; Daves, D.D.; Lambers, H. Plant life under oxygen deprivation: ecology, physiology and biochemistry. (eds.). Netherlands, SPB Academic Publishing, The Hague, p. 23-34, 1991.

JOLY, C. A. The role of oxygen diffusion to the root system on flooding tolerance of tropical trees. Revista Brasileira de Biologia 56: 375-382, 1996.

JUNK, W.J. Wetlands of tropical South America. In: Whigham, D.; Hejny, S.; Dykyjova, D. (eds.). Wetlands of the world I. Kluwer Academic Publishers, Dordrecht, p.679-739, 1993.

JUNK, W.J; BAYLEY, P.B; SPARKS, R.E.The flood pulse concept in river-floodplainsystems. In: Dodge, D.P. (ed.): Proceedings of the International Large River Symposium. Can. Spec. Publ. Fish. Aqut. Sci., 106:110-127, 1989.

KIDSON, R.; WESTOBY, M. Seed mass and seedling dimension in relation to seedling establishment. O ecologia. 125(1):11-17, 2000.

KLEIN, J; ZUCARELI, V; KESTRING, D; CAMILLI, L; RODRIGUES, J. D. Efeito do Tamanho da Semente na Emergência e Desenvolvimento Inicial de Mudas de Pitangueira (Eugenia uniflora. L). Revista Brasileira de Biociências, Porto Alegre, 2007.

KLINK, C. A.; MACHADO, R. B. A conservação do Cerrado brasileiro. Megadiversidade, v. 1, n. 1, p. 147-155, 2005.

KOLB, R. M.; JOLY, C. A. Germination and anaerobic metabolism of seeds of Tabebuia cassinoides (Lam.) DC subjected to flooding and anoxia. Flora, 205, p. 112-117, 2010.

KOZLOWSKI, T. T. Responses of woody plants to flooding and salinity. Tree Physiology, 17(7), 490-490, 1997.

KOZLOWSKI, T.T. e PALLARDY, S.G. Growth control in Woody plants. American Press: San Diego, 254p, 1997.

KOZLOWSKI, T.T. Water supply and tree growth. Part II. Flooding. For. Abstracts, v.43, p.145-161, 1982.

KHOSRAVI, G. R. e ANDERSEN, I. C. Pre-emergence flooding and nitrogen atmosfere effects on germinating corn inbreds. Agronomy Journal, Madison, v.82, n. 2, p. 495-499, 1990. 
KRAMER, P. Water relations of plants. New York: AcademicPress, 489 p, 1983.

KUHLMANN, M. Frutos e Sementes do Cerrado atrativos para a fauna: guia de campo. Brasília. : Rede de Sementes do Cerrado, 360p, 2012.

LABOURIAU, L. G. A germinação de sementes. Washington: OEA, 174 p, 1983.

LARCHER, W. Ecofisiologia Vegetal. Rima, São Carlos, 2000.

LIAO, C. T.; LIN, C. H. Physiological adaptation of crop plants to flooding stress. In: Proceedings of the National Science Council, Republic of China. Part B, Life sciences, v. 25 , n. 3, p. 148-57, 2001.

LIBERATO, M. A. R. Metabolismo energético e emissão de compostos orgânicos por Hevea spruceana (Benth.) Müll. Arg em diferentes ecossistemas inundáveis da Amazônia Central. Tese (Doutorado em Botânica)-INPA/UFAM, Manaus, 2010.

LOBO, P. C.; JOLY, C. A. Aspectos ecofisiológicos da vegetação de mata ciliar do Sudeste do Brasil. In: Rodrigues, R. R.; Leitão Filho, H. F. Matas ciliares: conservação e recuperação. (eds.). São Paulo, Editora da Universidade de São Paulo, p. 143-157, 2000.

LOBO, P. C.; JOLY, C. A. Tolerance to hypoxia and anoxia in neotropical tree species. In: Scarano, F.R.; Franco, A.C. (Eds). Ecophysiological strategies ofxerophytic and amphibious plants in the neotropics. PPGE-UFRJ, Rio de Janeiro, Brazil. p. 137-156, 1998.

LOPEZ, O. R.; KURSAR, T. A. Does flood tolerance explain tree species distribution in tropical seasonally flooded habitats? O ecologia, 136: 193-204, 2003.

LORENZI, H. Árvores brasileiras: manual de identificação e cultivo de plantas arbóreas nativas do Brasil, ed. Nova Odessa: Instituto Plantarum, vol. 1, 5, 2008.

LUO, FANG-LI; NAGEL, K. A; SCHARR, H; ZENG, B; SCHRR, U; MATSUBARA, S. "Recovery dynamics of growth, photosynthesis and carbohydrate accumulation after desubmergence: a comparison between two wetland plants showing escape and quiescence strategies.Annals of botany 107.1 49-63, 2011.

MARQUES, M. C. M.; JOLY, C. A. Germinação e crescimento de Calophyllum brasiliense (Clusiaceae), uma espécie típica de florestas inundadas. Acta Botanica Brasílica, São Paulo, v. 14, n. 1, p. 113-120, 2000.

MAURENZA, D.; MARENCO, R. A. \& PIEDADE, M. T. F. Efeito da inundação de longa duração sob o crescimento de Pouteria glomerata (Sapotaceae), uma arbórea da várzea da Amazônia Central. Acta Amazônica 39 (3): 519-526, 2009.

MAYER, A.M.; POLJAKOFF-MAYBER, A. The germination of seed. $2^{\text {nd }}$ ed. Pergamon Press, Oxford.192pp, 1975.

MEDEIROS, J. D. Guia de campo: vegetação do Cerrado 500 espécies. Brasília: MMA/SBF, 532 p, 2011. 
MEDINA, C.L.; SANCHES, M.C.; TUCCI, M.L.S.; SOUZA, C.A.F; CUZZUOL, G. R.F.; JOLY, C.A. Erythrina speciosa (Leguminosae-Papilionoideae) under soil water saturation: morphophysiological and growth responses Annals of Botany, v. 104, p. 671-680, 2009.

MEDINA, E. Nutrients requirements, conservation and cycles in the herbaceous layer. Determinants of Savannas, (B.H. Walker, ed.). IRL Press, Oxford, p.39-65, 1987.

MEDRI, C.; PIMENTA, J. A. RUAS, E. A.; SOUZA, L. A.; MEDRI, P. S.;SAYHUN, S.; BIANCHINNI, E.; MEDRI, M. E. O alagamento do solo afeta a sobrevivência, o crescimento e o metabolismo de Aegiphila sellowiana Cham. (Lamiaceae)? Semina, 33: 123-134, 2012.

MEDRI, M. E.; FERREIRA, A.C.; KOLB, R. M.; BIANCHINI, E.; PIMENTA, J. A.; DAVANSO-FABRO, V. M.; MEDRI, C. Alterações morfoanatômicas em plantas de Lithraea molleoides (Vell.) Engl. submetidas ao alagamento Acta Scientiarum -Biological Sciences, v.29, n.1, p.15-22, 2007.

MEDRI, M. E.; BIANCHINI, E.; PIMENTA, J. A.; COLLI, S.; MULLER, C. Estudos sobre a tolerância ao alagamento em espécies arbóreas nativas da bacia do rio Tibagi. In: MEDRI, M. E.; BIANCHINI, E.; SHIBATTA, O. A.; PIMENTA, J. A. (Ed.). A bacia do Rio Tibagi. Londrina: Edição dos editores, p. 133-172, 2002.

MEDRI, M. E., BIANCHINI, E., PIMENTA, J. A., DELGADO, M. F. e CORREA, G. T. Aspectos morfo-anatômicos e fisiológicos de Peltophorum dubium (Spr.) Taub. submetida ao alagamento e à aplicação de ethrel. Revista brasileira. Botânica. 21:261-267, 1998.

MELO, R. B. Caracterização das reservas das sementes e avaliação da germinação e formação de plântulas de nove espécies arbóreas de florestas alagáveis da Amazônia. Dissertação de Mestrado (Mestrado em Botânica)-UNB, Brasília, 2013.

MEIRELlES, L. M.; GUIMARÃES, A. J. M.; OLIVEIRA, R. C.; ARAÚJO, G. M.; RIBEIRO, J. F. Impactos sobre o estrato herbáceo de áreas úmidos de Cerrado. In: Aguiar, L. M. S.; Camargo, A. J. A. (ed.). Cerrado: ecologia e caracterização. $1^{a}$ ed. Brasília, DF: Embrapa Informação Tecnológica, 249p, 2004.

MENEGUCCI, Z. R. H. Estudo comparativo de respostas ao alagamento em plantas jovens de espécies arbóreas provenientes do pantanal, Mato Grosso do Sul, Brasil. Dissertação de Mestrado. Fundação Universidade Federal de Mato Grosso do Sul. 2008.

MIELKE, M. S.; ALMEIDA, A. F.; GOMES, F. P.; AGUILAR, M. A. G. e MANGABEIRA, P. A. O. Leaf gas exchange, chlorophyll fluorescence and growth responses of Genipa americana seedlings to soil flooding. Environment and Experimental Botany 50: 221-231, 2003.

NABINGER, C. Princípios da exploração intensiva de pastagens. In: SIMPÓSIO SOBRE MANEJO DE PASTAGENS, 13., 1997, Piracicaba. Anais... Piracicaba: Fundação de Estudos Agrários Luiz de Queiroz, p.15-95, 1997.

NETO, JOÃO. C. A.; AGUIAR, I. B.; FERREIRA, V. M. Efeito da temperatura e da luz na germinação de sementes de Acacia polyphylla DC. Revista Brasileira de Botânica, 26 (2): 249-256, 2003. 
OKAMOTO, J. M. Ecofisiologia da germinação e do metabolismo respiratório de quatro espécies do gênero Inga Mill. (Mimosaceae) submetidas à hipoxia e anoxia. Dissertação de Mestrado. Universidade Estadual de Campinas, 1998.

OLIVEIRA, A. S. Tolerância ao encharcamento, alterações morfológicas e anatômicas em algumas espécies lenhosas tropicais. Dissertação de Mestrado (Mestrado em Botânica)UNB, Brasília, 2012.

OLIVEIRA FILHO, A. T. e RATTER, J. A. Vegetation physiognomies and woody flora of the Cerrado Biome In: P. S. Oliveira \& R. J. Marquis (eds.). The cerrados of Brazil. New York, Columbia University Press. Pp. 121-140, 2002.

OLIVEIRA, V. C.; JOLY, C. A. Flooding tolerance of Callophyllum brasiliense Camb. (Clusiaceae): morphological, physiological and growth responses. Trees, Vancouver, v. 24, p. 185-193, 2010.

PAIVA, J. G. A., FRANK-DE-CARVALHO. S. M., MAGALHÃES, M. P. E GRACIANORIBEIRO, D. Verniz vitral incolor 500 ${ }^{\circledR}$ : uma alternativa de meio de montagem economicamente viável. Acta Botanica Brasilica 20:257-264, 2006.

PALHARES, D; FRANCO, A. C.; ZAIDAN, L. B. P. Respostas fotossintéticas de plantas do cerrado nas estações seca e chuvosa. Revista Brasileira de Biociências, v. 8, n. 2, 2010.

PAROLIN, P.; LUCAS, C; PIEDADE, M.T.F.; WITTMANN, F. Drought responses of floodtolerant trees in Amazonian floodplains. Annals of Botany 105: 129-139, 2010.

PAROLIN, P. Submerged in darkness: adaptations to prolonged submergence by woody species of the Amazonian floodplains. Annals of Botany.v. 103, p. 359-376, 2009.

PAROLIN, P. Fugitive and possessive establishment strategies in Amazonian floodplain pioneers. Flora, London, v. 198, n. 6, p. 436-443, 2003.

PAROLIN, P. Seed germination and early establishment of 12 tree species from nutrient-rich and nutrient-poor Central Amazonian floodplains. Aquatic Botany,70: 89-103, 2001.

PAROLIN, P. Morphological and physiological adjustments to water logging and drought in seedlings of Amazonian flooplain trees. O ecologia, 128: 326-335, 2001.

PAROLIN, P. Phenology and $\mathrm{CO}_{2}$ assimilation of trees in Central Amazonian floodplains. J. Trop. Ecology 16:465-473, 2000.

PAZ, A. R. Simulação Hidráulica de rios com grandes planícies de inundação. Tese (Doutorado em Recursos Hídricos e Saneamento Ambiental) - UFRGS/ IPH, Porto Alegre, 2010.

PAZ, H. e MARTÍNEZ-RAMOS, M. Seed mass and seedling performance within eight species of Psychotria (Rubiaceae). Ecology 84, 439-450, 2003. 
PEZESHKI, S.R. Wetland plant responses to soil flooding. Environmental and Experimental Botany, 46: 299-312, 2001.

PIEDADE, M.T.F.; JUNK, W.W. \& PAROLIN, P. The flood pulse and photosynthetic response of trees in a White water floodplain (várzea) of Central Amazon, Brazil. Verhandlungen der Internationale Vereinigung für Limnologie 27:1734-1739, 2000.

PISICCHIO, C. M., BIANCHINI, E.; PIMENTA, J. A.; SERT, M. A.; DEVANSO-FABRO, V. M.; MEDRI, M. E. Heliocarpus popayanensis (Malvaceae) tolera a hipoxia do substrato? Acta Scientiarum - Biological Sciences, v.32, n.2, p.201-209, 2010.

RAWYLER, A.; ARPAGAUS, S.; BRAENDLE, R. Impact of oxygen stress and energy availability on membrane stability of plant cells. Annals of Botany, v. 90, n. 4, p. 499-507, 2002.

RIBEIRO, J. F. e WALTER, B. M. T. Fitofisionomias do bioma Cerrado. In: SANO, M. S. e ALMEIDA, S. P. (Org.) Cerrado: Ambiente e Flora. Brasília, Embrapa - CPAC, pp. 89$166,1998$.

RODRIGUES, R. R. Análise estrutural de formações ripárias. In: L. M. Barbosa (Ed.), Anais do Simpósio sobre mata ciliar. Fundação Cargil, Campinas. pp. 99-119, 1989.

ROSSATTO, D. R.; HOFFMANN, W. A. e FRANCO, A. C. Características estomáticas de pares congenéricos de cerrado e mata de galeria crescendo numa região transicional no Brasil Central. Acta Botanica Brasilica, 23, 499-508, 2009.

SANTARELLI, E.G. Produção de mudas de espécies nativas para florestas ciliares. In: RODRIGUES, R. R.; LEITÃO FILHO, H. (Eds.). Matas ciliares: conservação e recuperação. São Paulo, EDUSP/ FAPESP. p. 313-318. 2001.

SANTIAGO, E. F.; PAOLI, A. AS. Respostas morfológicas em Guibourtia hymenifolia (Moric.) J. Leonard (Fabaceae) e Genipa americana L. (Rubiaceae), submetidas ao estresse por deficiência nutricional e alagamento do substrato. Revista Brasileira de Botânica, v. 30, n. 1, p. 131-140, 2007.

SCARANO, F. R.; PEREIRA, T. S.; ROCAS, G., Seed germination during flotation and seedling growth of Carapa guianensis, a tree from flood-prone forests of the Amazon. Plant Ecology 168, 291-296, 2003.

SCARANO, F. R. A comparison of dispersal, germination and establishment of wood plants subjected to distinct floodings regimes in Brazil flood-prone forests and estuarine vegetation. In: F. R. SCARANO E FRANCO, A. C. (Eds.), Ecophysiological strategies of xerophytic and amphibious plants in the neotropics. Series $\mathbf{O}$ ecologia brasiliensis vol. IV. PPGE-UFRJ, Rio de Janeiro. Pp. 177-194, 1998.

SCARIOT, A.; FELFILI J. M.; SOUSA-SILVA, J. C. Cerrado: Ecologia, Biodiversidade e Conservação. Ministério do Meio Ambiente. Brasília, Brasil. 2005. 
SHIMAMURA, S., YAMAMOTO, R., NAKAMURA, T., SHIMADA, S., e KOMATSU, S. Stem hypertrophic lenticels and secondary aerenchyma enable oxygen transport to roots of soybean in flooded soil. Annals of botany, 106(2), 277-284, 2010.

SILVA, E. C.; NOGUEIRA, R. J. M. C; VALE, F. H. A; ARAÚJO, F. P.; PIMENTA, M. A. Stomatal changes induced by intermittent drought in four umbu tree genotypes. Brazilian Journal of Plant Physiology, Londrina, v. 21, n. 1, p. 33-42, 2009.

SILVA JÚNIOR, M. C. 100 árvores do cerrado - sentido restrito: guia de campo. Brasília: Rede de Sementes do Cerrado, 2012.

SILVA JUNIOR, M. C. e LIMA, R. M. C e. 100 árvores urbanas - Brasília - Guia de Campo. Brasília. 292p, 2010.

SILVA JUNIOR, M. C. 100 árvores do Cerrado - Guia de campo. Brasília: Rede de Sementes do Cerrado. 278p, 2005.

SIOLI, H. Hydrochemistry and geology in the Brazilian Amazon region. Amazoniana, v. 1, n. 3, p. 267-277, 1968.

SMIRNOFF, N.The role of active oxygen in the response of plants to water deficit and dessiccation. New Phytol. 125:27-58, 1993.

SINGH, H. P.; SINGH, B. B.; RAM, P. C. Submergence tolerance of rainfed lowland rice: search for physiological marker traits. Journal of Plant Physiology, v. 158, n. 7, p. 883-889, 2001 .

SOBRINHO, S. D. P., SIQUEIRA, A. G., MORAIS, P. D. B., E SILVA, S. J. D. Superação da dormência em sementes de mutamba (Guazuma ulmifolia Lam.-Sterculiaceae). Revista Árvore, Viçosa-MG, v.36, n.5, p.797-802, 2012.

SORTE, N. V., RAUT, J., DEOTALE, R., PATEL, M., e KATEKHAYE, S. Effect of waterlogging on soybean at critical growth stages. Journal of Soils and Crops, 5(2), 141144, 1995.

TAIZ, L; ZEIGER, E. 4. Ed. Fisiologia vegetal. Porto Alegre: Artmed, 2009.

TAIZ, L.; ZEIGER, E. 3. Ed. Fisiologia vegetal. Porto Alegre: Artmed, 2004.

VÁLIO, I. F. M.; SCARPA, F. M. Germination of seeds of tropical pioneer species under controlled and natural conditions. Revista Brasileira de Botânica, 24 (1):79-84, 2001.

VARTAPERIAN, B.B.; JACKSON, M.B. Plant adaptations to anaerobic stress. Annals of Botany, v.79 (A), n.1, p.3-20, 1997.

VOESENEK, L.A.C.J., BANGA, M., THIER, R.H., MUDDE, C.M., HARREN, F.J.M., BARENDSE, G.W.M.B. \& BLOOM, C.W.P.M. Submergence induced ethylene synthesis, entrapment and growth in two plant species with contrasting flooding resistances. Plant. Physiol. 103:783-791, 1993. 
WITTMANN, F., J. SCHONGART, J. M. De BRITO, A.O. WITTMANN, M. T. F. Piedade, P. Parolin, W.J. Junk \& J.L. Guillaumet. Manual de árvores de várzeada Amazônia Central.Taxonomia, ecologia e uso. INPA. 2010.

WORBES, M. The forest ecosystem of the floodplains. Ecological Studies, v. 126, p. 223$265,1997$.

WORBES, M. How to measure growth dynamics in tropical trees: a review. IAWA J. 16:337-351,1995.

WORBES, M., H. KLINGE, J.D. REVILLA e C. MARTINS. On the dynamics, floristic subdivision and geographical distribution of várzea forests in Central Amazonia. Journal of Vegetation Science. 3:553-564, 1992.

YAMAUCHI, T., SHIMAMURA, S., NAKAZONO, M., e MOCHIZUKI, T. Aerenchyma formation in crop species: a review. Field Crops Research, 152, 8-16, 2013.

YIN, D.; CHEN, S.; CHEN, F.; GUAN, Z.; FANG, W. Morpho-anatomical and physiological responses of two Dendranthema species to waterlogging. Environmental and Experimental Botany, v. 68, n. 2, p.122-130, 2010. 


\section{ANEXOS}

Tabela 1. Média \pm desvio padrão e interações entre origens e tratamentos dos parâmetros de incremento em altura $(\mathrm{cm})$, razão raiz/parte aérea $(\mathrm{g})$ e biomassa de raiz, caule e folha ao final de 30 dias de experimento. Os efeitos significativos estão indicados por (**) e os não significativos por $(\mathrm{ns}) .(\mathrm{n}=10)$.

Tabela 2. Média \pm desvio padrão e interações entre origens e tratamentos dos parâmetros de açucares solúveis totais ( $\mathrm{ug} / \mathrm{mg}$ ) e amido (ug/mg), da raiz, do caule e da folha ao final de 30 dias de experimento. Os efeitos significativos estão indicados por (**) e os não significativos por (ns). Para os parâmetros, o número de repetições biológicas utilizadas por tratamento, foi $5(n=5)$. 
Tabela 3. Média \pm desvio padrão e interações entre origens e tratamentos dos parâmetros de incremento em altura $(\mathrm{cm})$, produção de folhas novas e biomassa de raiz, caule e folha $(\mathrm{g}) 30$ dias após a recuperação das plantas utilizadas no experimento. Os efeitos significativos estão indicados por (**) e os não significativos por (ns). Para todos os parâmetros avaliados, o número de repetições biológicas foi $5(\mathrm{n}=5)$.

\begin{tabular}{|c|c|c|c|c|c|c|c|c|c|}
\hline \multicolumn{10}{|c|}{ G. americana } \\
\hline \multirow{2}{*}{ Parâmetros } & \multicolumn{3}{|c|}{ Amazônia } & \multicolumn{3}{|c|}{ Cerrado } & \multicolumn{3}{|c|}{ ANOVA } \\
\hline & Controle & Al parcial & Al Total & Controle & Al parcial & Al Total & Origem & Tratamento & $\mathrm{O} \times \mathrm{T}$ \\
\hline Incremento em altura $(\mathrm{cm})$ & $1,74 \pm 1,49$ & $2,70 \pm 0,27$ & $1,70 \pm 0,57$ & $2,66 \pm 0,65$ & $1,02 \pm 0,90$ & $1,70 \pm 1,09$ & ns & ns & ** \\
\hline Produção de folhas novas & $0,0 \pm 0,0$ & $0,0 \pm 0,0$ & $2,0 \pm 0,0$ & $1,40 \pm, 89$ & $0,0 \pm 0,0$ & $2,0 \pm 0,0$ & ** & ** & ** \\
\hline Biomassa de Raiz (g) & $0,97 \pm 0,34$ & $0,85 \pm 0,09$ & $0,64 \pm 0,13$ & $1,43 \pm 0,71$ & $1,03 \pm 0,11$ & $0,76 \pm 0,50$ & ns & ns & ns \\
\hline Biomassa de Caule (g) & $1,66 \pm 0,99$ & $1,14 \pm 0,14$ & $0,62 \pm, 004$ & $1,43 \pm 0,73$ & $1,18 \pm 0,28$ & $0,86 \pm 0,64$ & ns & $* *$ & ns \\
\hline Biomassa de Folha (g) & $2,64 \pm 0,86$ & $2,23 \pm 0,32$ & $1,88 \pm 0,78$ & $3,14 \pm 1,08$ & $2,41 \pm 0,35$ & $2,11 \pm 1,14$ & ns & ns & ns \\
\hline \multicolumn{10}{|c|}{ G. ulmifolia } \\
\hline \multirow[t]{2}{*}{ Parâmetros } & \multicolumn{3}{|c|}{ Amazônia } & \multicolumn{3}{|c|}{ Cerrado } & \multicolumn{3}{|c|}{ ANOVA } \\
\hline & Controle & Al parcial & Al Total & Controle & Al parcial & Al Total & Origem & Tratamento & $\mathrm{O} \times \mathrm{T}$ \\
\hline Incremento em altura $(\mathrm{cm})$ & $5,42 \pm 2,12$ & $15,4 \pm 4,18$ & $1,8 \pm 2,04$ & $3,4 \pm 0,66$ & $3,6 \pm 2,50$ & $1,6 \pm 1,43$ & $* *$ & ** & ** \\
\hline Produção de folhas novas & $0,6 \pm 0,89$ & $5,8 \pm 2,16$ & $38,4 \pm 16,83$ & $0,0 \pm 0,0$ & $2,8 \pm 1,30$ & $12,4 \pm 5,52$ & $* *$ & $* *$ & $* *$ \\
\hline Biomassa de Raiz (g) & $3,30 \pm 0,35$ & $2,54 \pm 0,81$ & $0,56 \pm 0,02$ & $3,58 \pm 0,80$ & $1,37 \pm 0,68$ & $1,31 \pm 1,14$ & ns & $* *$ & ** \\
\hline Biomassa de Caule (g) & $4,92 \pm 0,86$ & $3,29 \pm 0,74$ & $0,82 \pm 0,16$ & $3,20 \pm 1,27$ & $1,19 \pm 0,51$ & $0,93 \pm 0,38$ & ** & $* *$ & ** \\
\hline Biomassa de Folha (g) & $2,63 \pm 0,44$ & $1,93 \pm 0,24$ & $0,40 \pm 0,16$ & $3,39 \pm 0,90$ & $1,16 \pm 0,63$ & $0,83 \pm 0,79$ & ns & ** & $* *$ \\
\hline
\end{tabular}

Tabela 4. Percentual do teor de carboidratos totais (Amido e AST) de raiz, caule e folhas das plantas de G. americana e G. ulmifolia, após 30 dias de imposição de tratamentos de alagamento (parcial e total). Para AST e amido ao final de 30 dias de tratamento, as médias seguidas de mesma letra não diferem entre si pelo teste Tukey $(\mathrm{p} \leq 0,05)$. Letras maiúsculas representam comparações entre espécies quanto à origem e letras minúsculas representam comparações entre os tratamentos (controle, alagamento parcial e alagamento total). Os valores apresentados são médias $(n=5)$.

\begin{tabular}{|c|c|c|c|c|c|c|}
\hline \multicolumn{7}{|c|}{ G. americana } \\
\hline \multirow[t]{2}{*}{ Parâmetros } & \multicolumn{3}{|c|}{ Amazônia } & \multicolumn{3}{|c|}{ Cerrado } \\
\hline & Controle & Al parcial & Al Total & Controle & Al parcial & Al Total \\
\hline Teor de AST (\%) - Raiz & $16,17 \mathrm{Aa}$ & $20,55 \mathrm{Aa}$ & $16,81 \mathrm{Aa}$ & $16,18 \mathrm{Aa}$ & $15,85 \mathrm{Aa}$ & $20,36 \mathrm{Aa}$ \\
\hline Teor de Amido (\%) - Raiz & $7,86 \mathrm{Aa}$ & 7,51 Aa & $7,16 \mathrm{Aa}$ & $11,6 \mathrm{Aa}$ & $13,58 \mathrm{Aa}$ & $8,45 \mathrm{Aa}$ \\
\hline Total de carboidratos - Raiz & 24,03 & 28,06 & 23,97 & 27,78 & 29,43 & 28,81 \\
\hline Teor de AST (\%) - Caule & $14,37 \mathrm{Aa}$ & $15,9 \mathrm{Aa}$ & $11,5 \mathrm{Aa}$ & $9,34 \mathrm{Aa}$ & 13,97 Aa & $14,57 \mathrm{Aa}$ \\
\hline Teor de Amido (\%) - Caule & $6,66 \mathrm{Aa}$ & $14,45 \mathrm{Aa}$ & $16,18 \mathrm{Ab}$ & $6,43 \mathrm{Aa}$ & $12,34 \mathrm{Aa}$ & 7,34 Aa \\
\hline Total de carboidratos - Caule & 21,03 & 30,35 & 27,68 & 15,77 & 26,31 & 21,91 \\
\hline Teor de AST (\%) - Folha & $25,21 \mathrm{Aa}$ & $25,66 \mathrm{Aa}$ & $27,57 \mathrm{Aa}$ & $26,78 \mathrm{Aa}$ & $29,43 \mathrm{Aa}$ & $30,16 \mathrm{Aa}$ \\
\hline Teor de Amido (\%) - Folha & $2,55 \mathrm{Aa}$ & 3,58 Aa & $2,67 \mathrm{Aa}$ & $3,12 \mathrm{Aa}$ & 5,41 Aab & 2,77 Aac \\
\hline Total de carboidratos - Folha & 27,76 & 29,24 & 30,24 & 29,9 & 34,84 & 32,93 \\
\hline \multicolumn{7}{|c|}{ G. ulmifolia } \\
\hline \multirow[t]{2}{*}{ Parâmetros } & \multicolumn{3}{|c|}{ Amazônia } & \multicolumn{3}{|c|}{ Cerrado } \\
\hline & Controle & Al parcial & Al Total & Controle & Al parcial & Al Total \\
\hline Teor de AST (\%) - Raiz & $20,75 \mathrm{Aa}$ & $14,76 \mathrm{Ab}$ & $16,89 \mathrm{Ab}$ & $24,61 \mathrm{Aa}$ & $21,86 \mathrm{Ba}$ & $21,38 \mathrm{Aa}$ \\
\hline Teor de Amido (\%) - Raiz & $16,84 \mathrm{Aa}$ & $12,02 \mathrm{Aa}$ & $5,79 \mathrm{Ab}$ & $25,77 \mathrm{Aa}$ & $17,61 \mathrm{Aa}$ & $25,5 \mathrm{Ba}$ \\
\hline Total de carboidratos - Raiz & 37,59 & 26,78 & 22,68 & 50,38 & 39,47 & 46,88 \\
\hline Teor de AST (\%) - Caule & $16,59 \mathrm{Aa}$ & $15,38 \mathrm{Aa}$ & $18,41 \mathrm{Aa}$ & $24,03 \mathrm{Ba}$ & $25,59 \mathrm{Ba}$ & $24,46 \mathrm{Ba}$ \\
\hline Teor de Amido (\%) - Caule & $5,99 \mathrm{Aa}$ & $6,08 \mathrm{Aa}$ & $2,95 \mathrm{Aa}$ & $4,52 \mathrm{Aa}$ & $9,61 \mathrm{Aa}$ & $10,64 \mathrm{Bb}$ \\
\hline Total de carboidratos - Caule & 22,58 & 21,46 & 21,36 & 28,55 & 35,2 & 35,1 \\
\hline Teor de AST (\%) - Folha & 9,7 Aa & $9,23 \mathrm{Aa}$ & 9,4 Aa & $9,19 \mathrm{Aa}$ & $16,97 \mathrm{Bb}$ & $14,58 \mathrm{Bb}$ \\
\hline Teor de Amido (\%) - Folha & $6,96 \mathrm{Aa}$ & $2,3 \mathrm{Ab}$ & $1,5 \mathrm{Ab}$ & $8,26 \mathrm{Aa}$ & $2,92 \mathrm{Ab}$ & $1,68 \mathrm{Ab}$ \\
\hline Total de carboidratos - Folha & 16,66 & 11,53 & 10,9 & 17,45 & 19,89 & 16,26 \\
\hline
\end{tabular}

